\title{
Histological, pathological and therapeutical aspects of osteoarthritis
}

Citation for published version (APA):

Bulstra, S. K. (1992). Histological, pathological and therapeutical aspects of osteoarthritis. [Doctoral Thesis, Maastricht University]. Datawyse / Universitaire Pers Maastricht.

https://doi.org/10.26481/dis.19921023sb

Document status and date:

Published: 01/01/1992

DOI:

10.26481/dis.19921023sb

Document Version:

Publisher's PDF, also known as Version of record

\section{Please check the document version of this publication:}

- A submitted manuscript is the version of the article upon submission and before peer-review. There can be important differences between the submitted version and the official published version of record.

People interested in the research are advised to contact the author for the final version of the publication, or visit the DOI to the publisher's website.

- The final author version and the galley proof are versions of the publication after peer review.

- The final published version features the final layout of the paper including the volume, issue and page numbers.

Link to publication

\footnotetext{
General rights rights.

- You may freely distribute the URL identifying the publication in the public portal. please follow below link for the End User Agreement:

www.umlib.nl/taverne-license

Take down policy

If you believe that this document breaches copyright please contact us at:

repository@maastrichtuniversity.nl

providing details and we will investigate your claim.
}

Copyright and moral rights for the publications made accessible in the public portal are retained by the authors and/or other copyright owners and it is a condition of accessing publications that users recognise and abide by the legal requirements associated with these

- Users may download and print one copy of any publication from the public portal for the purpose of private study or research.

- You may not further distribute the material or use it for any profit-making activity or commercial gain

If the publication is distributed under the terms of Article $25 \mathrm{fa}$ of the Dutch Copyright Act, indicated by the "Taverne" license above, 
Histological, pathological and therapeutical aspects of Osteoarthritis. 


\title{
Histological, pathological and therapeutical aspects of Osteoarthritis.
}

\author{
PROEFSCHRIFT \\ tẹr verkrijging van de graad van doctor aan de Rijksuniversiteit Limburg \\ te Maastricht, op gezag van de Rector Magnificus, Prof.mr. M.J. Cohen, \\ volgens het besluit van het College van Dekanen, \\ in het openbaar te verdedigen \\ op vrijdag 23 oktober 1992 om 14.00 uur
}

door

Sjoerd Klaas Bulstra

geboren te Bergen (NH) in 1955 . 


$\begin{array}{ll}\text { Promotor: } & \text { Prof.dr. AJ. van der Linden } \\ \text { Copromotor: } & \text { Dr. W.A. Buurman }\end{array}$

Beoordelingcommissie: Prof.dr. J.M. Greep (voorzitter) Prof.dr. J.W. Arends

Prof.dr. J. Drukker

Dr. G.P.J. van Kampen

Prof.dr. R.P.H. Veth

De uitgave van dit proefschrift werd financieel gesteund door:

De Nederlandse Orthopaedische Vereniging, Het Nationaal Rheumafonds, CAM Implants bv., Bournonville - Pharma bv, Osteonics International, Ebbink Orthopaedie bv, Aesculaap bv., Stryker Nederland bv, Pfizer bv., West Instrumenten bv.. 
Men moet even stoulmoedig zijn in de hypothese als

nouwgezel in de proefnemingen

Charles Richet (1850-1935) 
CIP-DATA KONINKLIJKE BIBLIOTHEEK، DEN HAAG.

Bulstra, Sjoerd Klaas

Histological, pathological and therapeutical aspects of osteoarthritis / Sjoerd Klaas Bulstra. - Maastricht :

Universitaire Pers Maastricht. - III.

Thesis Maastricht. - With ref. - With summary in Dutch.

ISBN 90-5278-041-2

NUGI 743

Subject headings: osteoarthritis / cartilage /

perichondrium.

Cover: Teake Bulstra, DMD Rotterdam

Lay-out: Guus van Rooy, Maastricht

Book Production:

DATAWYSE I Universitaire Pers Maastricht 


\section{CONTENTS}

Chapter 1: $\quad$ General introduction

1.1 Epidemiology 9

1.2 Pathophysiology of osteoarthritic cartilage 10

1.2.1 Macroscopy 10

1.2.2 Microscopy 11

1.2.3 Biochemical aspects $\quad 13$

1.3 Etiology and pathology 16

$\begin{array}{lll}1.4 & \text { Therapy } & 17\end{array}$

1.4.1 Conservative treatment $\quad 17$

$\begin{array}{ll}1.4 .2 \text { Drug treatment } & 17\end{array}$

$\begin{array}{ll}1.4 .3 \text { Surgical treatment } & 18\end{array}$

Chapter 2: Introduction to and discussion of the experimental work 21

Chapter 3: The reliability of the Mankin score for osteoarthritis 43

Chapter 4: Thionin staining of paraffin and plastic embedded cartilage sections

Chapter 5: Metabolic characteristics of in vitrocultured human chondrocytes in relation to the histo-pathological degree of osteoarthritis

Chapter 6: $\quad$ The potential of adult human perichondrium to form hyalin cartilage in vitro

Chapter 7: $\quad$ The effect of gentamicin on the metabolism of in vitro cultured rat patellar cartilage

Chapter 8: $\quad$ The effect of piroxicam on the metabolism of isolated human chondrocytes in vitro

Chapter 9: $\quad$ Summary

Samenvalting

Publications presented in this thesis

Dankwoord 



\section{General Introduction}

\subsection{Epidemiology}

Osteoarthritis $(O A)$ is a non-inflammatory disorder of joints, characterized by deterioration and loss of the bearing surface and proliferation of new osteoarticular tissue at the margins of the joint. In time the cartilage may erode upto the subchondial bone and proliferation of fibrous tissue may occur next to areas of bare bone.

Although with advancing age the biomechanical properties of cartilage decrease, the changes occuring in $O A$ are more severe and complex, occuring at a younger age. Only in about $20 \%$ of the patients with OA a clear cause of the disease, in most cases of traumatic or inflammatory origin, can be identified (Secondary OA). In most cases however no predisposing factor of OA can be identified (Primary OA).

$O A$ is a widespread disease. Due to the longer lifespan in recent decades, as well as mechanical overuse of the joints by increased sporting activities, the number of patients with OA has been growing (Acheson 1981. Altman 1987. Janssens 1987, Peyron 1986). Epidemiological sfudies have identified several groups of patients with O.A. (Hutton 1987, Spector 1989). Examples of such groups are female patients with $O A$ of the distal interphalangeal joints or knees and male patients with OA of the lumbar spine (Felson 1990, Harris 1986, Huskisson 1979, Kellgren 1952, McGoldrick 1989, Saase 1989). Until now, these epidemiological studies have not resulted in better insight in the etiology and pathogenesis of primary $\mathrm{OA}$; this is considered to be caused by the absence of a reliable methodological standardization in the measurement of OA (Acheson 1981, Benn 1975. Epidemiological 1988, Hart 1991. Mc Alindon 1989|. Also, radiographs used for the assessment of $O A$, often do not correlate with the clinical symptoms of $O A$ (Bagge 1991, Claessens 1990). Although OA can manifest itself with a wide spectrum of symptoms (Huskisson 1988), the features of the process of OA are characterized by typical symptoms and signs such as pain, osteophyte formation, crepitus on movernent, reduction of function and a variable degree of inflammation. These symptoms are however similar in different forms of $O A$ such as localized $O A$, polyarthrosis or post traumatic $O A$, thereby hampering epidemiological studies conducted to define etiological factors of $\mathrm{OA}$. One of the most important conclusions of studies using radiology for the assessment of $O A$, is that a correlation exists between physical stress and radiological signs of $O A$ in, e.g., frequent occurrence of disc degeneration in miners, or knee OA in soccer players (Anderson 1963, lee 1974). The greatest increase in the radiologically proven occurrence of the disease appears in patients between the age of 40 and 50 (38\% in males, $39 \%$ in females). 
Radiological signs of $O A$ can be diagnosed in $86 \%$ of the population over the age of 60 (Helminen 1987). About $25 \%$ of the patients with radiologically established OA turn out to have serious clinical symptoms of the disease (Lawrence 1987). In the Netherlands, in 1985 OA was the second most important disease responsible for early retirement from employment (Besseling 1988).

\subsection{Pathophysiology of osteoarthritic cartilage.}

\subsubsection{Macroscopy.}

Macroscopically one of the earliest defects seen in OA seems to be softening of the cartilage surface (Bentley 1983, 1985). Although softening of the cartilage is frequently found in patients with chondromalacia, not all these patients develop early $\mathrm{OA}$. It is therefore suggested that lesions of the cartilage may heal and that this may account for the disappearance of clinical symptoms in about $2 / 3$ of these young patients (Bentley 1970, Bentley 1985, Convery 1975). These findings are in accordance with the arrest of $O A$ observed in the first months after anterior cruciate ligament transection in the dog. In these dogs an active synthetic response of the chondrocytes was noted, resulting in hypertrophic cartilage repair, without an increase in chondrocyte number or an increase in collagen content typical for $O A$ (Adams 1991, Pritzker 1991). Only after longterm observation the cartilage of these dogs showed signs of progressive OA (Brandt 1991). However, in a certain percentage of the remaining patients with chondromalacia of the patella, early degenerative $O A$ is observed.

In OA focal disruption of the softened cartilage surface with fissures develops, resulting in fibrillation of the joint surface. Fissures penetrating more deeply into the cartilage do not heal, although progression to advanced $O A$ does not always occur (Thompson 1975). Fissures down to the subchondral bone lead to further roughening of the cartilage surface and cartilage detachment, until complete abrasion of the joint surface develops (Byers 1977. Dingle 1979, Maroudas 1977). Although spontaneous healing of small cartilage defects from the subchondral bone with hyalin cartilage has been demonstrated, in general these deep defects heal with fibro-cartilage. In an $\mathrm{OA}$ joint the different macroscopical stages of the disease are frequently seen at the same time, representing the focal character of $O A$. When cartilage is damaged, the subchondral bone reacts with structural adaptation by the formation of osteosclerosis and osteophytes. The breakdown of cartilage and bone in $\mathrm{OA}$ results in considerable debris in the synovial fluid, which is pressed into the subchondral bone, causing the formation of subchondral cysts. The opening of the subchondral bone layer allows blood vessels and fibrous fissue to emerge into the superficial defect. Proliferating nodules of fibrocartilage may be seen to cover the previously denuded subchondral bone (Furukawa 1980, Macys 1980, Mitchell 1976). 
Cartilage and bone debris in the synovial fluid may provoke an inflammatory response of the synovium. Occasionally loose cartilaginous bodies are formed (Sokoloff 1980). Inflammation is especially prominent after rapid break down of cartilage, e.g. after trauma. In contrast to rheumatoid arthritis. (RA), where inflammation causes cartilage destruction, the moderate chronic inflammation in $\mathrm{OA}$ is suggested to be a result of cartilage breakdown /Goldenberger 1982, Walker 1991). Extension of the synovial membrane across the subchondral bone layer is only seen at the margins of the joint, but destruction of the cartilage by the synovial membrane, as seen in RA, does not occur (Salvati 1977. Waxman 1973). In the rabbit knee, the primary inflammatory cell response does not seem to be mechanically induced (Konttinen 1990), and evidence exists that after initial cartilage damage, factors released by synovial cells stimulate the chondrocytes to produce matrix degrading enzymes (Aydelotte 1984, Dingle and Saklatvala 1979, Ehrlich 1986, Howell 1986, Pelletier 1985, Vittorio 1986). As a result this secondary synovitis becomes a pathological factor itself, responsible for further cartilage destruction and requiring treatment.

Hydrops as a result of synovitis is not always found in patients with OA joints. Especially after microtrauma a rise in the volume of synovial fluid is found, resulting in further reduction of the already diminished viscosity of the joint fluid in $\mathrm{OA}$. The capacity of the joint fluid to function as a lubricant decreases, reducing shock absorption of the cartilage and diffusion of nutrients into the cartilage (Balazs 1967. Seppala 1969, Sokoloff 19801.

\subsubsection{Microscopy.}

Gross and microscopical inspection of $O A$ cartilage shows a wide focal variation in the severity of the disease (Byers 1970, Harrison 1953, Mankin 1971! Microscopically, changes in cartilage structure, glycosaminoglycan (GAG) stainability, chondrocyte appearance, the calcified zone and the subchondral bone plate are seen. Characteristic in $\mathrm{OA}$ is the presence of two distinct pathological processes: the deterioration of hyalin cartilage with loss of the bearing surface and the proliferation of bone covered with cartilage near the margins of the joint (Sokoloff 19831 .

Microscopically, one of the first signs seen in $O A$, the loss of the specific stainability of proteoglycans (PG) at the surface of the cartilage, is indistinguishable from the microscopic aspect of chondromalacia of the patella. Macroscopically the cartilage surface may be intact, but microscopically cell-necrosis, degradation of intercellular matrix, and exposure of superficial collagen fibres are seen (Meachim 1975) (Fig 1, Fig2). Lafer on, focal disruption of the cartilage surface appears as a fibrillated surface. Depending on the extent of $\mathrm{OA}$, clefts in the cartilage down to the subchondral plate as well as regions with denuded bone develop. In contrast to cartilage destruction, cartilage regeneration is accompanied by emerging vascular 
connective fissue from the subchondral space. Fibrocartilage is formed, a relatively cell-rich fissue that lacks the typical organization of hyalin cartilage (Macys 1980, Moskowitz 1984). In the initial stages of the disease chondrocyte necrosis is seen near the fibrillated cartilage surface. Subsequent to chondrocyte necrosis, clusters of chondrocytes are found near the edges of the fibrillated clefts, in the middle and deeper regions of the cartilage (Bentley 1985, Poole 1991). In more advanced stages of $\mathrm{OA}$ the normal structure of cartilage, with superficial horizontally aligned

Fig. 1:

Healthy

human

cortilage

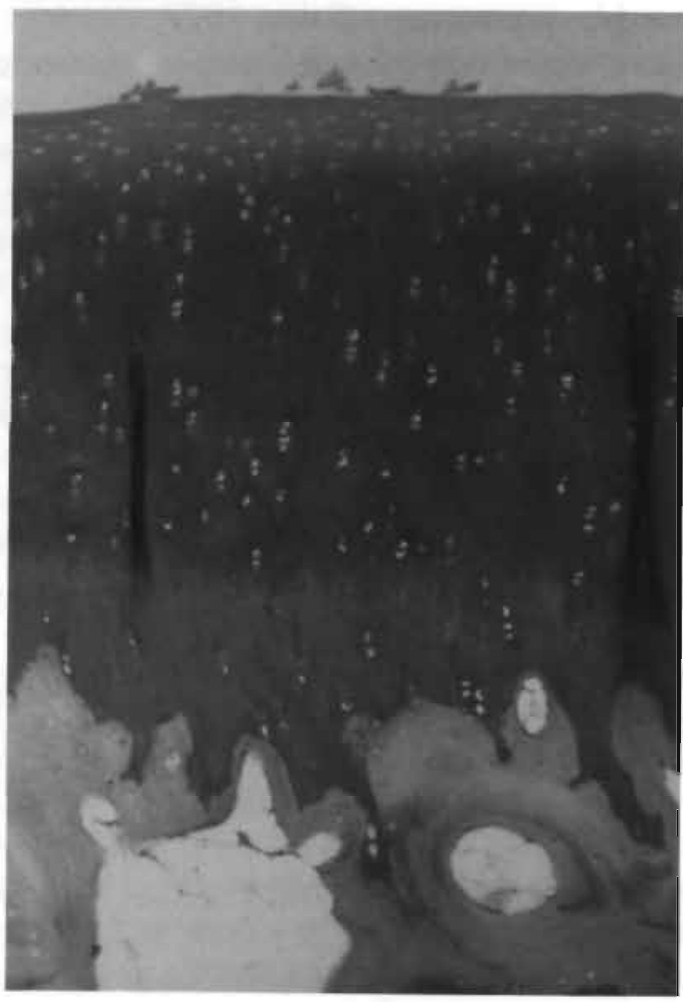

chondrocytes and, in the deep layers, vertically orientated rows of chondrocytes, is disturbed.

The continuity of the tidemark (TM), the boundary betwieen the deep cartilage layer and the calcified cartilage zone, is disrupted or doubled in more advanced stages of $O A_{;}$this is a sign of a disturbed mineralization of the calcified zone (Havelka 1984).

The changes in the PG content of cartilage may be quantified by the use of specific stains, such as safranin-O, alcian-blue and thionin (Kiviranta 1985, Rosenberg 19711. The staining with safranin-O, which binds stoichiometrically to 
chondroitin sulphate in paraffin embedded sections, is reduced in OA cartilage. However, in the deeper cartilage zones, intensified staining is observed around the chondrocytes. These chondrocyles are supposed to produce more GAG as a reaction to the loss of PG from the cartilage matrix in the superficial zone (Vignon 1987).

The changes in the subchondral bone vary according to the localization. locally, microfractures and osteoclastic bone resorption with formation of cysts are found. In other subchondral regions signs of repair are seen, such as new bone formation, leading to irregularity of the cement line (Reimann 1977). In these regions smooth bone surface abrasion is found, with dense osteoid formation. Also, new

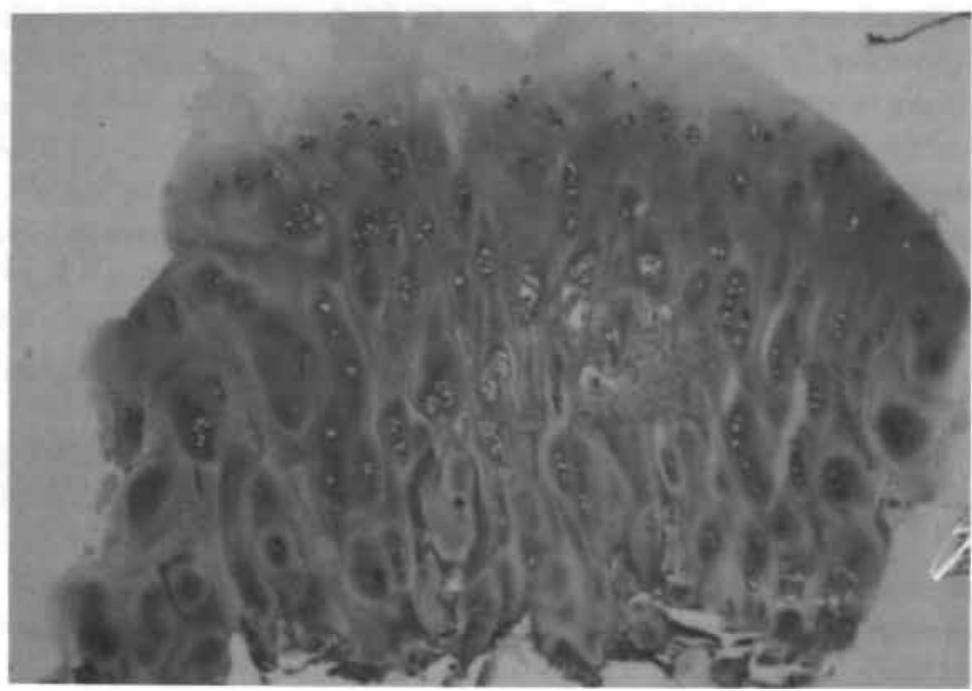

Fig, 2.

OA Human cartilage

bone formation at the joint margins causes remodelling of the joint, resulting in the formation of osteophytes (Allard 1990). These osteophytes, covered with fibrocartilage, are also found in elderly patients where reduced cartilage thickness requires a functional adaptation of shape to stabilize the joint (lawrence 1966, Mankin 1971).

\subsubsection{Biochemical aspects.}

In general $\mathrm{OA}$ is a slowly progressive disease. Cartilage of human origin can be obtained during autopsy, after amputation, or during joint arthroplasty, where in most of these cases OA has advanced to serious deterioration of the joint. Therefore, most 
of our knowledge of the pathogenesis of OA has been obtained from studies using animal models. In these animal models young animals are often used to study the process of secondary OA (Archer 1990, Aydelotte 1984, Brandt 1989, Pond 1973, Sokoloff 1990, Shuckett 1988, Stockwell 1983). We should realize that the results obtained in this way are not always relevant to the pathogenesis of $O A$ in humans.

Normally in healthy cartilage PG monomer consists of a large protein core to which approxirnately 150 GAG chains are covalently attached. in cartilage most PG monomers associate with hyaluronate to form large PG aggregates. The closely spaced $\left(5-15 A^{\circ}\right)$ negatively charged sulfate and carboxyl groups on the GAG chains of the PG create strong intra-molecular and inter-molecular charge repulsive forces. Ait the same time mobile cations $\left(\mathrm{Na}^{+}, \mathrm{Ca}^{2+}\right)$ are attracted to the negatively charged groups of the PG within the extrocellular matrix. Thereby a subsiantial swelling pressure in the cartlage is created (Donnon osmotic pressure). This swelling pressure is resisted and balanced by the tension developed in the collagen network, surrounding the proteoglycan aggregates. Under load, interstitial fluid flows out into the synovial fluid, resulting in an increase of the osmotic swelling pressure in the cartilage, due to an increased anion concentration in the matrix; thereby the PG trapped in the extracellular matrix carry load during compression. As soon as loading subsides, cations and $\mathrm{H}_{2} \mathrm{O}$ are aftracled from the synovial fluid, enhancing diffusion of nutritients from the synovial fluid into the cartiloge.

However with age the biochemical composition of human articular cartilage is changing, resulting in decreased tensile strength of collogen and diminished elasticity of the cartilage (Bayliss 1978, Roughley 1986, Venn 1977). Therefore, the same load, easily withstood at a young age may, at an older age, produces microfractures in the cartilage, eventually resulting in $\mathrm{OA}$. In ageing cartilage the contents of glycosaminoglycans (GAG) and collagen are rather constant, while the water content decreases with age (Maroudas 1976, Venin 1977). This is caused by a relative increase of both keratan sulfate $(K S)$ and hyaluronan $(\mathrm{HYA})$ in relation ta chondroitin sulfate (ChS), ChS being the major water-binding GAG in cartilage. Furthermore the ratio ChoS over Ch4S increases with increasing age. The increase of this ratio results in a decreasing hydrodynamic volume of $P G$ and in a decreased osmotic swelling pressure in the cartilage (Bayliss 1990). With age PG become more susceptible to proteolytic cleavage, which often results in loss of the HYA binding region of the core protein (Roughley 1980). This part of the core protein of cartilage PG laggrecan) remains bound to HYA, preventing the PG monomer to bind to HYA. As a result the size of the PG aggregates diminishes and so the waterbinding capacity is reduced. At the same time the size of the HYA molecules also decreases.

One of the first biochemical changes seen in OA cartilage is an increase of the water content, preceded by a disruption of the collagen fibres in the superficial 
cartilage layer (Armstrong 1982, Eyre 1980, Hesse 1988, Mankin and Treadwell 1986. Maroudas 1976, Muir 19886, Stockwell 1983). During the process of degeneration of cartilage the collagen content per dry weight does not change (Mankin and Lipiello 1970). However, due to changes in the differentiation stage of the chondrocytes, collagens not present in healthy articular cartilage (e.g. collagen types I, III and X) are synthesized and deposited in the cartilage matrix (Adams 1991. Archer 1990. Bruckner 1989, Iwamoto 1989, Kirsch 1991, Lefebvre 1990, Nimni 1983, Pacifici 1991, Rosenberg 1984). As a result of the altered collagen fibril structure and organization, further loading results in more extensive destruction of the cartilage, and fibrillation of the cartilage surface is observed (Broom 1982, Mc.Devitt 1977. Sweet 1977, Venn 1977, Weiss 19731.

An early phenomenon in the course of $O A$ is loss of $P G$ near the articular surface [Huber-Bruning 1987, Moskowitz 1979). The elevated PG synthesis that is found in OA cartilage is supposed to be an attempt to repair these lesions. However, in OA cartilage the newly synthesized PG have the same composition as PG in very young cartilage: a low KS content and a high ratio of Ch4S over ChoS resulting in a high hydrodynamic volume of the PG monomer McDevitt 1981, Vasan 1980, Kuijer 1986). The content of ChS and HYA is also reduced in OA cartilage (Michelacci 1979). The content and size of the functional link protein that stabilizes the HYA-PG bond are reduced. The result is a relatively small PG aggregate that is less well stabilized and of relatively small hydrodynamic size (Brandt 1976, Melching 1990, Oegema 19801.

Due to the changed metabolism of $O A$ chondrocytes, the breakdown of PG in OA cartilage is intensified. The balance between the production of metalloproteinases and tissue-inhibitors of metalloproteinases (TIMPs) in OA cartilage is changed in favor of the metalloproteinases, resulting in proteolytic cleavage of PG (Dean 1989, Pelletier 1983).

Normally, movement of the joint induces flow from the synovial fluid, through the joint cavity into the cartilage. Thereby the nutrition of the chondrocytes is achieved. In OA cortilage this flow of synovial fluid from and into the cartilage is reduced due to the less effective "water" pump and a reduced elasticity of the cartilage (Maroudas 1986). In the synovial fluid of an OA joint the HYA content decreases, while its average molecular weight is reduced. This results in diminished viscoelasticity of the joint fluid, thereby hampering lubrication and diffusion of nutrients, and inducing higher mechanical stress to the cartilage surface and the subchondral bone (Balazs 1967, 1974, Dahl 1985, Ohno 1986, Radin 1988).

The degradation products of the cartilage matrix will accumulate inside the synovial cavity and may lead to inflammation of the synovial membrane. A large number of inflammatory mediators such as cytokines and proteolytic enzymes are released within the synovial fluid, capable of inducing and activating catabolic processes (Sapolsky 1973, Dingle 1991, Ehrlich 1985, Martel-Pelletier 1988. 
Morales 1983, Wilbrink 19911.

In conclusion, the biochemical changes found in aged and $O A$ cartilage reduce its capacity to absorb peak stress. Insufficient repair by articular chondrocytes, synovitis, and remodelling of the subchondral bone lead to increased susceptibility to loading and further breaking down of the cartilage.

\subsection{Etiology, and Pathology}

Numerous animal models have been developed to clarify the mechanisms that may cause OA. A clear correlation between the disturbance of mechanical properties of a joint and the pathogenesis of $O A$ has thus been established. Patients with a congenital malformation, a history of trauma, biochennical abnormalities of cartilage or a generalized process affecting cartilage are at risk of developing early $O A$ (Altman 1986, Child 1986, Davis 1990, Felson 1990, Harris 1986, Jahanson 1985, Peyron 1986, Saase 1988, Villacin 1979). In these: patients, with so-called secondary OA abnormal mechanical loading is responsible for deterioration of the cartilage.

In most patients, however, the etiology of OA remains unclear, which is why these cases are classified as primary OA. (Altman 1987). Because it proved to be difficult to study the pathogenesis of $O A$ in human cartilage, the sequence of the remodelling process in $O A$ is studied in experimental models in animals. Different theories to clarify the etiology of primary OA have been formulated.

One of these concepts suggests that peak stress is mainly absorbed by the subchondral bone layer and the soff tissues (Geesink. 1984, Radin 1970). Normally the undulating calcified layer converts sheer stress into compressive and tensile stress |Redler 1975). Frequent sudden high stress on the subchondral bone couses the development of microfractures, followed by new bone formation |Layton 1988. Jurvelin 1985, Simon 1972). This results in local sclerosis and thickening of the subchondral plate, which causes an increase in the stiffness gradient in the subchondral bone [Rodin 1986). Due to the stiffened subchondral bone, the forces exerted on articular cartilage under normal load are increased and microfractures in the cartilage matrix may occur (Radin 1978). According to another theory, a minor disruption of the cartilage surface is followed by secondary remodelling of the bone components of the joint (Muir 1977, Mankin 1986). Overloading of the cartilage, primary superficial cell death, or malfunction of the chondrocytes are the most probable causes mentioned (Hammerman 1985, Ohno 1988, Poole 1991, Schenk 1986, Sokoloff 1987).

The role of cytokines, metalloproteinases, their inhibitors, and other mediators of $O A$, is the issue of discussion in many recent reports. The proteolytic degradation of the extracellular matrix is an important step in the process of $O A$. In patients where synovial inflammation (RA, gout) plays an essential role, enzymes responsible for 
cartilage degeneration may come from exogenous sources and from the cartilage itself. Prostaglandines, interleukins 1, 6, 8, TNF- $\alpha$ and stromelysin are secreted by mononuclear cells in the blood, by macrophages in the lining-cells. All these factors are directly or indirectly involved in cartilage breakdown. On the other hand endogenous factors produced by the chondrocyles have been proved to cause cartilage degeneration. The disturbance of the equilibrium between metalloproteinases and tissue-inhibiting metalloproteinases (TIMP) in cartilage and the synovium does not seem to be caused by exogenous factors alone, but may also represent a localized and primary event in the pathogenesis of OA (Andrews 1990, Brandt 1989. Campbell 1989, Dean 1989, Ehrlich 1986, Enomoto 1990, Gadher 1990, Ghosh 1991, Guerne 1989, Hamerman 1989, Huber-Bruning 1980, Lefebvre 1990, Maisushima 1989, May 1989. Muir 1988, Nieffeld 1990, Thonar 1985, Wilbrink 1991, Woessner 1991, Zanetti 1985).

With age, not only the thickness of articular cartilage changes but also its composition. The PG content decreases, the structure of the collagen fibrils changes, and the calcified zone gets thinner (Bayliss 1990, Bullough 1981. Gray 1988. Kuijer 1985, Mallinger 1987, Sokoloff 19831. In elderly people chondrocytes also appear to have a diminished metabolic capacity in responding to compressive forces.(Hammerman 1989, Rosenberg 1985). These changes in old cartilage result in impaired mechanical properties of the joint. Due to diminished mechanical loading in the elderly, however, the impaired mechanical properties do not always lead to degenerafive $O A$.

We may conclude that a lot of information about the sequence of events in the process of $\mathrm{OA}$ is available, but only very little is known about the onset of primary OA. So far, it has not been possible to detect a sole cause responsible for primary $\mathrm{OA}$ and unto now $\mathrm{OA}$ is assumed to be the result of a multifactorial process.

\section{4 Therapy}

\subsection{Conservitive Ereatment}

In a large number of patienis with OA, the sequence of symptoms, such as pain, loss of function, and reduced weight bearing capacity: results in serious disability.

Therefore, the treatment of the patient with $\mathrm{OA}$ should be directed at interference with this chain of symptoms. Conservative treatment directed at pain reliet and increased mobility of the patient can often provide an important reduction of disability.

Operative treatment may be used for mechanical realignment of the joint, and may thus reduce the speed of cartilage degener ion. Due to the lack of knowledge about the etiology of $\mathrm{OA}$ up to now there is no real therapeut $C$ special exercises to ensure good muscle balance are beneficial to most of the patients (Al Arfag 1991).

\subsubsection{Drug treatment}

In most cases, patients with $\mathrm{OA}$ consult physicians because they are in pain. In cases 
without synovitis simple analgesics are advised. Non steroidal anti-inflammatory drugs (NSAID) are widely used for OA patients with transient synovitis, although general side effects and effects on the pathological process itself have been described (Agrawal 1990, Baum 1985, Brand 1984, Collier 1991, Doyle 1981, Graham 1988, Herman 1986, Palmoski 1983, Vries 1987). The intra-articular administration of steroids is especially beneficial to patients having acute inflammation of the synovium as well as OA. These agents have an inhibiting effect on the synthesis of cartilage matrix degrading factors produced by chondrocytes and inflamed synovium (Ghosh 1991, Mankin 1986, Moskowitz 1975). Although NSAID have beneficial effects on the synthesis of inflammatory mediators, the possibility of direct cartilage injury by these drugs should be kept in mind. Although pain relief is essential to the patient, it may also lead to overuse of the joint, causing aggravated breaking down of cartilage (Behrens 1976, Brandt 1988, Collier 1991, Moskowitz 1970, Redini 1990). Besides NSAID, a number of drugs are available for the treatment of OA. In in vitro and animal experiments high molecular weight compounds such as:

glycosaminoglycan peptide complex (Rumalon?), glycosamino (poly)sulfate (DONA. $S^{R}$, Arteparon ${ }^{R}$ and growth factors stimulate chondrocyte metabolism and inhibit the activity of cartilage degrading enzymes (Altman 1989, Francis 1989, Hannan 1987. Howell 1986, Malze 1983, Moskowitz 1989, Nishikawa 1988, Olijhoek 1988, Poul 1974, Prins 1982). In clinical studies the beneficial effects of these drugs on symptoms of $\mathrm{OA}$ frequently have been reported. Because these agents have no analgesic effect, the observed clinical improvement seems to be the result of an advantageous effect on cartilage or synovium itself. Not only has hyaluronic acid (HYA) a lubricating effect, but it also improves diffusion of nutrients from the synovial fluid into the cartilage. However, the most important property of HYA is its capacity to inhibit synovitis and thereby synthesis of cartilage degrading substances by the inflamed synovium. Clinically it provides pain relief when the patient is at rest as well as moving about, while in vitro at least the cartilage breakdown is delayed (Abatangelo 1989, Dixon 1988, Melching 1990. Schiavinato 1989. Seppala 1969, Strachan 1990). It is only recently that the potential beneficial effect of some of these chondroprolective agents was confirmed in well- documented trials in patients with OA (Pastinen 1988, Raaitikainen 1990).

\subsubsection{Surgical treatment}

If conservative treatment fails, pain persists and $O A$ progresses, eventually resulting in invalidating loss of function of the joint. Re-alignment osteotomies and open debridement used to be the most frequently performed operations. Uackson 1961. Pridie 1959, McMurray 1935). Recently the possibilities of arthroscopic debridement, combined with adequate post-operative treatment have enlarged the operative prospects (Burks 1990, Dandy 1991, Friedman 1984, Jackson 1986, Johnson 1986, Livesly 1991, Ogilvie-Harris 1991. Small 1988). By abrasion 
arthroplasiy, cartilage flaps that might encroach are removed. Also, degenerated menisci, causing further destruction of the joint, may be removed arthroscopically. Drilling of the subchondral bone plate allows vascular ingrowth from the subchondral bone, which is considered to be a prerequisite for a regenerative process (Convery 1972, De Palma 1968, Salter 1980). By continuous passive motion (CPM) in the immediate postoperative care restoration with fibrocartilage and acceptable joint function are achieved (Convery 1972, Frank. 1984، O'Driscoll 1984).

Especially for younger patients with small defects of the cartilage surface, biological resurfacing techniques using chondrocytes, periosieum, perichondrium or osteochondral grafts have been proposed (Bentley 1971, Czitrom 1990, Coutts 1992, Homminga 1990, Kon 1983, Linden 1972, Meyers 1978, Skoog 1975. O'Driscoll 1986, Ottolenghi 1972, Zarnett 1987). The advantage of these techniques is the possibility of repairing the cartilage defect with tissue that differentiates into hyclin cartilage (O'Driscoll 1980, Tanaka 1971, Woo 1987). In clinical practice, however, many problems will have to be tackled. Not only the fixation of the transplant causes difficulties, but also the viability of the cells, metaplasia of the transplant, possible contamination by fresh allo-grafts, and rejection of an allograft.

All the conservative and operative procedures employed are important intermediary steps in the treatment of $O A$ patients. If pain and disability persist, replacement of a joint with an artificial implant has to be considered.

Up to now, however, prosthesis survival in the patient is limited, due to fixation problems of the implant to the bone. Therefore prosthetic implantation is restricted to patients with a more or less limited life expectation. Recent developments in the fields of biology and biomechanics offer new perspectives for the survival rates of artificial implants (Engh 1987. Geesink 1987). 


\section{CHAPTER 2}

\section{Introduction to and discussion of the experimental work}

\subsection{Introduction}

The experimental part of this thesis is directed at three important facets of the field of osteoarthritis $|O A|$ research: the histological processing and histopathological qualification of cartilage, the culture characleristics of human chondrocytes in a short lerm high density system and three diffe- rent therapeutical options used in the treatment of patients with $O A$.

The histological evaluation of cartilage sections plays a fundamental role in the study of $O A$. In most studies histological sections are used as the starting point for the analysis of research on pathogenesis and biochemical aspects of $O A$. We therefore evaluated the histological methods used for the study of $|O \mathrm{~A}|$ cartilage. A modified histopathological score for OA based on new histological methods is presented.

The majority of experiments to elucidale the process of OA has been carried out in animal cartilage. It was shown however that the pathophysıology of experimentally induced $O A$ in animals differs considerably from the process of primary $O A$ in man. We therefore studied a culture system in which human chondrocytes might retain their phenotypic characteristics. Such a culture systern would then enable us to study the pathophysiology of human $O A$ chondrocyles in vitro.

In the newly designed culture model the effects of a non steroidal antiinflammatory drug (NSAID), frequently used as a plain painkiller was studied on chondrocyle metabolism in vitro.

Spontaneous recovery as well as most of the surgical procedures used, result in repair of cartilage defects with fibrocartilage that has reduced biomechanical properties compared to hyalin cartilage. Therefore we evaluated the properties of adult human perichondrium for the formation of hyalin cartlage in vitro

The demolishing effect of septic arthritis on cartilage integrity, prompled the study of the feasibrility of local administration of antibiotics into the point. The effect of a frequently used antibiotic for the treatment of septic arthritis (gentamicin) on cartilage metabolism was therefore studied in vitro on animal cartilage 


\subsection{The reliability of the Mankin score for osteoarthritis}

For both in vivo and in vitro studies of OA cartilage, a consistent and uniform system for the evaluation of the severity of $O A$ is of importance. The histopathological classification of the severity of OA according to Mankin et al. (Mankin 1971) is frequently used. In this grading system the structural, cellular, and staining abnormalities of $O A$ cartilage are assessed. From our experience with this grading system, we learned that the original Mankin criteria seemed not to be applicable to our OA cartilage sections. In our material we found that the depth of the clefts into the cartilage did not correlate with the extent of the disorganization of the cartilage structure. The amount and localization of the chondrocyte clusters proved to vary with the extent of the cartilage destruction. The stainability of the cartilage matrix, with stains used to quantify the content of negatively charged GAG, was reduced in $O A$ cartilage, compared to healthy cartilage. It proved to be difficult, however, to express this reduction in terms of slightly, moderately and severely reduced matrix stainability as was proposed by Mankin et al.

In order to design a more convenient histopathological score for $O A$, five experienced observers examined the sections of experimentally induced $O A$ in rabbits. The basic characteristics of the Mankin score were used: sfrucfural changes, cellular abnormalities and matrix stainability. We introduced two new aspects, I: thickness of the superficial layer and II: a more extensive description of the cartilage arganization for the qualification of the structural changes in $\mathrm{OA}$ cartilage. Furthermore, the description of the cellular abnormalities was changed by adding the: localization as well as the quantity of the chondrocyte clusters. The quantification of the stainability of the cartilage matrix was modified. Increased structural and cellutiar disorganization was observed to accompany decreased stainability with specitic matrix stains from the surface down ta the deep cartilage layer, and decreased stainability from the interterritorial to the territorial layer. These parameters were also introduced into the new system for the qualification of the matrix stainability.

In order to compare the validity of the original Mankin score with the newly developed score for $O A$ cartilage, the observers studied 71 sections of experimentally induced $O A$ in the rabbit. The score of the severity of OA was recorded twice by the five observers, with an interval of two weeks. The inter- and intra-observer reliability was determined. The data obtained with the original Mankin score showed that the inter- and intra-observer differences both were 1.7 points on a scale of 0 to 14 points. The newly developed criteria for the severity of $O A$ produced a slight reduction in the inter-observer variability to 1.5 points. However: the new criteria were found to make posșible a more rapid qualification of the extent of $\mathrm{OA}$ in our tissue sections. This accelerated process was caused by the more accurate description of the structural changes and the more suitable quantification of the stainability of the matrix for the five observers. 
From this study we conclude that the Mankin score can be used as an adequate histo pathological means. The newly developed criteria proved to improve the qualification of $O A$ cartilage by the observers and did not reduce the sensitivity of the score. In later experiments we therefore used the newly developed criteria for the histopathological score of $\mathrm{OA}$.

\subsection{Thionin staining of paraffin and plastic embedded cartilage sections}

During the evaluation of the histopathological score of preparations of normal and OA cartilage it became obvious that in paraffin-embedded cartilage sections the structure of the chondrocytes had been partly destroyed.

Normally the cartilage samples are embedded in paraffin after decalcification and dehydration. Quantitative histochemical methods ore then used io measure the content of negatively charged glycosaminoglycans (GAG]. The methods used to asses the quantity of GAG in the cartilage matrix involve the use of specific cationic dyes. Safranin- $O$ is frequently used in permanently mounted sections, because it has been proven to bind stoichiometrically to the matrix polyanions of cartilage in its orthochromatic form. In order to clarify the histological aspect of the subchondral bone, fast green is frequently used as a counierstain to safranin- $\bigcirc$.

During our previous experiments, the procedure of safranin- $O$ fast green staining turned out to be especially sensitive, to the incubation time of the dyes. Slight changes in the incubation time with fast green clearly changed the stainability with safranin- $O$, hampering the qualification of the cartilage matrix. A further disadvantage of decalcification, dehydration, and paraffin-embedding is the change of chondrocyte morphology due to shrinkage of the cell. Also in paraffin-embedded sections the stainability of the perilacunar network was partially losi due to collapse of the territorial zone.

We studied the effects of dehydration, decalcification, and paraffin and glycolmethacrylate (GMA)-embedding on cartilage morphology. GMA was used because in general tissue structure is better pertained in these sections. Thionin was used as an alternative dye for safranin-O.

The effect of decalcification with 10\% EDTA as well as with $5 \%$ formic acid on cartilage morphology was examined. Furthermore the effect of dehydration combined with paraffinembedding was investigated. Short decalcification with each of the decalcifying agents did not affect the stainability or the morphology of the cartilage, but dehydration in combination with histosol and paraffin embedding caused a collopse of the perilacunar network and of the chondrocytes within their lacunae. The characteristics of thionin staining of cartilage components was studied by the densitometric analysis of the effect of different enzyme digestions on cartilage morphology. The intensity of the thionin stained matrix was invariable over a range of incubation periods. Thionin stained negatively charged GAG in paraffin and in GMA 
embedded cartilage sections. Thionin, in contrast to safranin-O, however, did not show metachromasia in undehydrated GMA-embedded cartilage sections. Therefore, thionin seems to have advantages compared to safranin-O for the qualification of cartilage in GMA-embedded sections. GMA-embedded cartilage sections allow a better judgement of cellular abnormalifies than paraffin-embedded cartilage sections, which show a clear chondrocyte collapse. Microscopically the perilacunar network in the GMA-embedded tissue appeared to be intact, permitting a better insight in the process of (de-)differentiation of cartilage than possible in paraffin-embedded tissue.

We conclude therefore that, although paraffin embedded cartilage sections stained with safranin-O give an accurate impression of the quantity of negatively charged GAG, the structure of the cartilage is partially destroyed in such sections. In contrast, a more accurate analysis of cartilage structure and the amount of negatively charged GAG is possible in GMA-embedded cartilage sections stained with thionin.

\subsection{Metabolic characteristics of in vitro cultured human chondrocytes in relation to the histo-pathological degree of osteo-arthritis}

Studies using animal models for $O A$ have elucidated biological changes which accompany $\mathrm{OA}$. The advantages of using animal models lie in the possibility of controlling the number of variables. The comparison of different groups of animals, subjected to certain manipulations, enables. us to follow the macroscopic, microscopic and biochemical evaluation of the process of $\bigcirc A$ step by step. Animal models correspond to, in part and on a temporal basis, the biological changes that characterize $O A$ as seen in humans. The introduction of $O A$ lesions in animals, however, relies on the induction of abnormal biomechanical stresses or responses to induced inflammation. However by using these lechniques the process of secondary $O A$ is studied in these animals. In most of the animal models $O A$ resembles the early phase of human $O A$, but does not develop into the more advanced stages of $O A$. In fact, the process of $O A$ in most animal models deviates from $O A$ in human beings, e.g. in the Pond-Nuki model, which does not lead to more advanced OA until several years later. Moreover, impariant species differences regarding histological and biochemical composition of articular cartilage have been reported, which makes comparison of experimental animal data with human pathology difficult, if not impossible.

Unfil recently human chondrocytes have not been used frequently, because of the difficulties in obtaining a reliable source of human cartilage. The material obtained at surgical procedures often shows advanced $O A$. Furthermore, in experiments in vitro acquiring a culture system that could maintain the phenotypic characteristics of chondrocytes proved to be difficult. Monolayer cultures induce rapid degeneration of the cells and the production of deviated matrix substances. Explant cultures show an initial period of enhanced PG synthesis, while at the same time the 
loss of newly synthesized PG and PG subunits increases.

Only more recenily it has become clear that, in in vitro culture, the environmental conditions of the chondrocytes are of eminent importance for chondrocyte growth and differentiation. Experiments with isolated embryonic chicken chondrocytes have shown that high cell density and reduction of the surrounding matrix favoured chondrogenesis. De-differentiation of already differentialed isolated chondrocytes could be prevented by suspension culture, culture of cells in gels or in pellets.

The aim of this study is to investigate if isolated adult human chondrocytes maintain their characteristic phenotype in a high density culture system, and whether such a culture syslem offers an opportunity to study the role of the chondrocyte itself in the early phases of $O A$ as well as during more advanced $O A$. The relation between the histopathological degree of $O A$ and the merabolic capacities of the chondrocytes in culture could then be studied in this shorkterm culture system.

For this study we used human cartilage derived from the hip and the knee. All cartilage was obtained during arthroplastic surgery for OA only. The cartilage used for these experiments was carefully selecied from small areas with uniform $O A$ in the weight bearing zone of the joint. Histopathological evaluation was done by' adaptation of the criteria originally described by Mankin. After isolation of the chondrocyles with collagenase the cells. were counted, resuspended and culfured in a drop culture.

After 5 days of culture a coherent aggregate had been formed. Histological evaluation showed chondrocytes surrounded by matrix that stained intensively with safranin-O and alcian-blue, thereby demonstrating features of normal cartilage. The proliferation and metabolic capacity of the isolated chondrocytes was expressed as the ${ }^{3} \mathrm{H}-\mathrm{TdR}$ and the ${ }^{35} \mathrm{~S}$-sulfate incorporation into the cultured aggregate. Proliferation of the cells and quantification of the GAG synthesis after 5 days of culture showed close correlation with the histopathological degree of $O A$ in these experiments. The DNA concentration of the pellets was measured from day zero onwards during culture and showed no change in DNA content, regardless of the severity of $O A$. These data suggest that the increase in GAG production was an intrinsic property of the cultured chondrocytes. Autoradiography showed that ${ }^{3} \mathrm{H}-\mathrm{TdR}$ and ${ }^{35} \mathrm{~S}$-uptake was scattered over the cell pellets atter 5 days of culture, indicating that the cultured cells consisted of a homogenous population of metabolically active and living cells

From these experiments we concluded that, under the conditions used, adult human chondrocytes form aggregates of chondrocytes, surrounded by matrix that contains GAG typical for hyalin cartilage. The chondrocytes, retained their metabo-lic capacities in culture, and a consistent relationship between the severity of $\mathrm{OA}$ and the proliferative and metabolic capacity of the cells in vitro was found. So the culture system seems to offer a suitable in vitro technique to study the pathogenesis of OA. In vitro, however, exogenous factors influencing cartilage 
metabolism in vivo are excluded. Nevertheless, chondrocytes cultured in high density represent characteristics of the histopathological degree of OA. These data support the hypothesis, that $O A$ chondrocytes differ from healthy chondrocytes in their phenotypic properties.

\subsection{The potential of adult human perichondrium to form hyalin cartilage in vitro}

The potential of human chondrocytes to repair traumatic and osteoarthritic (OA) cartilage defects is limited. From our previous studies we learned that $O A$ chondrocytes retain their metabolic and proliferative characteristics, distinctive for a certain degree of OA. Quantitatively, at least no changes towards the metabolic. properties of healthy chondrocytes are observed. Even if repair of cartilage defects takes place, the degenerated chondrocytes produce tissue that resembles fibrous tissue or fibro-cartilage. Moreover, only partial restoration of these cartilage defects results in incongruency of the joint and even more cartilage degeneration will develop.

Animal studies have shown that only a limited number of tissues can form hyalin cartilage. Perichondrium proved to be one of the few tissues with the essential properties to form hyalin cartilage in vitro and in vivo. These studies, however, were generally done with immature animal perichondrium. So far, human perichondrium has only been used in a limited number of cases with a varying success rate.

Therefore the ability of adult human perichondrium to form hyalin cartilage has been questioned. Besides, in humans, the depth of a cartilage defect that has to be restored largely exceeds the thickness of animal cartilage (e.g. in the knee).

Consequently, the aim of this study was to investigate the qualitative and quantitative pofential of adult human rib perichondrium to form hyalin cartilage in vitro.

For this study we cultured adult human perichondrium, having removed all residual cartilage. The explants were studied histologically, using specific stains for glycosaminoglycans (GAG) normally present in healthy hyalin cartilage. The thickness of the explant was measured before culture and after 7 and 10 days of culture. In order to define the localization of proliferation, autoradiography was performed after labelling with ${ }^{3} \mathrm{H}-\mathrm{TdR}$. The histological evaluation revealed that the dissected perichondrium consisted of three layers, rib cartilage was only seldom present. The mean thickness of adult human rib perichondrium proved to be $470 \mu \mathrm{m}$. After 7 days of culture the morphology of the cells in the inner layer had changed towards chondrocyte-like cells. Also, the newly synthesized matrix was stained with dyes specific for hyalin cartilage. The thickness of the newly formed cartilage layer increased (from 0 to $300 \mu \mathrm{m}$ ) during the time of culture. Autoradiography showed that the majority of the cells of the inner layer proliferated. 
From these experiments we concluded that the inner layer of adult human perichondrium can form hyalin cartilage in vitro. The potential of human perichondrium to form cartilage is higher than that of rabbit perichondrium. A relative hypocellularity, normal in adult human cartilage, is found compared to the hypercellular tissue found in animal cartilage. Compared to cartilage derived from animal perichondrium, the newly synthesized cartilage in these experiments resembles more closely human cartilage, although the orientation of the chondrocytes normal for hyalin cartilage is not present. We presume that this may be caused by the lack of compressive forces in vitro.

Our data indicate that adult human perichondrium might be used as an autologous transplant for the restoration of cartilage defects in a joint. If it can fill the defect with tissue that resembles hyalin cartilage, the inevitable progressive cartilage destruction that normally takes place in a joint with a cartilage defect might be prevented.

\subsection{The effect of gentamicin on the metabolism of in vitro cultured rat patella cartilage}

Septic arthritis of a joint may not only cause rapid and inevitable cartilage destruction of the joint, but also bears the risk of affecting the general condition of the patient. Sepfic arthritis is often difficult to diagnose, because it frequently occurs in patients with a reduced capacity to eliminate bacterial organisms, which do not show all the characteristic symptoms of arthritis. That is why there frequently is a delay of two to three days in the treatment of arthritis. Aggressive surgical drainage, combined with appropriate antibiofic treatment cannot prevent considerable cartilage destruction due to the residual bacteria adhering to the cartilage surface (Nade 1987).

Penetration of intravenously administered antibiotics into the joint space is generally good in the first few doys. Thereafter it is difficult to maintain the essential local high concentration of antibiotics needed for the elimination of bacteria. This is caused by the inter- and intra-patient variability in drug concentration and the toxicity of the antibiotics. As the same time the production of intra-articular debris and the fast development of fibrous tissue in the synovial lining cause the decrease of intraarticular antibiotic concentrations.

local treatment of septic arthritis, consisting of frequent debridement combined with the intra-articular administration of antibiotics, could overcome some of these problems. Little is known, however, about the effect of antibiotics on cartilage metabolism. The subject of this study was to evaluate the effect of gentamicin on cartilage metabolism. Gentamicin was chosen because it is one of the most frequently used anfibiotics in the treaiment of septic arthritis. Another reason for the selection of gentamicin was the wide experience that has been gained in the treatment of osteomyelitis, using local delivery systems containing gentamicin. 
Our primary choice was to evaluate the effect of gentamicin on human cartilage in short term cultures. Pilot experiments proved that, due to the aggressiveness of the bacteria, quick destruction of the newly forned cartilage aggregates took place, even in the presence of high concentrations of antibiotics; the destructive effect of bacteria on cartilage was proven, but it became clear that the culture system was not accurate enough for the study of septic arthritis. Accordingly we decided to determine the effect of gentamicin on cartilage explanis. It has been proven, however, that in order to prevent leakage of proteoglycans into the culture medium, anatomically intact explants should be used (de Vries 1987). Because these anatomically intact human explants are not available, we decided to use the anatomically intact rat patella for this study.

The patellae were incubated with different doses of gentamicin for 6 , respectively 48 hours. The metabolic activity of the chondrocyles was measured by the incorporation of ${ }^{35} \mathrm{~S}$-sulfate in the GAG. The final concentration of gentamicin and the protein binding was assessed. For the assessment of the histo-pathological aspects of the patellae we used the modified Mankin score.

The results of this study indicate that gentamicin did not influence the metabolic capacity of the chondrocytes in these short term explant cultures. Moreover the histopathological aspect of the patellae showed unaffected cartilage in the gentamicin treated patellae. We conclude that the intra-articular administration of gentamicin, even in very high doses, does not inhibit cartilage mefabolism. If is well known from other studies that these high local concentrations of gentamicin do not affect the general health of the patient. Local antibiotic treatment of sepfic arthritis, therefore, offers the possibility of maintaining a constant high concentration of gentamicin in the joint, necessary for eliminating the adhering bacteria and those that have intruded into the joint cartilage.

\subsection{The effect of piroxicam on the metabolism of isolated human chondrocytes in vitro}

Pain is the primary feature in Osteoarthritis $(O A)$ and Rheumatoid arthritis (RA). Synovitis and effusion of the joint cause pain in RA and in OA; therefore nonsteroidal anti-inflammatory drugs (NSAID) are often used for the treatment of both these disorders. Synovitis, however, is not the only cause of pain in $O A$ and certainly not a constant phenomenon in patients with OA. Pain in OA joints may also be caused by impingement of loose cartilage flaps and the presence of regions of bare subchondral bone on the articular surface. In contrast to RA, in OA the disease in most patients is confined to a single joint. The main purpose of NSAID is to inhibit the release of various humoral factors released by the inflamed synovium, thus impeding the negative effects of these factors on cartilage metabolism. At the same time, 
however, several NSAID have been reported to impair cartilage proteoglycan metabolism in vitro as well as in vivo.

It is therefore questionable if the primary choice of NSAID in the treatment of localized OA, frequently without synovitis, would not in fact be more harmful to the patient and accelerate the process of the disease. Accordingly, the aim of this study was to investigate whether NSAID influence the metabolism of human cartilage.

During our previous experiments it became clear that isolated human chondrocytes retained their phenotypic characteristics in high density culture. Due to the relation between the histopathological degree of $O A$ and the proliferative and metabolic capacity, the culture model seemed appropriate to test the effect of NSAID in vitro on separate degrees of $O A$. Piroxicarn was chosen because it is a frequently used NSAID which must only be taken once a day. In explant cultures piroxicam seemed to have no negative effect on the metabolism of animal cartilage (de Vries 1987). We studied the effect of piroxicam on the metabolism of isolated human chondrocytes derived from different degrees of $O A$.

For these experiments cartilage was obtained during reconstructive surgery of the hip and knee joint. Isolated chondrocytes were cultured in high density. Piroxicam was added in concentrations from $0-10 \mu \mathrm{g} / \mathrm{ml}$ on day 5 of culture, and metabolic. activity and cell proliferation were measured using ${ }^{35} \mathrm{~S}$-sulfate and ${ }^{3} \mathrm{H}-\mathrm{TdR}$ incorporation respectively. Samples of the medium were used to determine the total and free concentration of piroxicam.

The data showed that, over the concentration range used, $40 \%$ of total piroxicam concentration was protein-bound. The proliferafive capaciry of healthy chondrocytes was inhibited from a concentration of $1.6 \mu \mathrm{gg} / \mathrm{ml}$ and higher, while the metabolic activity was inhibited at a concentration of $2.5 \mu \mathrm{g} / \mathrm{ml}$ and higher. In contrast to these results, piroxicam did not influence the metabolism of moderately OA cartilage. In severely damaged cartilage, however, piroxicam inhibited cell proliferation at concentrations of $1.25 \mu \mathrm{g} / \mathrm{ml}$ and over.

From these data we concluded that piroxicam, in concentrations that are within the limits of those found in vivo, clearly inhibits the proliferative capacity of severely OA cartilage. Moreover, the metabolic and proliferative capacity of healthy cartilage in vitro is inhibited, which is to say that, in vivo, the metabolism of cartilage. in the healthy joints might be at risk after infake of NSAID such as piroxicam. We should therefore restrict NSAID, such as piroxicam, to the treatment of OA joints with synovitis and not use them as, normal analgesics for patients with painful $O A$ without synovitis. 


\section{Literature}

Abalangelo G., Bolth P., Del Blue M., Gei G. Samșon J. C., Cortivo R., De Galaleo A and Martelli M. Intraarticular sodium hyaluronate injections in the pond nuki experimental model of asteoarthritis in dogs. Clin. Ont, Rel. Res. 1989; 241:278-285.

Acheson R.M. Heberden oration 1981: Epidemiology and the arthritides. Ann. Rheum. Dis. 1982: $41: 325-334$.

Adamas M.E. and Brandt K.D. Hypertrophic repair of canine articular cartilage in osteoarthritis after anterior cruciate ligament transection. J. Rheum. 1991; 18, 3:428-435.

Adams S.L., Pallante K.M. Niu Z., leboy P. S., Golden E. B and Pocifici M Rapid induction of type X. collogen gene expression in cultured chick vertebral chondrocyles. Exp. Cell Res. 1991: 193 190-197

Agrawai N.M. and Dajani E.Z. Options in the treatment and prevention of NSAID induced gastroduodenal mucosal damoge. J. Rheum. 1990; 17 (suppl. 20):7.11

Al Arfag A and Davis P. Osteoarthritis 1991. Current drug treatment regimens. Drugs 1991; 2.193-201

Allard S.A. Bayliss M.T. and Maini R.N. The synovium-cartilage junction of the normal human knee Arthritis Rheum. 1990; 8:1170-1179.

Aliman R.D. Dean D. D. Muniz O.E and Howell D. S. Prophylactic treatment of canine osteoarthritis with glycosaminoglycan polysulfuric acid ester Arthritis Rheum. 1989; 6.759-766

Altman R D Overview of osteoarthritis. The Am. I. Med 1987, 83:65-70

Altman R.D. Osteoarthritis. Aggrevating factors and therapeutic measures. Postgrad Med. 1986; 2:150. 163.

Altman R.D., Dean D.D., Muniz O.E. and Howell D.S. Therapeutic treatment of canine osteoarthritis with glycosaminoglycan polysulfuric acid ester. Arthritis Rheum. 1989; 10:1300-1306.

Anderson J.D., Duthie J J.R. and Moody B.P. Social and economic effects of rheumatic disease in a mining population. Ann. Rheum. Dis 1962; 21:342.352.

Andrews J.L. and P. Ghosh. Low molecular weight serine profeinase inhibitors of human articular cartilage Arthr. Rheum. 1990; 33,9:1384-1393

Archer C.W., McDowell J., Bayliss M T., Stephens M.D and Bentley G. Phenotypic modulation in subpopulations of human articular chondrocyles in vitro. J. Cell Science 1990; $97: 361.371$

Armstrong $C$. Mow V. Variations in the intrinsic mechanical properties of human articular cartilage with age, degeneration and water content. J. Bone Joint Surg. 1982; 64.A. 88-94

Aydelotte M. B. and Kueltner K.E. A. histochemical study of distributions of proteoglycans in cultures of aduilt bovine chondrocytes in agarose gel Trans 30th meeting. Orth Res Soc 1984:9117 
Bagge E., Bjelle A., Eden S. and Svanborg A. Osteoarthritis in the elederly: clinical and radiological findings in 79 and 85 year olds. Ann. Rheum. Diss, 1991; 50:535-539.

Balazs E.A., Watson D., Duff I.F. and Roseman S. Hyaluronic acid in synovial fluid I. Molecular parameters of hyaluronic acid in normal and osteoarthritic human fluids. Arthritis Rheum. 1967; 10:357-376.

Balazs E.A. The physical properties of synovial fluid and the special role of hyaluronic acid. ed. Helfet A. Disorders of the knee. Philidelphia, Lippincott 1974, 61.74.

Baum C., Kennedy D.L. and forbes M. B. Unilization of nonsteroidal antinflammatory drugs. Arthritis Rheum. 1985; 6:686-692.

Bayliss M.T. Proleoglycan structure and metabolism during maturation and aging of human articular cartilage, Biochem. Trans. 1990; 18:799-802.

Bayliss M.T. and Ali S.Y. Age related changes in the composition and structure of human articular cartilage proteoglycans. Biocem. J. 1978; 176:683-694.

Behrens F., Shepard N. and Mirchell N. Melabolic recovery of articular cartilage after intra articular injection of glucocortcoids. J. Bone Joint Surg. 1976; 58.A:11 157.1160

Benn T. and Wood P.H.N. Generalised osteoarthrosis. A problem of definition. Arthritis Rheum. 1975 . 34. $466-470$.

Bentley G., Dowd G. and Orth MCh. Current concepts of etiology and treatment of chondromalacia patellae. Clin. Orthop. Rel. Res. 1983; 189:209-228.

Bentley G. Articular cartilage changes in chondromalacia patellae. J. Bone Joint Surg. 1985; 67. B:769. 774

Bentley G. and Greer R.B. Homotransplantation of isolated epiphyseal and articular cartilage chondrocytes into joint surfaces of rabbits. Nature 1971:230:385.388

Bentley G. Chondromalacia patellae 1. Bone Jount Surg. 1970; 52.A.221.232

Besseling 」. WAO toetreders uit 1985. T Verzek Gen 1988; 4:130-135

Brand H.S., Kampen van G.PJ., Stadt van de RJ., Kuijer R. and Korst van der J.K. Effect of sulfate. concentration on glycosaminoglycan synthesis in explant cultures of bovine articular cartilage. Cell Biol. Int Rep. 1989; 2:153.162.

Brandt K.D. A pessimistic view of serologic markers for diagnosis and manogement of ostecarthrilis. Biochemical, immunologic and clinicopathologic barriers. J. Rheum. 1989; 16:39:44.

Brandi K.D. and Palmosky M. Organization of ground substance proteoglycans in normal and osteoarthritic knee cartiloge. Arthritis Rheum. 1976; 19:209-216.

Brandt K.D., Braunstein E.M. Visco D.M., O Connor B., Heck D and Albrecht M. Anterior (Cranial) cruciate ligament transection in the dog: a bona fide model of osteoarthritis, not merely of cartilage injury and repair. J. Rheum. 1991: 18, 3:436-446.

Brand! K.D. NSAID's and their effects on articular cartilage. Eular I for Education and Information in Rheumatology 1988; 1:19.2.1. 
Broom N.D. Abnormal softening in articular cartilage: its relationship to the collagen framework. Arthritis Rheum. 1982; 25:1209-1216.

Bruckner P., Horler I., Mendler M. Houze Y., Winterhaller K.H., Eich-Bender S.G. and Spycher M.A. Induction and prevention of chondrocyte hypentrophy in culture. I. Cell Biol. 1989; 109:2537-2545.

Bullough P.G. The geometry of diarthrodial joints, its physiological maintenance and the possible significance of age related changes in geometry to load distribution and the development of osteoarthritis: Clin. Ort. Rel. Res. 1981; 156:61-66.

Burks R.T. Arthroscopy and degenerative artrhritis of the knee: A review of the literalure. Arthroscopy $1990 ; 1: 43-47$.

Byers P. D. Maroudas A., Oztop F. Stockwell R. and Venn M.F. Histological and biochemical studies on cartilage from osteoarthrotic femoral heads with special reference to surface characteristics. Connect: Tissue Res. 1977, 5.41.49

Byers P.D. Conteporni C.A and Farkas T. A. A postmortern study of the hip joint. Ann Rheum. Dis. 1970, 29. 15.31

Campbell I.K., Guttman A., Golds E.E, Roughly PJ. and Mort J.S. Variation in the effects of mononuclear cell products from different individuals on metalloproteinase secretion from human articular cartilage. J. Rheum. 1989; 16:1552-1558.

Child A.H. Joint hypermobility syndrome: inherited disorder of collogen synthesis J. Rheumatol. 1986: 2:239-243

Claessens A.A.M. C. Schoulen I.S.A. G. Ouweland van den F.A. and Valkenburg H.A. Do clinical findings associale with radiographic osteoarthritis of the knee? Ann Rheum Dis 1990, 49.771.774

Collier S, Ghosh P. Comparison of the effects of non steroidal anti inflammatory drugs (NSAID) on proteoglycan synthesis by articular cartilage explant and chondrocyte monolayer cultures Biochem Pharmacol. 1991: 9:1375-1384.

Convery F.R., Akeson W.H. and Keown G.H. The repair of large osteochondral defects. Clin. Ort. Rel. Res. 1972; 82:253.262.

Coutts RD. Woo S L-Y. Amiel D. Schroeder von H.P and Kwan M.K Rib periochondrial aulografts in fullthickness articular cartilage defects in rabbits. Clin. Orthop. Rel. Res. 1992, 275:263-273.

Czitrom A.A., Keating S and Gross A.E. The viability of articular cartilage in tresh osleochondral allografts after clinical transplantation. J. Bone Joint Surg. 1990; 72-A.574.58 I

Dahl L.B., Dahl I.M. Engstrom-Laurent A. and Granath K. Concentration and molecular weight of sodium hyaluronate in synovial fluid from patients with rheumatoid arthritis and other arthropathies. Ann. Rheum Dis. $1985 ; 44: 817-822$.

Dandy DJ. Arthroscopic debridement of the knee for osteoarthritis. J. Bone Joint Surg. 1991; 73-B, 6:877. 878.

Davis M.A., Ettinger W.H. Neuhaus J M Obesity and osfeoarthritis of the knee evidence from, the national health and nutrition examination: survey. Semin. Arthritis Rheum. 1990; (suppl 1):34-4) 
De Palma A.F., McKeever C.D. and Sabin D.K. Process of repair of articular cartilage by histology and autoradiography with tritialed thymidine. Clin, Orthop. Rel, Res. 1968; 148:229.

Dean D.D., Martel-Pelletier J., Pelletier JP. Howell D.S. and Woessner J.F. Evidence for metalloproleinase and meialloproteinase inhibitor imbalance in human osteoarthritic cartilage. J. Clin. Invest. 1989; 84:678685.

Dingle J.T., Saklatvala J., and Hembry R. A cartilage catabolic factor from synovium. Biochem. J. 1979: 184:177-180.

Dingle J.T. Recent studies on the control of joint dạmage Ann. Rheum. Dis. 1979; 38:201-214.

Dingle J.T. Cartilage maintenance in osteoarthritis, interaction of cylokines, NSAID and prostaglandins in articular cartilage damage and repair. J. Rheum. 1991; 18/281:30-37

Dixon A.SH., Jacoby R.K., Berry H. and Hamilton E. B.D Clinical trial of intraarticular injection of sodium hyaluronate in patients with osteoarthritis of the knee Curr. Med. Res. Opin. 1988; 11:205-213

Doyle D. V., Dieppe P.A., Scott J and Huskisson E. C. An articular index for the assesment of osleoarthritis Ann. Rheum, 1981; 40:75-78

Ehrlich M.G., Armstrong A.L., Treadwell B.V. and Mankin HJ. Degradative enzyme systems in cartilage. Clin. Ort. Rel. Res. 1980; $213: 62-68$

Ehrlich M.G. Degradative enzyme systems in osteoarthritic cartilage. J Orthop, Res. 1985, 3:170-184

Engh C.A., Bobyn J.D. and Glassman A.H. Porous coated hip replacement: The foctors governing bone ingrowth, stress shielding and clinical results. I. Bone Joint Surg. 1087; 69-B:45-55

Enomoto M. Pan H-O, Kinoshita A., Yutani Y. Susuli F. and Takigawa M. Effects of fumor necrosis facior $\alpha$ on proliferation and expression of differentiated phenotypes in rabbit costal chondrocytes in cullure. Calcit. Tissue Int. 1990; 47: 145-751.

Epidemiological aspects of ostecoarthritis. Scand. J. Rheumatol. Suppl. 1988, 7729.33

Eyre D., MçDevitt C.A., Billingham M.EJ and Muir H. Biosynthesis of collagen and orther matrix proteins by articular cartiloge in experimental osteoarthrosis. Biochem. J. 1980, 188.823-837

Felson D.T. The epidemiology of knee osteoarthritis: results from the Framingham osteoarthritis study Semin Arthritis Rheum. 1990; 20, (supp! 1):42.50

Francis DJ., Forrest M.J., Brooks P.M and Ghosh P. Retordation of articular cartilage degradation by glycosaminoglycan polysulfate, pentosan polysulfate and $\mathrm{DH}-4 \mathrm{O}$ in the rat air pouch model. Arthritis Rheum. 1989; 32:008-616

Frank C., Acheson W.H., Woo S. L-Y, Amiel D. and Coutts R.D. Physiology and therapeutic value of passive joint motion. Clin. Orth. Rel. Res. 1984; 185:113-125.

Friedman M.J., Berasi C.C., Fox !.M., Del Pizzo W., Snyder S.J. and Ferkel R.D. Preliminary results with abrasion arthroplasty in the osteoarthritic knee. Clin. Ort. Rel. Res. 1984; 182:200-205.

Furukawa T., Eyre D.R., Koide S. and Glimcher M.J. Biochemical studies on repair of cartilage, resurfacing experimental defects in the rabbit knee. I. Bone Joint Surg. 1980; 62.A.79-89? 
Gadher S.J., Eyre D.R., Wolton S.F., Schmid T.M and Woolley D.E. Degradation of cartilage collagens type II, $I X, X$ and XI by enzymes derived from human articular cartilage Matrix 1990; 10:154-163.

Geesink R.G.T., Drukker J, and Linden van der AJ. Stress response of articular cartilage. Int. J. Sports Med 1984: 5: 100-101.

Geesink R.G.T., Groot de K. and Klein C.P.A.T. Chemical implant fixation using hydroxylapatite coatings. Clin. Orthop. Rel. Res. 1987: 225:147-170.

Ghosh P. and Brooks P. Editorial, Chondroprotection, exploring the concept. I. Rheum. 1991; 18:2:161. 166.

Goldenberger D.L., Egan M.S. and Cohen A.S. Inflammatory synovitis in degenerative joint disease J. Rheurnatol. 1982; 9:204-209.

Graham D.Y. Agrawal N.M and Roth S.H. Prevention of NSAID induced gastric ulcer with misoprostol: a double blind placebo controlled trial. lancet 1988:2:1277-1280

Gray M.L., Pizzanelli A.M., Grodzinsky AJ. and lee R.C. Mechanical and physiochemical delerminants of the chondrocyle biosynthetic response. J. Orthop. Res. 1988; 6:777.792.

Guerne P.A, Zuraw B.L., Voughan J.H., Carson D.A. and lotz M. Synovium as a source of interleukin 6 in vilto. J. Clin. Invest. 1989; 83:585-592

Hammerman D. The biology of osteoarthritis. New EnglandJ. Med. 1989: 20:1322-1330.

Hammerman D. and Klagsbrun M Osteaarthritis Emerging evidence for cell interactions in the breakdown and remodeling of cartilage. Am. J. Med. 1985, 78.495.499.

Hannan N, Ghosh P., Bellenger C and Taylor I. Systemic administration of glycosaminoglycan. polysulphate (Arteparon) provides partial protection of articular cartilage from damage produced by meniscectomy in the canine. J. Orth. Res. 1987:47.59

Harris W.H. Eliology of osteoarthritis of the hip. Clin. Ort. Rel. Res. 1986; 213:20-33.

Harrison M.H.M., Schajowicz F. and Truela J. Osteo-Arthritis of the hip: A study of the nature and the evolution of the disease. J. Bone Joint Surg. 1953: 35-B:598-626.

Hart D. S. Spector T.D., Brown P., Wilson P., Doyle D.V. and Silman AJ. Clinical signs of early osteoarthritis:reproducibility and relation to $X$ ray changes in 541 women in the general population. Ann. Rheum. Diss. 1991; 50:467.470

Havelka S., Hom V., Spohrova D. and Valouch P. The calcified-noncalcified cartilage interface: the tidemark. Acta Biol. Hung. 1984; 35:271-279.

Helminen HJ., Kiviranta I., Saamanen A.M. Tammi M. and Paukonen K led /. Joint loading, biology and health of articular structures Bristol, Wright, 1987

Herman J.H. Appel A.M. Khosla R.C. and Hess E.V. The in vitro effect of selected classes of non steroidal anti inflammatory drugs on normal cartilage metabolism. J. Rheum 1986, 13.1014-1018

Hesse I. and Hesse W. The ultrastructure of articular șurfoces in osteoarthritis. Sandorama 1988; 1.21-26 
Homminga G.N., Bulstra S.K. Kuijer R. and van der Linden AJ. Repair of sheep articular cartilage defects with a rabbit costal perichondrial graft. Acta Ort. Scand. 1991. Vol 62; 5:415.419.

Homminga G.N., Bulstra S.K., Borwmeester SJ.M and van der Linden A.J. Perichondrial grafting for cartiloge lesions of the knee. I. Bone Joint Surg. 1990; Vol 72-B; 6:1003-1008.

Huber-Bruning O., Wilbrink B., Vernooii J.E., Biilsma. Pathogenesis of osteoarthritis. Am. J. Med. 1986;

Den Other W. and Huber J. Contrasting in vitro effects of retinol and mononuclear cell factor on young and old human cartilage. J. Pathol. 1986; 150:21.27

Huber-Bruning $\mathrm{O}$. Of human cartilage The induction of proteoglycan loss in human articular cartilage explants of different ages. Thesis 1987; Utrechi, The Netherlands.

Huskisson E.C. The disease spectrum of osteoarthritis. 1. EULAR. 1988: 1:2-4

Hutton C.W. Generalised osteocithritis: an evolutionary problem? The lancet 1987; June 27:14631405

Iwomoto M., Salo K., Shimazu A and Kato Y. Hypertrophy and calcification of rabbit permanent chondrocytes in pelleted cultures: Synthesis of alkaline Phosphalase and 1,25-Didroxycholecalciferol receptor. Dev. Biol. 1989; 136:500-507.

Jackson R.W. Silver R. and Marans H. Arthroscopic treatment of degenerative joint disease. Arthroscopy $1986 ; 2: 114$.

Jockson J.P. and Wough W. Tibial osteotomy for osteoarthritis of the knee J. Bone Joint Surg. 1961; 43. B:746.

Janssens $M$. The standard diagnosis register of theumatic diseases and standardization of theumatoid serology. Dissertation, Roflerdam, The Netherland's, 1987.

Johanson N.A. Endocrine arthropathies; Clinics in Rheum. Dis. 1985; Vol II, No 2.297.323

Johnson L.L. Arthroscopic abrasion arthroplasty Historical and pathologic perspective present status Arthroscopy 1986; 1:54-69.

Jurvelin J. Helminen HJ., Lauritsalo S. Kivirania I. Saamaanen A. M. Poukkonen K and Tammi M Influences of joint immobilisation and running exercise on articular cartilage surfaces of young rabbits. Acta Anat. $1985 ; 122: 62.68$

Kellgren J.H and Moore. Generalized osteo-arihritis and Heberden's nodes. Br.Med. 1. 1952; 1:18 1. 187.

Kirsch $T$. and Mark von der $K$. Isolation of human ype X collagen and immunolocalization in felal human cartilage. Eur. I. Biochem. 1991; 196:575-580.

Kiviranta N.I., Jurvelin I., Tommi M. and Helminen HJ Microspectrophotometric quantitation of glycosaminoglycans in articular cartilage sections stained with safranin-0 1. Histochem. 1985; 82:249. 255.

Kon M. Cartilage formation from perichondrium in a weight bearing joint. Eur. Surg Res. 1981; 13:387. 369. 
Kontlinen Y.T., Michelson J.E., Tolvanen E. and Bergroth V. Primary inflammatory reaction in synovial fluid and tissue in rabbit immobilization osteoarthritis. Clin. Ort. Rel. Res. 1990; 250:280-286.

Kuijer R. Age related changes in the interaction between proteoglycans and collogen in human articular cartilage. 1985; Thesis, Amsterdam, The Netherlands,

Lawrence I. S. The epidemiology of degenerative joint disease: Occupational and ergonomic aspects. Ed. Helminen HJ., Kiviranta I., Tammi M., Saamanen A.M. Paukkonen K. and Jurvelin J. Joint loading. biology of articular structures, Butterworth and Co 1987; 334.351.

Lawrence I.S. Bremmer J.M. and Bier F. Osfeogrthrosis: prevalence in population and relationship between symploms and xray changes. Ann. Rheum. Dis. 1966; 25:1-24.

Layton M.W., Goldstein S.A., Goulet R.W., Feldkamp L.A., Kubinsky DJ. and Bole G.G. Examination of subchondral bone archilecture in experimental osteoarthritis by microscopic computed axial tomography. Arthritis Rheum. 1988; 11:1400-1405.

Lee P., Rooney PJ and Sturrock R.D. Aethiology and pathogenesis of OA. Semin. Arthritis Rheum. 1974. 3:189-218.

Lefebvre V., Peeterstoris C and Vaes G. Modulation by interleukin I and tumor necrosis factor _of production of collagenase, tissue inhibitor of melalloproteinases and collogen rypes in differentiated and dediffrentiated articular chondrocyles. Biochem. Biophys. Acta 1990, 1052 366-378

Lefebvre V., Peetersforis C and Vaes G. Production of collagens, collagenase inhibitor during the dedifferentiation of articular chondrocytes by serial subcultures. Biochem. Biophys. Acta 1990: 1051:200. 275 .

Linden van AJ. Experimentele kraakbeen transplantaties. NIG 1972; 116:2078.

Livesly PJ., Doherty M. Needoff M. and Moulton A. Arthroscopic lavage of osleoarthritic knees. J. Bane Joint Surg. 1991; 73-B, 6:922-926.

Macys J.R., Bullough P.G. and Wilson ir. P.D. Coxarthrosis: a study of the natural history based on a correlation of clinical, radiographic and pathologic findings. Semin. Arthritis Rheum. 1980; 10:66-80

Mallinger R. and Slockinger L. Hislochemistry of the extracellular matrix of aging hyalin cartilage. Histochem. Cylobiol. 1987; 25:129-132.

Malze H. Die chondropathia patelloe und ihre behandlung mit arteparon. Rheumamed. 1983; 1:3.7

Mankin HJ and lipiello L. Biochemical and metabolic abnormalities in articular cartilage from osteoarthritic human hips. J. Bone Joint Surg. 1970, 52-A.424-434.

Mankin HJ. and Treadwell B.V. Osteoarthritis a 1987 updale. Bull. Rheum. Dis. 1986; 36 1-10

Mankin HJ and Conger K.A Acule effects of intra articular hydrocortisone on articular cartilage in rabbils J. Bone Joint Surg. 1986; 48-A: 1383-1388.

Mankin HJ., Dorfman H., Lipiello L. and Zarins A. Biochemical and metabolic abnormalities in articular cartilage from osleo-arthritic human hips. J. Bone Joint Surg. 1971; 53-A.523-537 
Maroudas A. and Venn M. Chemical composition and swelling of normal and osteoarthrotic femoral head. cartilage. Ann. Rheum. Dis. 1977; 36:399-406.

Maroudas A. Swelling pressure versus collagen tension in normal and degenerate cartilage. Nature $1976 ; 260: 808$

Maroudas A., Mirzahi J. Katz E.P., Wachiel EJ and Soudry M Physiochemical properties and functional behavior of normal and osteoarthritic human cartilage ed: Kuettner KE. Schleyerbach R. and Hascall V.C. Articular cartilage biochemistry: Workshop conference Hoechst-Werk. Albert, 1985. New York. Raven Press. 1986; 311 -327.

Martel-Pelletier J., Pelletier J.P. and Malemud CJ. Activation of neutral metalloproteose in human osteoarthritic knee cartilage: evidence for degradation in the core protein of sulfated proteoglycan. Ann. Rheum Dis. 1988; 47:801-808.

Malsushima K and Oppenheim JJ. Interleukin 8 and MCAF: Novel inflammalory cylokines inducible by II. 1 and TNF. Cytokine 1989; 1:2-13.

May L.T., Torcia G., Cozzolino F., Ray A., Tatter S. B., Santhanam U., Seghal P B. and Stern D. Interleukin-6 gene expression in human endothelial cells: rna start sites, multiple ll.6 proteins and inhibition of proliferation. Biochem. Biophys. 1989; 3:991-998

McAlindon T. Dieppe P. Osteoarthritis: definitions and criteria. Ann. Rheum Dis. 1989: 48:531-532

McDevitt C.A., Billingham M.EJ., Muir H. In vivo metabolism of proleoglycans in experimental osteoarthritic and normal canine articular cartilage and the intervertebral disc. Semin. Arthr. Rheum 1981. 11.17 .18

McDevitt C.A. and Muir H. Biochemical changes in the cartilage of the knee in experimental and natural osteoarthritis in the dog. J. Bone Join' Surg 1977; 59.A 94-101

McGoldrick F. and O'Brien T.M. Osteoarthrilis of the hip and heberden's nodes. Ann Rheum. Dis 1989. $48: 53 \cdot 55$

McMurray T.P. Osteoarthritis of the hip joint. Br. I. Surg. 1935; 22:716

Meachim G. and Fergie !. A. Morphological patterns of articular cartilage fibrillation. J. Parhol. 1975, 102:1-8.

Melching L.I. and Roughly PJ. studies on the interaction of newly secreted proteoglycan subunits with hyaluronate in human articular cartilage. Biochim. Biophys, 1990; 1035:20-28

Meiching L.I. and Roughily PJ. Studies on the interaction of newly secrefed proteoglycan subunits with hyaluronate in human articular cartilage. Biochem. Biophys. 1990: 1035:20-28

Meyers M.H. and Chatteriee N. Osteochondrạ transplạntation. Surg. Clin. North Am. 1978; 58.429 434

Michelacci Y.M., Mourao A.S., Laredo J and Dielrich C.P. Chondroifin sulphates and proteoglycans from normal and arthrofic human cartilage. Connect Tiss Res 1979, 7:29-36

Mitchell $N$ and Shepard $N$. The resurfacing of adult rabbit articular cartilage by multiple pertoration through the subchondral bone. J. Bone Joint Surg 1976: 58.A 23-33 
Morales T.L., Kuettner K.E., Howell D.S. and Woessner J.F. Characterization of the metalloproteinose inhibitor produced by bovine articular chondrocyle cultures. Biochim. Biophys. Acta 1983; 760:221-229

Moskowitz R.W. Experimentally induced corticosteroid arthropathy. Arthritis Rheum. 1970; 13:236-243.

Moskowitz R.W., Howell D.S., Goldberg V.W., Miniz O. and Pita J.C. Cartilage proteoglycan alterations in an experimentally induced model of rabbit ostecarthritis. Arthritis Rheum. 1979; 22:155-163.

Moskowiz R.W. Experimental models of osteoarthrosis. ed. Moskowitz. Howell, Goldberg and Mankin. Osteoarthritis diagnosis and management. Philedelphia: W. B. Saunders Co. 1984; 6:109-128.

Moskowitz R.W., Goldberg V.W. and Schwab W. Effects of intra articular cortico steroids and exercise in experimenfal models of inflammalory and degenerative arthritis. Arthritis Rheum. 1975; 18:417.

Muir H. Heberden oration: molecular approach to the understanding of osteoarthrosis. Ann. Rheum. Dis 1977: 36:199.208

Muir H. Osteoarthritis: Biochemical aspects. EULAR J. Education and Information in Rheumatology 1988, $1: 14 \cdot 16$

Nade S and Speers DJ. Staphylococcal adherence to chicken cartilage. Acta Orthop. Scand. 1987. $58: 351 \cdot 353$

Nieffeld JJ., Wilbrink B., Helle M. Van Roy J.L.A.M. Den Otter W., Swaak A J.G. and Huber-Bruning O Interleukin-l' induced interleukin-b required for the inhibition of proteoglycan synthesis by interleukin-1 in. human articular cartilage. Arthritis Rheum. 1990; 33:1695-1701

Nimni M.E. and Dewshmukh K. Differences in collagen metabolism between normal and osteoarthritic human articular cartilage. Science 1978; 181:751.752:

Nishikawa H., Mori l. and Umemolo J. Glycosaminoglycan polysulfate induced stimulation of hyoluronic acid synthesis in rabbit knee synovial membrane: involvement of binding protein and calciurn ion. Arch. Biochem. 1988; 266:201-209

O'Driscoll S.W. and Salter R.B. The induction of neochondrogenesis in free intra articular periostal aurografts under the influence of continuous passive motion. J. Bone Joint Surg. 1984; 66-A-1248-1257

O'Driscoll S.W. and Salter R.B. The repair of major osfeochondral defects in joint surfaces by neochondrogenesis with autogenous osteperiosteal grafts stimulated by continuous passive motion Clin Orth. Rel Res. 1986; 208:131-140

Degema T.R. Delayed formation of proteoglycan aggregate structures in human articular cartilage disease states. Nalure 1980; 288:583-585.

Ogilvie-Harris DJ. and Fitsialos D.P. Arthroscopic management of the degenerative knee. Arthoscopy $1901 ; 2: 1510157$

Ohno O., Nailo J., Iguchi T., Ishikawa K., Hirohata K., Cooke T.D. An electron microscopic study of early pathology in chondromalacio of the patella, J. Bone Joint Surg. 1988; 70-A:883-899

Olijhoek G., Drukker J., Linden van der AJ and Terwindt-Rouwenhorst E. A.W. Drug effects on arthrosıs. Acla Ort. Scand. 1988; 2:186-190. 
Ottolenghi C.E. Massive osteo and osteo-articular grafts. Clin. Ortho Rel. Res. 1972; 87:156-166

Pacifici M., Golden E.B., Adams S.L. and Shapiro I.M. Cell hypertrophy and type X collagen synthesis in cultured articular chondrocyies. Exp. Cell Res. 1991: 192:266-270

Palmoski M.J. and Brandt K.D. In vivo effect of aspirin on canine osteoarthritic cartilage. Arthritis Rheum. 1983; 26:994-1001.

Pastinen O., Forsskah/ B. and Marklund M. Local glycosaminoglycan polysulphale injection therapy in osteoarthritis of the hand. A placebo controlled clinical sfudy. Scand. I. Rheum. 1988; 17131:197-202

Paul B: and Franke K. Die chondropathia patellae und die intraartikulare injektionstherapie mit einem mukopolysaccharidpolyschwefelsaureester (MPSSE). Beitr. Orthop. Traumatol. 1974; 21, 3:169-178.

Pelletier J.P., Martel-Pelletier J., Ghandur-Mnaymneh L., Howell D.S. and Woessner J.F. Role of synovial membrane inflammation in cartilage matrix breakdown in the pond-nuki dog model of osleoarthritis. Arthritis Rheum. 1985; 5:554-561.

Pelletier J.P. Martel-Pellitier J.M. Howell D.S., Ghandur Mnaymneth L., Enis J.E abd Woessner J.F Collagenase and collagenolytic octivity in human osteoarthrotic cartialeg. Arthritis Rheum 1983, 20.63. 68

Peyron!.G. Osteoarthritis, the epidemiologic viewpoint. Clin. Orth Rel Res 1986:213.13.19

Pond MJ. Experimentally induced osteoarthritis in the dog. Ann. Rheum. Dis. 1973: 32.387.388.

Poole C.A. Malsuoka A. and Schofield J.R. Chondrons from articular cartilage. Morphologic changes in the cellular microenviroment of chondrons isolated from osteoarthritic cartilage. Arthritis Rheum. 1991: 1:22-35

Pridie K.H. A method for resurfacing osteoarthritic joints. J. Bone Joint Surg. 1959:41.8:618.

Prins A.P. A., Lipman J.M. and Sokoloff L. Effect of purified growth factors on rabbit articular chondrocyles in monolayer culture. Arthritis Rheum 1982; 10:1217.1227.

Pritzker K.P.H. Posttroumatic cartilage hypertrophy:edema or repair? Editorial. J. Rheum. 1991; 18 , 3:314-315.

Raaitikainen $T$, Vaananen K. and Tamelander G. Effect of glycosaminoglycan polysulfate on chondromalacia patellae. Acta Ort. Scand. 1990; 5:443-448.

Radin E.L., Paul I.L and Lowy M.A. A comparison of the dynamic force transmitting properties of bone and articular cartilage. J. Bone Joint Surg. 1970; 52-A.444-456.

Radin E.L. and Rose R.M. Role of subchondral bone in the initiation and progression of cartilage damage Clin. Ori. Rel, Res. 1986; $213: 34.40$

Radin E.L., Paul I.L. Does cartilage reduce skeletal impact loads? The relative force attentuating properties of articular cartilage, synovial fluid, periarticular soft tissues and bone. Arthritis Rheum. 1970; 13:139= 144.

Redini F., Mauviel A., Loyau G. and Pujol J.P. Modulation of extracellular matrix melabolism in rabbil articular chondrocytes and human rheumatoid synovial cells by the non steroidal anti inflammatory drug 
elodolac. II: Glycosaminoglycan synthesis. Agents Actions 1990; 3.4.358.367

Redler I. Mow V.C., Zimny A.L. and Mansell I. The ulfrastructure and biomechanical significance of the tidemark of articular cartilage. Clin. Orthop, Rel. Res. 1975; 112:357.

Reimann 1., Mankin HJ. and Trahan C. Quantitative histological analysis of articular cartilage and subchondral bone from osleoarthritic and normal hips. Acta Orthop. Scand. 1977; 48:63-73.

Rosenberg L.C., Choi A.V., Tang L.H Isolation of dermatan sulfate proleoglycanns from mature bovine articular cartilages. J. Biol. Chem. 1985; 260:6304-6313.

Rosenberg L. Chemical bosis for the histological use of safranin-O in the study of articular cartilage. J. Bone Joint Surg: 1971: 53-A:69-82.

Rosenberg L. Biological basis for the imperfect repair of articular cartilage following injury. Ed: Hunt T.K. Heppenstall R.B., Pines E., Rovee D. Soft and hard lissue repair, biological and clinical aspects. Surgical science series, New York, Praeger, Vol 2 1984; 143-169.

Roughley PJ. and Mort J.S. Ageing and the aggregating proteoglycans of human articular cartilage Clinical Science 1986: $71: 337-344$

Roughly PJ and White RJ. Age related changes in the structure of the proteoglycan subunits from human articular cartilage. J Biol Chem. 1980; 255.217.224.

Saase van J L.C.M. Vandenbroucke J.P. Romunde van L.KJ. and Valkenburg H.A. Osteoarthritis and obesity in the general population. A relationship calling for an explanation I Rheumatol. 1988; 7.1152 . 1158

Saase van J.L.C.M., Romunde van L.KJ., Cals A., Vandenbroucke J.P. and Valkenburg H.A. Epidemiology of osteoarthritis: Zoetermeer survey. Comparison of radiological osteoarthritis in a dutch population with that in 10 other populations. Ann. Rheum. Dis. 1989:48:271.280.

Salter R.B., Simmons D.F., Malcolm B.W., Rumble DJ., McMichael Douglas and Clements N.D. The biological effect of confinuous passive motion on the healing of full thickness defects in articular cartilage. An experimental investigation in the rabbil J. Bone Joint Surg. 1980; 62-A: 1232-1251

Salvati E.A., Granda J. L. Mirra J. and Wilson P.D. Clinical, enzymatic and histologic study of synovium in coxarthrosis, Int. Orthop. 1977: 1:39-42.

Sapolsky A. I. Aliman R.D., Woessner J.F. and Howell D.s. The action of cathepsin D in human articular cartilage on proteoglycans. f. Clin. Invest. 1973; 56:624-633.

Schenk R.K., Eggli P.S. and Hunziker E. B. Articular cartiloge morphology. ed: Kuettner K.E., Scleyerbach R and Hascall VC Chap. I. Articular cartilage biochemistry. 1986; Raven press. New York.

Schiavinato A., Lini E. Guidolin D. Pezzoli G. Botti P. Martelli M. Cortivo R. De Galateo A and Abatangelo $G$ Intraarticular sodium hyaluronate injections in the pond-nuki experimental model of osteoarthritis in dogs Clin Ont Rel Res 1989:241:280-299

Seppala PO and Balazs E A. Hyaluronic acid in synovial fluid. III Effect of maturation and aging on the chemical properties of bovine synovial fluid of different joinis. J. Geront. 1909: 24:309.314

Shuckett R. and Malemud CJ. Qualitative changes in human osteoarthritic hip cartilage proteoglycan 
synthesis during longterm explant culture. Mech. Ageing and Develop. 1988; 46:33-45.

Simon S.R., Radin E.L., Paul I.L. and Rose R.M. The response of joints to impact loading II. In vivo behavior of subchondral bone. J. Biochem. 1972; 5:267.272.

Skoog T., Ohlsen L and Sohn S.A. The chondrogenic polential of the perichondrium. Chir. Plastica 1975; 3:91-103.

Small N.C. Camplications in arthroscopic surgey performed by experienced arthroscopists. Arthroscopy $1988 ; 3: 215-221$.

Sokoloff L. Osteoarthritis as a remodeling process. J. Rheum. 1987: 14:7.10

Sokoloff l. The joints and synovial fluid 1980; Vol I and 2: Orlando, Academic Press.

Sokoloff L. Aging and degenerative disease affecting cartilage ed: Hall B.K. Cartilage, Biomedical Aspects, 1983; Vol 3: 110-141. Academic Press, New York.

Sokoloff L. Aging and degenerative diseases affecting contilage ed: Hall B.K. Cartilage biomedical aspects, aging and degeneration, New York, Academic Press 1983; Vol 3:117-127.

Sokoloff L. Editorial: Animal models of osteoarthritis J. Rheum, 1990; 17:5-6.

Spector T.D. and Campion G.D. Generalised osteoarthritis: a hormonally mediated disease? Ann. Rheum. Dis. 1989; $48 \cdot 523-527$.

Stockwell R.A., Billingham M.EJ and Muir H. Uitrastructural changes in articular cartilage offer experimental section of the anterior cruciate ligament of the dog knee. I. Anat. 1983; 136:425.439.

Strochan R.K., Smith P. and Gardner D.L. Hyaluronate in rheumatology and orthopaedics: Is there a role? Ann. Rheum. Dis. 1090; 49:940.952.

Sweet M.B.E., Thonar E.M.A.A. Immelman A.R. and Solamon L. Biochemical changes in progressive osieoarthrosis. Ann. Rheum. Dis 1977, 36:387-398.

Tanaka H and Shinno $\mathrm{N}$ Histochemical studies on regeneration of articular cartilage Tok f Exp Med $1971 ; 18.63 .73$.

Thompson R.C. Experimental evidence for an injury threshold for articular cartilage. Ann. Rheum. Dis $1975: 34: 140-142$

Thonar E.JMA., lenz M.E., Klintworth G.K. Quantification of keratan sulfate in blood as a marker of cartilage caiabolism. Arthritis Rheum. 1985; 28:1367.1376

Vasan N Proleoglycans in nomal and severely osteoarthritic human cartiloge. Biochem. J. 1980; 187:781-787.

Venn M.F. and Maroudas A. Chemical composition and swelling of normal and osteoarthrotic femoral head cartilage. 1. Chemical composition. Ann. Rheum. Dis. 1977: 36:121.129.

Venn M.F. and Maroudas A. Chemical composition and swelling of normal and osteoarthrotic femoral head cartilage I. Chemical composition. Ann. Rheurn. Dis. 1979; 38:57-62. 
Vignon E., Bejui J., Mathieu P., Hartmann J.D., Ville G., Evreux J.C. and Descottes J. Hislological cartilage changes in a rabbil model of osteoarthritis. J. Rheum. 1987; 14:104-111.

Villacin A.B., Brigham !.N and Bullough P.G. Primary and secondary synovial chondromeraplasia: histologic and clinicoradiologic differences. Hum. Pathol. 1979; 10:439-451.

Vittorio N., Crissman J.D., Hopson C.N. and Herman J.H. Histologic assessment of cathepsin D in osteoarthritic cartilage. Clin. Exp. Rheumatol. 1986; 3:221-230.

Vries de BJ. Murine patellar cartilage and its susceptibility to non steroidal antiinflammafory drugs. 1987. Thesis, Nijmegen, The Netherlands.

Walker E.R., Boyd R.D., Wu D.D. Lukoschek M. Burr D. B. and Radin E.L. Morphologic and morphometric changes in synovial membrane associaled with mechanically induced osleoarthrosis. Avithritis Rheum. 1991; 34:515-524.

Waxman B.A., Sledge B.C. Correlation of histochemical, histologic and biochemical evaluations of human synovium with clinical activity. Arthritis Rheum. 1973; 16:376-382.

Weiss C. Ulitrastructured characteristics of osteoarthritis. Fed. Proceed. 1973: 32: 1459-1466.

Wilbrink B. Cartilage destruction: antigen specific T cell activation and cytokines. Doctoral Thesis I99I: Utrecht, The Netherlands

Wilbrink B. Cartilage destruction: antigen specific T cell activation and cytokines. Thesis 1991; Utrecht, The Netherlands.

Woessner J.F. Matrix metalloproteinases and their inhibitors in connective fissue remodeling. Faseb J! $1991 ; 5: 2145-2154$

Woo S. L.Y, Kwan M.K. Lee T O. Field F.P. Kleiner J.B. and Coutts R.D. Perichondrial aulograft for articular cartilage. Acta Orthop. Scand 1987: 58:510-515

Zanetti M., Ratcliffe A and Watt F.M. Two subpopulations of differentiated chondrocytes identified with a monoclonal antibody to keratan sulfate. Cell Biol. 1985: 101:53.59

Zarnett R., Delaney J.P., O'Driscoll S.W and Salter R.B. Cellular origin and evolution of neochondrogeneșis in major full thickness defects of a joint surface treated by free aurogenous periosteal grafts and subjected to continuous passive motion in rabbits. Clin. Orth. Rel. Res. 1987; 222:267-274. 


\title{
The reliability of the mankin score for Osteoarthritis
}

\begin{abstract}
For the histo-pathological classification of the severity of osteoarthritic lesions of cartilage, the Mankin score is frequently used. A necessary constraint on the validity of this scoring system is the consistency with which cartilage lesions are classified. The intra- and inter-observer agreement of the Mankin score, was determined. The intra-observer and inter-observer agreement of the 14 point Mankin score was adequate. Between observers $95 \%$ of differences were less then approximately 7 points.

By a more strict definition of the elements of the Mankin score the intra-observer differences were reduced only for some observers. The inter-observer differences were only slightly reduced: between observers $95 \%$ of differences were less then approximately 6 points.

We found the Mankin score to be an adequate histo-pathological tool.
\end{abstract}

\section{Introduction}

In osteoarthritis (OA) biochemical, biomechanical, and morphological changes have been described in the articular cartilage. A variety of morphological changes was found, ranging from macroscopical to ultrastructural abnormalities $|6|$.

For the histopathological classification of the severity of OA, the Mankin score (5) has been frequently used. The Mankin score is a combined score assessing structure 10-6 points), cellular abnormalities (0-3 points), matrix staining (0-4 points) and tidemark integrity $(0-1$ point). As a result 0 points implies normal cartilage, whereas 14 points represent the most severe cartilage lesions.

The histo-pathological gradation of the severity of OA according to Mankin appeared to be directly correlated with the metabolic state of the chondrocytes in the different stages of OA $(2,5)$.

A necessary constraint on the validity of this scoring system is its reliability, i.e. the consistency with which cartilage lesions are classified.

The Mankin score is classically determined on sections stained with safranin $\bigcirc$ - fast green (SOFG). With this technique the staining intensity correlates well with the proteoglycan concentration (3).

There are several nonparametric and parametric methods to assess reliability 
$(1,4,7,8)$. We studied the intra-observer and inter-observer reliability of the Mankin score for cartilage lesions.

\section{Material and methods}

In six adult female rabbits, Flemish giants, experimental osteoarthritis was induced in the knee joint by medial meniscectomy or plaster immobilization in extension for 6 weeks.

This caused osteoarthritis, the severity of which showed large topographical variations. After 12 weeks ten osteocartilaginous biopsies (diameter $2.1 \mathrm{~mm}$ ) were taken from the experimental joint on standardized locations: on the femaral side four from the medial condyle, one from the surface opposite the patella, three from the lateral condyle. On the ribial side one from both medial and lateral tibial plateau. Two biopsies were taken from the control joint at random localizations. After fixation in $10 \%$ formalin $(\mathrm{pH}=7.4)$ and graded alcohol dehydration the undecalcified fissues were embedded in glycol methacrylate (Technovit 7100, Kulzer, Bad Homburg, BRD). Five $\mu$ thin sections were stained with safranin $O$ - fast green $11 \%$ aq. safranin $O$ for $15 \mathrm{~min}$. ; $0.1 \%$ ethyl-aicohol fast green solution for 1.2 min.). The tidemark is nor adequarely shown on plastic sections and was excluded from the determination of the Mankin score.

Five experienced observers determined the Mankin score for OA lesions of cortilage for 71 technically adequate biopsies.

The observers determined the score twice with a 2 . week interval, using the criteria formulated by Mankin et al (5) (Table la) and twice again with the same interval using more strict criferia as formulated in Table $\mathrm{lb}$. The reliability was quantified using a standard method (1).

The intra-observer reliability of each observer was determined by plotting the difference of the wo Mankin scores of each section against the mean of the two scores for that section as determined by that observer. The inter-observer reliability was determined by plotting the difference of the Mankin score of each section against the average score for that section found by all five observers.

We assessed the reliability of both the standard Mankin score and the Mankin score using stricter criteria. 
Table la.

Mankin score

\section{CARTILAGE STRUCTURE}

Normal

Surface irregularifies

Pannus and surface irregularities

Clefts to transitional zone:

Clefts to radial zone

Clefts to calcified zone

Complete disorganization

CARTILAGE CELLS

Normal

Pyknosis, lipid degeneration,

Hypercellularity

Clusters

Hypocellularity

MATRIX STAINING

Normal

Slight reduction

Moderate reduction

Severe reduction

No Staining

TIDE MARK INTEGRITY

Intact

Destruction

\section{Resulłs}

Mankin score

The intrabserver agreement of the five observers is shown in Table 2.

The mean difference (d) between the first and second score of the sections, was small (rarige -0.7 to 1.1 points of the Mankin score).

However the standard deviation of the differences (SD) varied between 1.5 and 2.6 points. Theoretically $95 \%$ of the differences are expected between $d+2 *$ SD and $d-2 *$ SD. This interval varied from $b$ points (observer $A$ ) to 10.4 points (observer $C$ ). The inter-observer variability is shown in Table 2. 
A comparison of the different observers. showed a mean difference (d2) between the observer and the average of the five observers varying between -2.7 and 1.8 points. This indicated that some observers showed a systematic bias, determining either a lower or a higher score for some sections than their colleagues.

This systematic bias was small, and there is reasonable agreement between the observers: the SD of the differences of the scores varied between 1.5 and 2.1 points (resulting in $95 \%$ confidence intervals between 6 and 8.4 points).

All three categories (strucfure :, cellular abnormalities - and matrix staining categony) contributed to the variation between the observers. We could not discern a pattern in the differences between the raters.

Table 1b.

Modified mankin score

\section{CARTILAGE STRUCTURE}

Normal

Irreguiar suffoce includ. fissures into the radial loyei

Pannus

Superficial cartilage layers ( at least 6) absent

Slight disorganization ( cellular rows absent.

Some small superficial clusters )

fFissures into calcified cartilage layer

Disorganization ( chaotic structure, clusters,

Osteoclast activity !

\section{CARTILAGE CELLS}

Normal

Hypercellularity, including small superficial clusters

Clusters

Hypocellularity

\section{MATRIX STAINING}

Normal / slight reduction

Staining reduced in radial layer

Reduced in inter-territorial matrix

Only present in pericellular matrix

Absent

General Remarks:

* cartilage at the edge of the section is not representative because of processing artefacts.

* incidental cartilage changes are irrelevant.

* disorganization should be present in at least $25 \%$ of the section. 
Modified mankin score

The reliability of the modified Mankin score is shown in Table 3.

In general the reliability was somewhat improved.

The intra-observer variability of some observers (e.g. observer B and C) was reduced (The SD was reduced from 1.8 resp. 2.6 to 0.7 resp. 0.9 points I.

The inter-observer agreement was slightly improved, both by a slight reduction of the systematic bias and the standard deviation of the differences.

Table 2.

Intro- and interobserver agreement of standard Mankin score.

\begin{tabular}{lllll}
\hline & \multicolumn{2}{c}{ inter-observer } & \multicolumn{2}{c}{ intra-observer } \\
observer & $\mathrm{d} 1^{\circ}$ & $\mathrm{SD}$ & $\mathrm{d} 2^{6}$ & $\mathrm{SD}$ \\
$\mathrm{A}$ & -0.5 & 1.5 & 1.8 & 1.7 \\
$\mathrm{~B}$ & -0.7 & 1.8 & 1.8 & 1.7 \\
$\mathrm{C}$ & -0.3 & 2.6 & 2.7 & 2.1 \\
D & 1.1 & 1.8 & -1.8 & 1.8 \\
E & -0.2 & 1.8 & 0.8 & 1.5 \\
\hline
\end{tabular}

values given in Mankin score points

$d l=$ mean difference between first and second score,

$\mathrm{d} 2=$ mean difference between score of observer and average of five observers

$\mathrm{SD}=$ standard deviation of differences.

Table 3.

Intra- and inter-observer agreement of the modified Mankin score

\begin{tabular}{lrrrr}
\hline & \multicolumn{2}{c}{ inter-observer } & \multicolumn{2}{c}{ intra-observer } \\
observer & $\mathrm{d}^{a}$ & $\mathrm{SD}$ & $\mathrm{d} 2^{\mathrm{b}}$ & $\mathrm{SD}$ \\
$\mathrm{A}$ & -0.4 & 1.8 & 1.2 & 1.3 \\
$\mathrm{~B}$ & 0.2 & 0.7 & 2.0 & 1.8 \\
$\mathrm{C}$ & -0.3 & 0.9 & -1.9 & 2.1 \\
$\mathrm{D}$ & 0.2 & 2.2 & -1.4 & 1.4 \\
$\mathrm{E}$ & 0.1 & 2.0 & 0.0 & 1.5 \\
\hline
\end{tabular}

values given in Mankin score points.

$\mathrm{d} \mathrm{l}=$ mean difference between first and second score.

$\mathrm{d} 2=$ mean difference between score of observer and average of five observers

$\mathrm{SD}=$ sfandard deviation of differences. 


\section{Discussion}

The reliability of many clinical and biological classification systems is not known. According fo this study the reliability of the Mankin score appears to be adequate, although not quite as good as expected. It seems, however that the same holds true. for many other classification systems used in clinical medicine (7).

Although the elements of the Mankin score are nominal or ordinal, the 14 point combined score can be treated as interval data, which makes the statistical method used appropriate.

Most of the scores used in this study were below 6 points. This is representative for the severity of most osteoarthritic lesions present in the experimental models used. The standard deviation of the inter-obsenver differences of the standard Mankin score was approx. 1.7 points which means, that the $95 \%$ confidence interval was approx. 7 points. It is remarkable that the intra- observer difference is about the same. We could not find a specifically arbitrary aspect of the Mankin score: differences

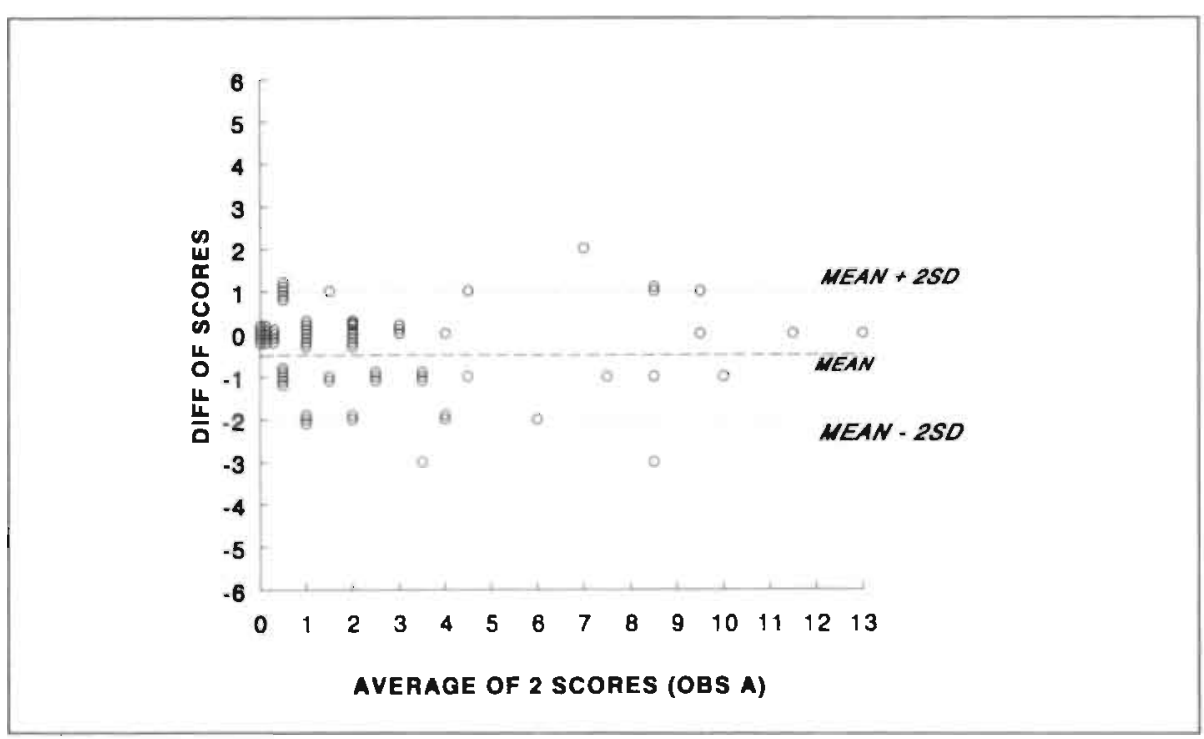

Fig 1.

intra-observer agreement of observer A. Relation between difference of first and second Mankin score plolted against the average of the 2 scores

between observers are found in all 3 categories. Because the structure category has the largest influence on the Mankin score (six points /, differences in this category play a substantial, but not exclusive role.

We expected a reduction of differences by a more strict definition of the different subcategories and the introduction of other subcategories. These modified criteria 
reduced the intra-observer differences of some observers, while the results of other observers were hardly influenced. There was however no strong reduction in interobserver variability: the Standard deviation then was 1.5 points $195 \%$ confidence interval approx. 6 points 1 .

Overall the use of stricter criteria resulted in a slightly increased reliability.

We found the Mankin score to be an adequate histo-pathological tool; the wide spectrum of morphological changes present in osteoarthritic cartilage limits the reliability of any morphological scoring system. However it is possible that other more strict, possibly quantitative, criteria could lead to a strong reduction of the variability.

\section{Acknowledgement}

The advice of Hubert J.A. Schouten (PhD) of the department of Medical Statistics is greatly appreciated.

\section{REFERENCES}

1. Bland J.M. and Altman, D. G. : Statistical method's for assessing agreement between two methods of clinical measurement. Lancet 1:307-310,1986

2. Bulstra, S.K., Buurman, W.A., Walenkamp, G.H.I.M., and Van Der Linden, A. J. Metabolic characieristics of in vitro culfured human chondrocytes in relation to the histopathologic grade of ostecarthritis. Clin. Orthop.242:294-302, 1989.

3. Kiviranta, 1., Jurvelin, J., Tammi, M. Saamanen, A.M., Helminen. HJ.: Microspectrophotomelric quantitation of glycosaminoglycans in articular cartilage sections stained with Safranin 0 . Hislochemistry 82:249-255, 1985

4. Landis, I.R. and Koch, G G. The measurement of observer agreement for categorical data Biometrics 33-159.174, 1977

5. Mankin, HJ., Dorfman, H. Lippiello, L, and Zarins, A : Biochemical and melabolic abnormalities in articular cartilage from osteoarthritic human hips. J. Bone Joint Surg 53. A.523.537. 1971

6. Moskowitz, R.W. Howell, D.S., Goldberg, V.M. and Mankin, HJ.: Osteaarthritis, diagnosis and managemeni. Philadelphio, Saunders Company, 1984

7. Schouten,HJ.A.: Statistical measurement of interobserver agreement Rotterdam, Thesis Erasmus University Rotterdam, Netheriands, 1985

8. Siegel,S and Castellan, NJ.: Nonparametric statistics for the behavioral sciences. New York, McGraw-Hill Book Comp, 1988, pp 272.290 



\section{Thionin staining of paraffin and plastic embedded sections of cartilage}

\section{Abstract}

In this study the usefulness of thionin for staining cartilage sections embedded in glycol methacrylate (GMA) and the effect of decalcification on cartilage sections embedded in paraffin and GMA were assessed. Short decalcification periods using $5 \%$ formic acid or $10 \%$ EDTA did not influence the staining properties or the morphology of cartilage matrix and chondrocytes. The standard stain safranin Ofast green for differential staining of cartilage was used as control in these experiments. Prolonged exposure of safranin $\mathrm{O}$ stained sections to fast green resulted in disappearance of the safranin $O$ stained matrix, thereby hampering the quantitative measurement of negatively charged glycosaminoglycans (GAG). Thionin stained evenly throughout all cartilage layers, independent of the staining times. in contrast to safranin $\mathrm{O}$, thionin did not show metachromasia in nondehydrated cartilage sections, which makes it more suitable for assessing cartilage quality in GMA embedded cartilage. To evaluate the selectivity of thionin-staining in cartilage, chondroitinase $A B C$ and trypsin digestions were carried out. Thionin staining was prevented by these enzymes in the territorial matrix, representing the interlacunar network and the chondrocyte capsule. Staining with thionin of the interterritorial matrix was only slightly reduced, possibly representing keratan sulfate and hyaluronic acid in cartilage of elderly patients. Comparison of thionin-stained GMA embedded cartilage with safranin $O$ stained paraffin-embedded sections showed significant similarity in optical densitometry, indicative for the specificity of thionin bound to negatively charged GAG in cartilage. In GMA embedded cartilage morphology was relatively undestroyed compared to paraffin embedded sections due to less shrinkage of chondrocytes and the interlacunar network.

\section{Introduction}

Articular cartilage is composed of chondrocytes embedded in extracellular matrix, which mainly consists of a network of collagen fibres with aggregated proteoglycans [PG]. The use of stains such as safranin $O$ which bind stoichiometrically to negatively charged glycosaminoglycans (GAG) in PG (Rosenberg 1971, Kiviranta et al. 1985). makes quantitative analysis of cartilage studied by light microscopy possible. The ability of GAG's to be stained with safranin Ofast green is considered an important parameter for grading osteoarthritis (Mankin et al. 1971., Bulstra et al. 1989). Decalcification and dehydration are essential steps in preparing paraffin embedded 
sections; however, controversy exists about the effect of these procedures on the staining properties of the cartilage matrix and the morphology of the chondrocytes (lppolito et al. 1981, Kiviranta et al. 1984). The morphological changes caused by the methodology employed were considered detrimental to evaluation of the degree of cartilage deterioration ICole 1984, Poole 1970, Sayers et al. 1987, Goldstein and Horobin 1974).

We studied the effects of decalcification and dehydration on the staining properties of paraffin embedded cartilage sections with safranin $O$ and compared these with thionin stained glycol methacrylate (GMA) embedded cartilage (Bennet et al. 1976, Blaauw ef al. 1987, Cole and Sykes 1974, Rosenberg et al. 1960). The data obiained indicated that the latter method is less complicaled and faster than the safranin $\mathrm{O}$ - fast green staining method and resulted in improved morphology of the cartilage structure giving better assessment of cartilage morphology.

\section{Material and methods}

\section{Tissue preparation}

Articular cartilage was obtained from six patients during arthroplastic surgery for fracture of the hip (mean age of the patients was 72 years). From each patient eight macroscopically uniform biopsies of healthy cartilage from the subchondral bone were taken from the weightbearing part of each femoral head. Patients with osteoarthritis or rheumatoid arthritis were excluded from this study. All biopsies were fixed in cold $4 \%$ neutral buffered formalin for $24 \mathrm{hr}$, then rinsed in water. Four samples were subsequently demineralized for 12 hours, two samples in $5 \%$ formic acid and two in neutral 10\% EDTA, then dehydrated with ethanol, transferred to Histosol (National Diggnostics, Sommerville, NY) and embedded in paraffin. The secand group of samples was not demineralized: two were embedded in paraffin and two in GMA (Technovit 7100, Kulzer, Wehrheim, Germany). Sections $5 \mu \mathrm{m}$ thick were cut perpendicularly to the articular cartilage surface and affixed to glass slides, stained with safranin $O$ or thionin and mounted with Entellan Merck, Darmstadt, Germany).

\section{Enzyme digestions}

Enzyme digestions were carried out on the paraffin embedded sections. Adjacent sections were incubated with culture medium alone as a control. The enzymes used were:

Chondroitinase $A B C$ (Miles, England); $2 \mathrm{IJ} / \mathrm{ml}, 0.1 \mathrm{M}$ Tris buffer, $\mathrm{pH} 7.5$ at $37^{\circ} \mathrm{C}$ for $4 \mathrm{hr}$ (Yamada and Hoshima 1973); Pronase (Boehringer, Germany) $1 \mathrm{mg} / \mathrm{ml}$ distilled water, pH7.4 at $60^{\circ} \mathrm{C}$ for $2 \mathrm{hr}$; Trypsine (Worthington, UK) $1 \mathrm{mg} / \mathrm{ml} 0.01 \mathrm{M}$ phosphate buffer, $\mathrm{pH} 7.0$ at $37^{\circ} \mathrm{C}$ for $30 \mathrm{~min}$. 


\section{Staining procedure}

The sections were stained with $0.04 \%$ thionin (Gurr, Essex, UK) in 0.01 M aqueous sodium acetate $\mathrm{pH} 4.5$ for $2.5,5$ or $15 \mathrm{~min}$ or $1 \%$ filtered safranin $\mathrm{O}(\mathrm{BDH}$, Germany) in distilled water pH 6.7 for 10 min (Conn 1946, Lillie 1965). The latter sections were counterstained for $5 \mathrm{~min}$ with a $0.1 \%$ solution of fast green in water for 5 minutes (Mankin el al. 1971).

\section{Densitometric analysis}

A leitz MPV 3 microspectrophotometer was used for densitometric analysis at 500 and $560 \mathrm{~nm}$ for safranin $\mathrm{O}$ and thionin, respectively. Spectral curves of the stained sections were made to determine the wavelength of maximum absorption for each dye. Six sections of eight biopsies in each experimental group were onalyzed by calculating the mean of the transmission of 20 fields (diameter $0.16 \mu \mathrm{m}$ ) in the upper, middle or deep interterritorial layer of cartilage in each section. The territorial zone was defined as the region directly adjacent to the chondrocyte capsule, representing the collapsed interlacunar network, and measured a diameter of $0.08 \mu \mathrm{m}$. Eight fields were measured in each cartilage layer. For statistical analysis Student's t test was used. Thionin was dissolved I $\mathrm{mg} / \mathrm{ml}$ in distilled water, then diluted with distilled water to a concentration of 1:50 or 1:100. The absorbance spectra of thionin were obtained using an ultrospec III UV/VIS spectrophotometer (Pharmacia, Upsala, Sweden). Thionin 1:50 stock solution was analyzed in water, after the addition of $0.5 \mathrm{mg} / \mathrm{ml} \mathrm{PG}$, and in ethanol.

\section{Results}

\section{Thionin staining}

The optimal staining period for thionin staining of paraffin embedded cartilage proved to be independent of the exposure time. The wavelength of maximum absorption occurred at $560 \mathrm{~nm}$. The addition of ethanol did not alter this wavelength nor did we find another peak absorption af a different wavelength. The addition of excess PG to thionin dissolved in water did not induce metachromasia (Fig 1). The territorial matrix, representing the collapsed interlacungr network and the chondrocyte capsule, stained intensely purple by thionin throughout the superficial, middle and deep layers of cartilage, independent of the exposure times (data not shown). Measurement of the percent iransmission at $560 \mathrm{~nm}$, revealed a narrow band of more intense territorial staining $15 \%$ transmission) compared to the interierritorial zone (1.5\% transmission). This phenomenon was detected throughout most of the middle and deep cartilage zones. The interterritorial matrix stained somewhat more intensely in the superficial layer than in the middle and deep layers of cartilage, regardless of the staining-time (Fig 2). In further experiments a staining period of $5 \mathrm{~min}$ was used for thionin. 


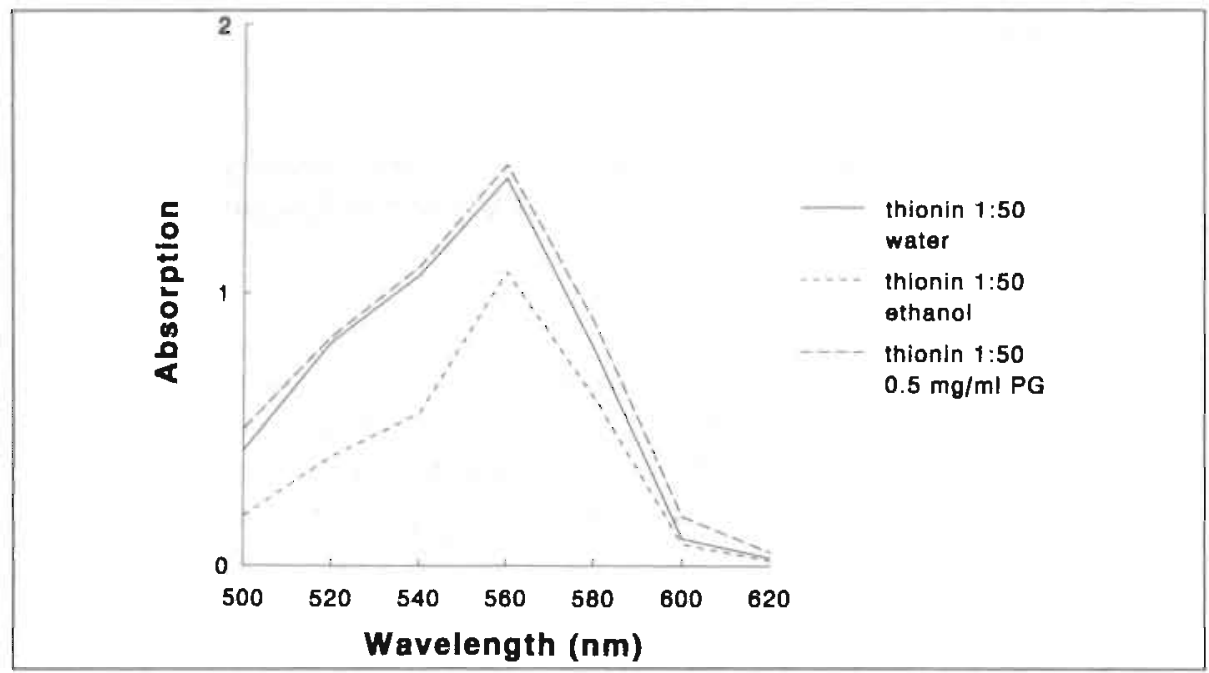

Fig 1:

Absorbance spectra of thionin in water and ethanol, after the addition of proteoglycans show that melachromasio is nor present.

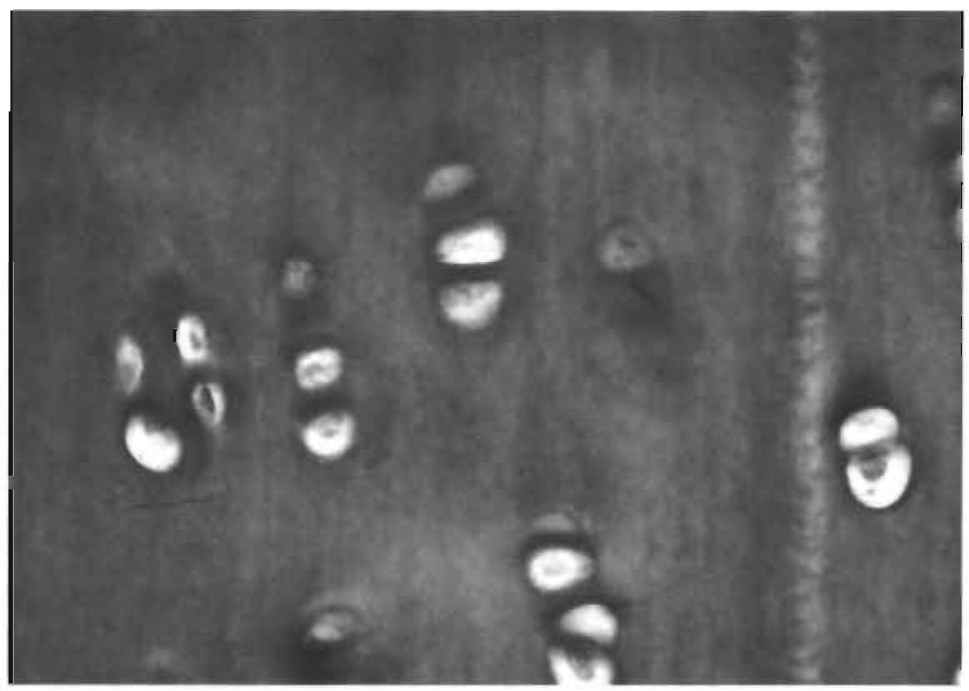

rig 2.

Histological section of the middle zone of femoral head carnilage embedded in paraffin and stained with thionin. The matrix is stained evenly purple; the nuclei stain blue. 
Safranin O-fast green staining

Safranin O-fast green staining of paraffin embedded sections revealed the typical staining pattern: a green stained superficial layer (6 cell layers) and a subchondral bone layer with evenly red stained middle and deep layers of the cartilage.

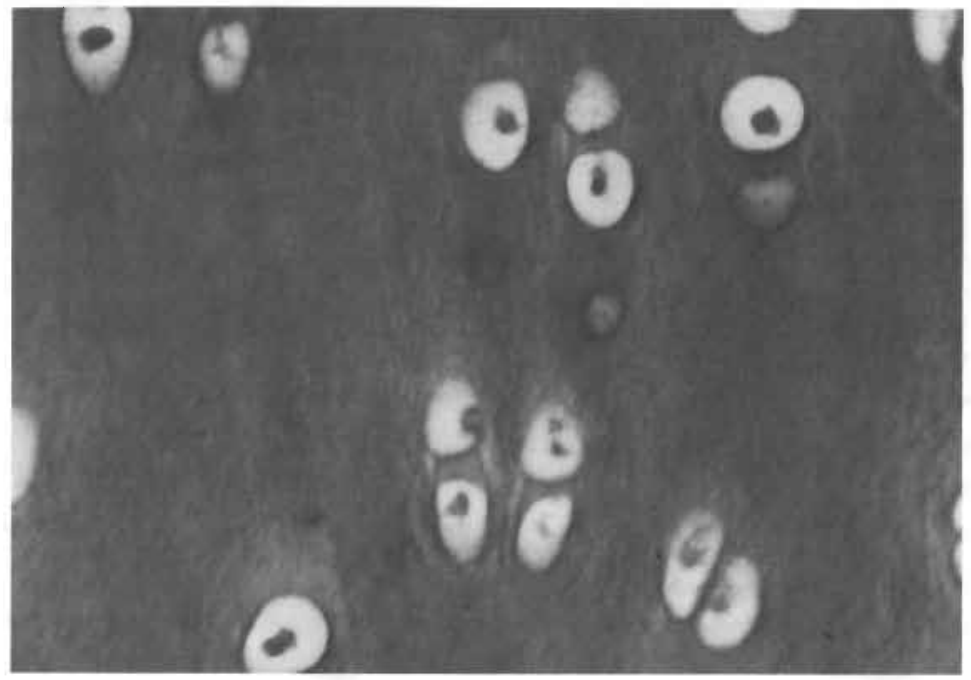

The Fig 3 .

Histological section of the middle zone of femoral head cartilage embedded in paraffin and slained with safranin O-fast green. Shor $(2.5 \mathrm{~min} /$ exposure to lasi green stained the superficial layer green while the middle and deep layers stained evenly red.

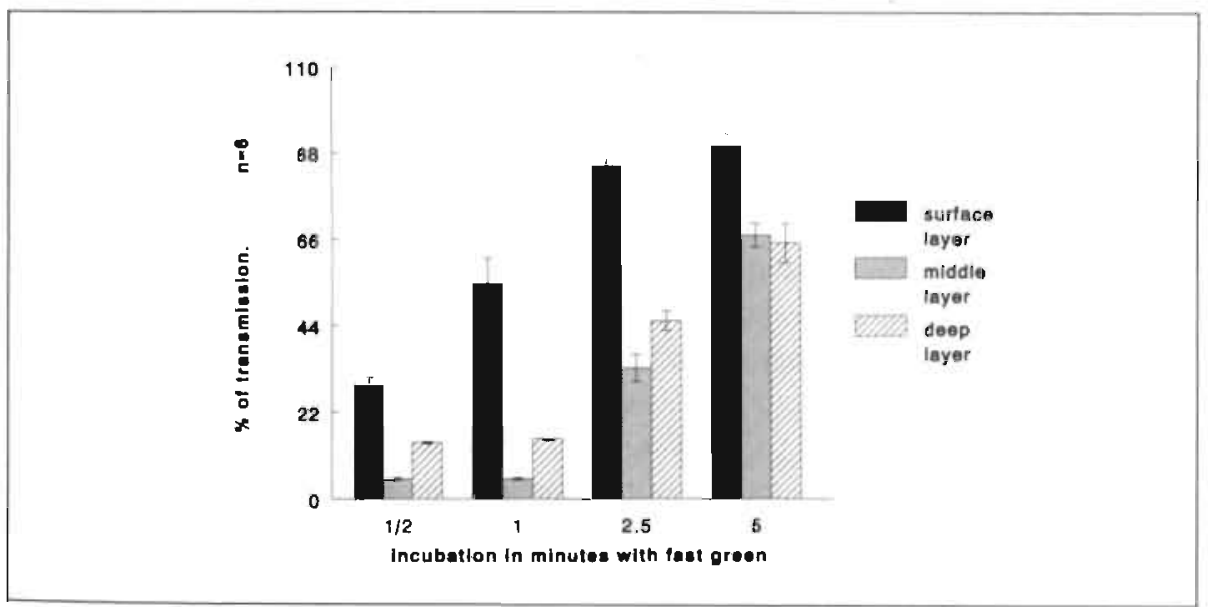

Fig 4.

Densitometric analysis at $500 \mathrm{~nm}$ of safranin 0 sfained cartilage sections, subjected to increasing staining times with fast green. After staining for 5 min with fast green, safranin O staining had largely disappeared in the middle and deep layers. ( $p<0.001)$. 
chondrocytes were surrounded by a slightly more intense band of red, representing the collapsed nerwork and chondrocyle capsule [fig 3]. Prolonged staining with fast green appeared to affect the safranin O-staining. Increasing the staining time of fast green caused the green stained carilage region to extend from the superficial layer into the middle layer (Fig 4).

\section{Effecl of decalcificalion}

Densitometric analysis revealed that decalcification of paraffin embedded cartilage with $5 \%$ formic acid or $10 \%$ EDTA did not result in loss of staining by safranin $\mathrm{O}$ or thionin compared to the undecalcified sections [Figs: $5 a$ and $5 b$ ].

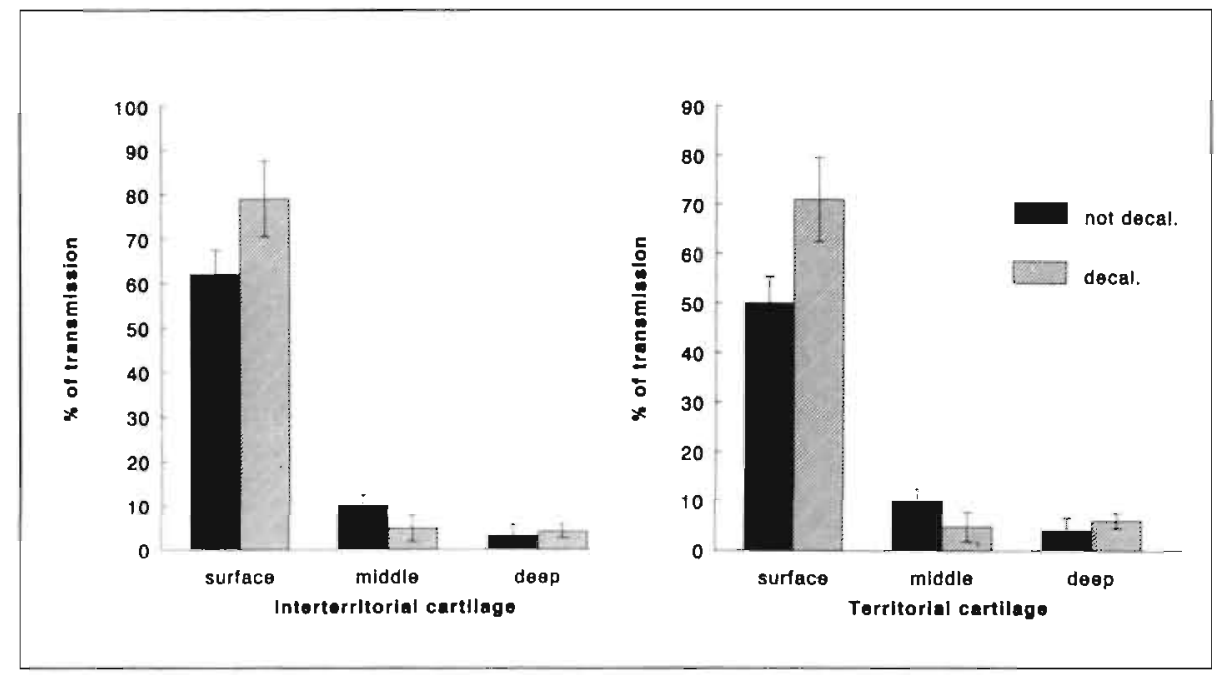

Fig $5 a$ and $5 b$.

Densitometric anolysis of paraffin embedded canilage, ainterterritorial zone, bterritorial zone.

Decalcification did not influence staining by satranin $O$ (surface loyer $p<0.1$; middle and deep layers not significant).

Comparison of safranin O-fast green and thionin staining

Salranin O-fast green and thionin provided even staining throughout all the cartilage layers. The territorial region appeared as a dense and inlensely stained zone. Using microspectrophotometry in paraffin-embedded cartilage sections, no significant differences between safranin O-fast green and thionin staining could be detected (Figs: ba and 6 b). However, the superficial zone of the sections showed a statistical difference in percent transmission $(p<0.05)$. This difference was mainly due to the fast green slained superticial layer of the cartilage. In the deep layer of the cartilage, thionin stained somewhat less intensely in the territorial zone (20\% transmission) than did satranin $\mathrm{O}(5 \%$ transmission]. 

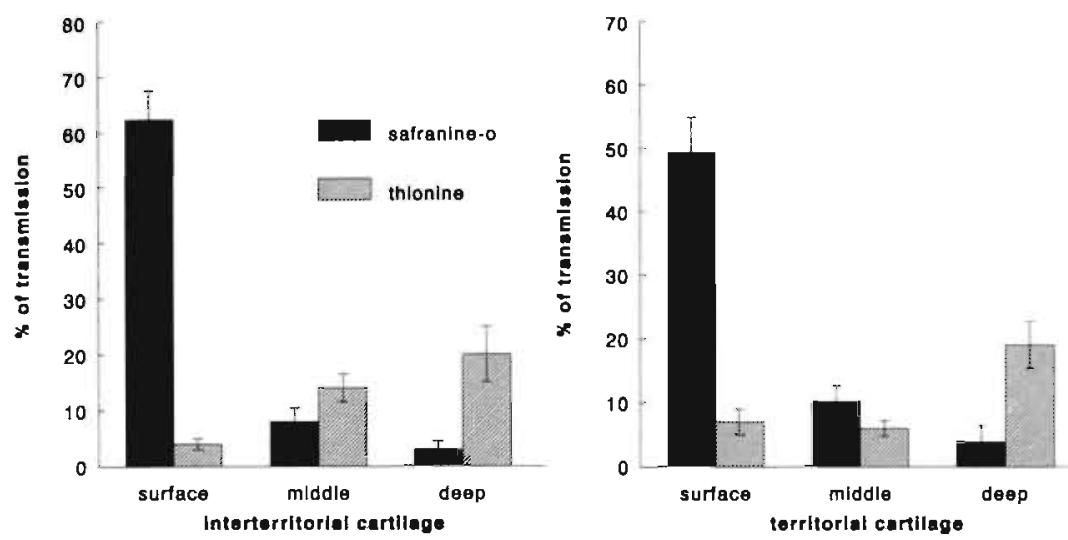

Fig ba and $b b$.

Comparison by densitometric analysis of paraftin embedded cartilage sections stained with thionin and safranin Ofast green, a-interterritorial zone, b-territorial zone. The difference in transmission of thionin and safranin Ofast green stained sections in the superficial zone may be explained by last green staining of this layer (surface layer $p<0.001$ ); middle layer difference not significont, deep layer $p<0.011$.

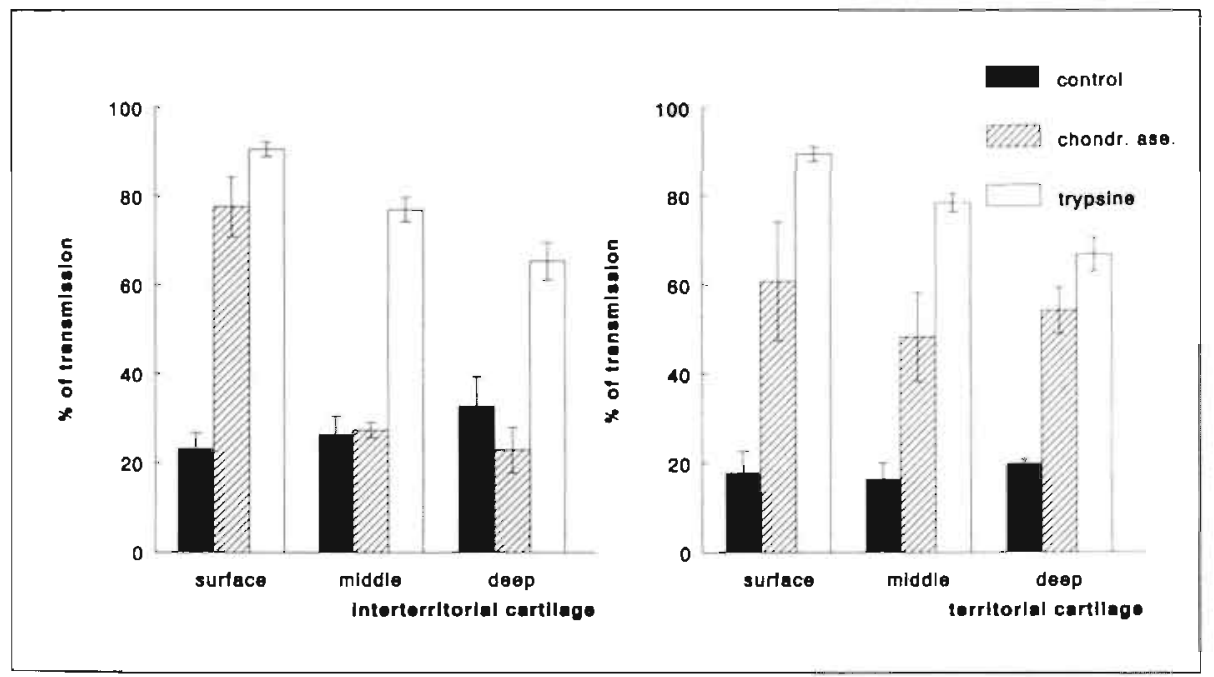

Fig $7 \mathrm{a}$ and $7 \mathrm{~b}$.

Chondroitinase $A B C$ digested cortilage sections stoined with thionin, ginterteritorial zone, blentoria! zone. Staining of the teritorial matrix and the chondrocyte capsule have been removed almost completely. 


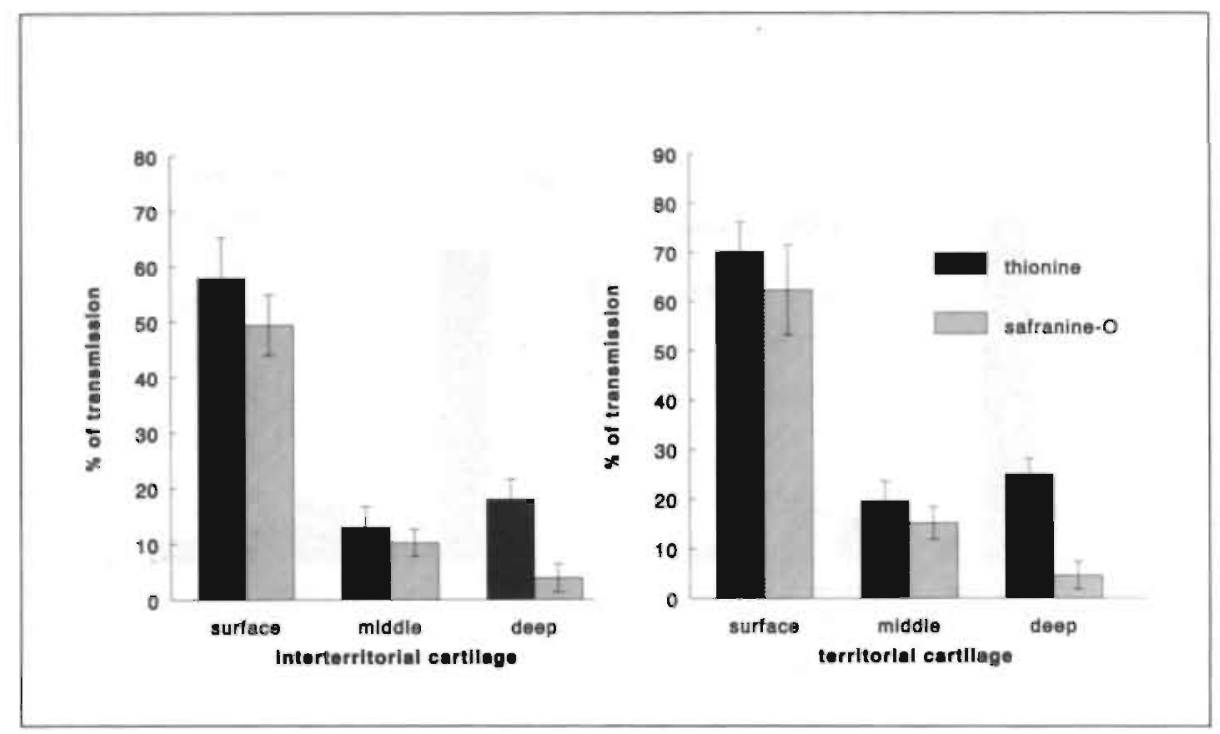

Fig $8 \mathrm{a}$ and $8 \mathrm{~b}$.

Comparison by densitometric analysis of thionin stained GMA embedded sections and safranin $Q$ stained paraffin embedded sections; a-interterritorial zone, b-territorial zone. Both procedures provide similar appearance of the sections (surface and middle layers, difference not significant, deep layer $p<0.01$ )

Enzyme digestions

The specificity of thionin binding to GAG was evaluated using enzyme digestions. Chondroitinase $\mathrm{ABC}$. digestion in paraffin embedded sections reduced thionin staining of the territorial matrix (perilacunar network), while the interterritorial matrix was not affected (Figs: $7 \mathrm{a}$ and $7 \mathrm{~b}$ ). Thionin staining also disappeared after trypsin digestion.

When we compared the GMA embedded sections stained with thionin to the paraffin embedded sections stained with safranin O-fast green, the transmission data were largely similar (Figs: $8 \mathrm{a}$ and $8 \mathrm{~b}$ ). The deep layer of cartilage stained somewhat more intensely with safranin $\bigcirc$ ( $5 \%$ transmission) than with thionin (20\% transmission). The chondrocyte cytoplasm was not stained in either GMA or paraffin embedded sections. However, the chondrocyte morphology remained intact in plastic embedded sections, compared to the poor cellular morphology in paraffin sections (Fig 9). 


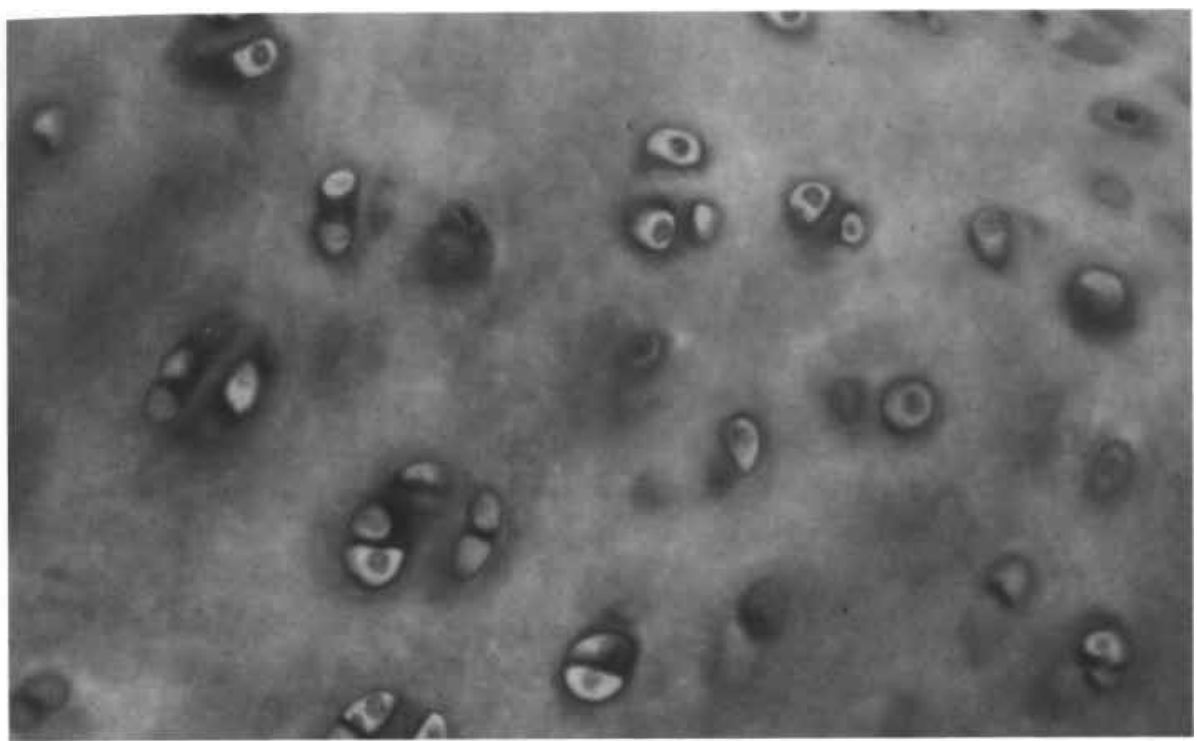

Fig 9.

Thionin-stained GMA embedded cartilage section. Chondrocyle morphology was successfully preserved and interlacunar network was partially intact.

\section{Discussion}

The intensity of thionin staining of cartilage matrix and chondrocytes was constant for staining times ranging from $2.5-10 \mathrm{~min}$. The consistency of thionin staining despite different staining times has advantages over safranin O-fast green staining, which varies directly with time of exposure.

The territorial zone in each layer of paraffir embedded cartilage was intensely stained with thionin as well as with safranin $\bigcirc$. This corresponds with the observations of others (Anderson and Dajdera 1971. Campo 1981. Cole 1984). who described the collapse of the interlacunar network resulting in intensified staining and broadening of the chondrocyte capsules. Decalcification in 10\% EDTA or in 5\% formic acid did not influence the slaining of cartilage matrix or the chondrocyte capsule by safranin $O$ or thionin in paraffin embedded tissue, in contrast to other reports (Eggert et al. 1981, Ippolito et al. 1981, Kiviranta et al. 1984). The successful preservation of the staining properties of the tissue resulted from reduction of the decalcification time to $12 \mathrm{hr}$, the use of biopsies on a thin layer of bone and. the use of relatively low concentrations of decalcifying agents. Further evidence for the limited effect of decalcification was obtained by comparison of decalcified and nondecalcified GMA embedded tissue. Both showed no signs of cellular and pericellular collapse. Decalcification followed by dehydration in alcohol solutions, the use of Histosol and paraffin embedding did, however, cause the collapse of the 
interlacunar network, resulting in widening of the distance between more intensely stained territorial zones of chondrocytes. Thionin did not show metachromasia in watermounted sections, in contrast to safranin $O$, which makes thionin more suitable than safranin $O$ for evaluating nondehydrated GMA embedded sections.

The specificity of thionin staining of GAG was assessed using enzyme digestions. The staining characteristics indicate that thionin is bound to GAG in the perilacunar network and in the chondrocyte capsule. Digestion of the interterritorial matrix with chondroitinase did not prevent complete staining with thionin in the middle and deep layers. In contrast to the surface of the cartilage, which lacked staining after enzyme digestion. The origin of the staining in the middle and deep layers may be the presence of relatively large amounts of keratan sulfate in the cartilage of elderly patients (Bayliss et al. 1983, Stockwell and Scott 1967, Shuckett and Malemud 19901. However, trypsin digestion showed almost complete digestion of interterritorial matrix, which suggests interaction between chondroitin sulfate and rissue protein in this region, as suggested by others (Hasty et al. 1983, Cole 1982, Yamada and Hoshino 1973). Earlier experiments showed that thionin did not stain collagen fibers (data not given).

In GMA embedded cartilage, the network between the chondrocytes was intact and could be visualized. The network plays an important role in differentiation and maturation of cartilage (Hjertquist 1972, Mallinger and Stockinger 1987. Sayers et al. 1987, Shuckett and Malemud 1990, Stockwell and Scott 1967) Therefore, the use of GMA-embedded cartilage may offer the opportunity to study the degeneration of cartilage in osteoarthritis more carefully. Preservation of the morphology of the chondrocytes within their lacunae and the partially intact interlacunar nework has clear benefits for the assessment of cartilage structure as a whole.

In conclusion, the cationic dye thionin offered more reliable staining of cartilage embedded in paraffin and in GMA than satranin $O$ combined with fast green. The characteristics of thionin in GMA and in paraffin embedded cartilage sections were comparable to safranin $O$ staining negatively charged GAG, alkhough safranin $\bigcirc$ stains chondroilin sulfate more specifically /Cole 1984, Cole and Kamal 1984, Dingerkus and Uhler 1977, Goldstein and Horobin 1974, Kincaid and Evander 1985, Kiviranta ef al. 1985, Poole 1970, Sayers ef al. 1987). The absence of metachromasia and its staining properties with cartilage matrix make thionin a favorable stain for the assessment of the quality of cartilage embedded in GMA. 


\section{REFERENCES}

Anderson H.C. and Saidera S.W. 1971. The fine structure of bovine nasal cartiloge. Extraction as a tachnique to study proteoglycans and collagen matrix. J. Cell Biol. 49:050-663.

Boytiss M.T., Venn M., Maroudas A. and Ali Y. 1983. Structure of proteoglycans from different layers of human cartiloge. Biochem. J. 209:387-400.

Bemer H.S., Wyrick D., lee S.W. and MCNeil J.H. 1970. Science and arl in preporing tissues embedded in plastic for light microscopy, with special reference to glycol methacrylate, glass knives and simple siains. Stain Technol. 51:71-97.

Blaouw E.H., Jonkman M.F. and Gerrils P.O. 1987. A rapid connective tissue stain for glycol methacrylate embedded lissue. Acta Morphol. Neerl. Scand. 25:167.172.

Bulstra S.K., Buurman W.A., Wolenkamp G.H.I.M. and van der Linden A.J. 1989. Metabolic characleristics of in vilto cultured human chondrocyles in relation to the hislopathologic grade of osleoarthritis. Clin. Orth. Rel. Res. 242:294-302.

Campo R.D. 1981. Studies on extractable and resistant proteoglycans from metaphyseal and cortical bone and cartilage. Calcif. Tissue Int, 33:89-99.

Cole M.B. 1982. Glycol methocrylate embedding of bone and cartilage for light microscopic slaining. J. Microsc. 127:139.148.

Cole M.B. 1984. Disappearance of the cartilage interlacunar network during histological dehydration. Stain Technol. 59:259-264.

Cole M.B. and Kamal R. 1984. Staining glycol methacrylate embedded corthoge with trielhytcorbocyanin DBTC ("ethyl-stains all $\left.{ }^{\circ}\right)$ with special reference to the interlacunar network. Stoin Technol 59:323.333.

Cole M.B. and Sykes S.M. 1974. Glycol methacrylate in light microscopy: a routine method for embedding and sectioning animal tissues. Stoin Technol. 49:387.400

Conn HJ. Darrow M.A and Emmel V.M. Staining procedures of the biological Stain Commission Williams and Wilkins Comp., Baltimore 1960, page 180

Dingerkus $G$. and Uhler L.D. 1977. Enzyme clearing of alcian blue siained whole small vertebrates for demonstration of cortilage. Stain Technol. 52:229-232.

Eggent F.M. Linder J.E. and Jubb R.W. 1981. Staining of demineralized cartiloge. 1. Alcoholic versus aqueous demineralization at neutral and ocidic $\mathrm{pH}$. Histochemistry. 73:385-390.

Goldstein DJ. and Horobin R.W. 1974. Surface staining of cartilage by alcion blue, with reference to the role of microscopic dye aggregales in histological staining. Hislochem. J. 6:175-184

Hashy K.A., Smith G.N. and Kang A.H. 1983. Histochemical identificalion of sulfation position in chondroitin sullate in various cartiloges. J. Hisłochem. Cytochem. 31:1367-1374.

Hierlquist S-O 1972. Identification and conceniration of the glycosaminoglycans of human articular cartilage in relation to age and osiecarthritis. Calcil. Tissue Res. 10:223.237. 
Ippolito E., Lo velle S. and Pedrini V. 1981. The eflect of various decolcihying agents on cartilage proleoglycans. Slain Technol. 56:367-373.

Kincoid S.A. and Evander S.A 1985. En bloc stoining of anticular cartilage and bone. Stain Technol. $60: 21-28$.

Kivirania 1, Tammi M. jurvelin J., Scomoanen A.M and Helminen H.J. 1984. Fixation, decalcification and tissue processing effects on onticular conliloge proteoglycans. Histochemisty 80:569.573.

Kiviranta 1., Jurvelin J., Tammi M. and Helminen HJ. 1985. Microspectrophotomelric quantitation of glycosaminoglycans in articular cortiloge sections stained with sofronin $O$. Histochemistry. 82:249-255

Lillie R.D. 1965. Histopathologic Technic and Praclical Hislochemisiry, 3rd ed. Mc Graw Hill Book Company, New York.

Mollinger R. and Stockinger L. 1987. Histochemistry of the extracellular malrix of aging hyalin cartilage. Folio Hislochem. Cytobiol. 25:129.132.

Mankin H.J., Dorfman H., Lippiello L. and Zarins A. 1971. Biochemical and melabolic abnormalities in articular contiloge from osteoathritic human hips. J. Bone Joint Surg. 53(A) 523.537.

Poole A.R. 1970. The relationship between tohidine blue staining and hexuronic acid content of cartlage matrix. Histochem. J. 2:425.430.

Rosenberg M. Barl P. and lesko J. 1960. Waler soluble methacnlale as an embedding medium tor the preparation of ultrathin sections. J. Ulirastrucl. Res. 4:298-303.

Rosenberg L. 1971. Chemical basis for the histological use of satronin $O$ in the study of articulor cartilage. J. Bone Joint Surg. 53/A):89-82.

Sayers D.C.J. Volpin G. and Benlly G. 1987. The demonsiration of bone and cartloge remodelling using alcian blue and haemaloxylin. Stain Technol. 03:59-63.

Shuckell R. and Malemud C.J. 1990. Distinct cantloge proleoglycan chromatographic elution patterns in advanced human hip osleoorthritis: correlations with hislologic analysis. J. Rheum 17:357-363.

Stockwell R.A. and Scott J.E. 1967. Distribution of acid glycosaminoglycons in human anticular cartilage. Noture 215:1376.1378

Yamada K and Hoshino M. 1973. Digestion with chondroitinoses of acid mucosoccharides in rabbit cartilages as reveded by electron microscopy. Histochem. I. 5:195-197 


\section{Metabolic characteristics of in vitro cultured human chondrocytes in relation to the histopathological degree of osteo- arthritis}

\section{Summary}

Isolated human chondrocytes derived from healthy and osteoarthritic (OA) cartilage were cultured in high density in a newly designed microculture system. The severity of OA was graded according to a modified histo-pathologic score originally described by Mankin et al.

Chondrocytes from adult parients with $O A$ showed ${ }^{35} \mathrm{~S}$-sulphale and ${ }^{3} \mathrm{H}$-thymidine incorporation in vitro, which increased with severity of the disease through Mankin 11-12. Incorporation rapidly declines after Mankin 11-12. Both matrix synthesis and cell proliferation were strongly reduced in the severe grades of $\mathrm{OA}$.

Histologic examination of the newly formed cartilage was only possible if the chondrocytes were derived from less severe grades of OA. Microscopy showed healthy chondrocytes surrounded by newly synthesized marix, which stained well with specific dyes, indicating the ability of the cells to synthesize normal matrix components.

The phenotype of human articular chondrocyles, derived from different grades of OA, was maintained in a high- density culture system. The data suggesi disregulation of the cell metabolism in OA cartilage. The increased cell metabolism was directly related to the histopathologic grade of $O A$.

\section{Introduction}

Osteoarthritis (OA) is a progressive destructive disease of articular surfaces of joints. Characteristic of $O A$ is the macroscopical focal variation $[4,7,9)$. Clear microscopic changes in structure, cell content, integrity of the tide mark and conceniration of glycosaminoglycans (GAG) are observed $(29,35)$. Both the histology of the cartilage and the biochemical composition of proteoglycans (PG) change wilh severity of the disease $(3,6,8,20,22-24,33)$. OA appears to be a heterogeneous disease, which makes if difficult to establish the pothogenesis in vivo.

Several in vitro and in vivo systems have been developed to sludy the pathogenic mechanism of $\mathrm{OA} .(5,10,13,17,19,32,36)$. In vitro studies with human 
and experimental $O A$ cartilage explants showed an initial period of enhanced proteoglycan (PG) synthesis. At the same time, however, an increased loss of newly synthesized PG and PG subunits was noted $(21,26,34)$. It was concluded that the repair mechanism fails to be effective. Also, the rate of cell proliferation was observed to increase with severity of $O A$. In the mosl severe forms of $O A$, however, a strongly reduced mitotic activity of chondrocytes was noted $(21,27,34)$.

The vast majority of in vitro experiments has been carried out with animal cartilage. In these studies, cartilage from joints with experimentally induced $O A$ and embryonic cartilage were frequently used $(12,13,27,35)$. In the evaluation of the pathological mechanism of $O A$ in humans, such experiments were considered to be of limited value (10).

Culture of human chondrocytes leads to fast degeneration in most culture systems $(1,2,9,15)$. Recently, it became obvious that a rather critical cellto-cell contact is necessary to maintain the characteristic phenotype of the chondrocytes in vitro $(5,9,10,14,30,31\}$. A new culture system for isolated human articular chondrocyles was developed. This culture syslem is a modification of a system used for culture of embryonic chick chondrocytes (31). The close cell-to-cell contact in these cultures facilitates the continued expression of the cartilage phenotype.

Chondrocytes of $O A$ joints and normal joints were studied using this culture system. The synthesis of sulfated GAG and cell proliferafion were determined in relation to the severily of $O A$. A modification of the histologichistochemical method originally proposed by Mankin et al. was used to evaluate the grade of OA (28)

Analysis of the data showed significant correlations among GAG synthesis, cell proliferation and the severity of $O A$, which indicated that the chondrocytes in this culture system retained their phenotypic characteristics. The rate of PG synthesis and cell proliferalion was direclly correlaled to the histologic severity of the disease. The culture model used seems to be a favorable model to study factors modulating the pathogenesis of OA.

\section{Material and methods}

\section{Materials}

Carlilage was obrained from 28 patients during arthroplastic surgery for primany $O A$. Patients with rheumatoid arthritis were excluded. Cartilage from the weight-bearing part of the femoral head and the medial femoral condyle was used. After removal, the specimen was inspected and uniform areas representative for the disease process were selected. Osteophytes and marked focal variations are characteristic for $O A$; however, the osteophytic region of the joints was not used in the experiment to prevent the use of neocartilage. 


\section{Histopathology}

A biopsy with a diameter of $1.2 \mathrm{~mm}$ into the subchondral layer of the selected area was raken. The biopsies, which were not decalcified were fixed in 10\% formalin and embedded in plastic Technovit 7100 (Kulzer, Wehrheim, Germany) or in paraffin after dehydration in alcohol. Sections $(5 \mu \mathrm{m})$ were cul perpendicular to the arlicular surface. For the histopathologic score, a modification of a procedure originally proposed by Mankin et al. [21) was used (table 1). Sections were stained with hematoxylin and eosin, Alcian blve-periodic acid-Schiff (PAS), thionin and safranin-O. a special stain for acid mucopolysaccharides $(16,25,28,35)$.

Table 1

Modified Mankin score

\section{CARTILAGE STRUCTURE}

Normal

Irregular surface includ. fissures into the radial layer

Pannus

Superficial cartilage layers (at leasi b) absent

Slight disorganization ( cellular rows absent,

Some small superficial clusters !

fFissures into calcified cartilage layer

Disorganization ( chaotic structure, clusters,

Osteoclast activity !

CARTILAGE CELLS

Normal

Hypercellularity, including small superficial clusters

Clusters

Hypocellularity

MATRIX STAINING

Normal / slight reduction

Staining reduced in radial layer

Reduced in interterritorial matrix

Only present in pericellular matrix

Absent 


\section{Cell isolation}

After removal the cartilage was transferred into a sterile vial containing $0.9 \% \mathrm{NaCl}$ and kept at $4^{\circ} \mathrm{C}$. Within two hours after removal, the cartilage adjacent to the biopsy spot was cut from the subchondral layer with a scalpel. The cartilage parts were cut into $1 \times 1 \mathrm{~mm}$ pieces and digested in crude collagenase CLS 2, Worthington, Freehold, New Jersey; $200 \mathrm{U} / \mathrm{mll}$ for one hour at $37^{\circ} \mathrm{C}$. To minimize the contamination with fibroblasts, erythrocytes, and such, the first digest was discarded The digestion was then continued for another 14 hours. The isolated chondrocyles were washed and resuspended in culture medium M 199 (Gibco, Paisley, Scotland) supplemented with L-glutamine, $250 \mu \mathrm{g} / \mathrm{ml}$, ascorbic acid, $50 \mu \mathrm{g} / \mathrm{ml}$ and an antibiotic-antimycotic solution, $50 \mu / 10,000 \mathrm{U} / \mathrm{ml}$ penicillin; $10,000 \mathrm{U} / \mathrm{ml}$ streptomycin; and $25 \mathrm{mg} / \mathrm{m} /$ Fungizone, E.R. Sqibb and Sons, Princeton, New Jerseyl.

\section{Culture technique}

A sample of the cell suspension was used for cell counling and determination of the viability of the cells with trypan blue. Another sample was used for cytologic examination. The isolated cells were stained with May-Grünwald-Giemsa Merck, Darmstadt, Germany) to evaluate the amount of matrix remaining around the chondrocytes after the isolation procedure.

The cells were resuspended in a concentration of $2 \times 10^{5}$ cells $/ \mathrm{ml}$ in a medium supplemented with $10 \%$ fetal calf serum (FCS). Drops of $10 \mu$ of the cell suspension were placed on plastic petri-dishes (bacterial culture type). During the following days, $10 \mu \mathrm{l}$ of medium supplemented with $10 \%$ FCS was added to the individual drop cultures

\section{Metabolic study}

After a 96 -hour culture period, the synthesis of GAG by the cells was determined. Cells were labeled for 16 hours with $5 \mu \mathrm{Ci} / \mathrm{ml} \mathrm{Na}_{2}{ }^{35} \mathrm{SO}_{4}$ ispecific activily, $47 \mathrm{mCi}$ / $\mathrm{mmol}$, Radiochemical Center, Amersham, United Kingdom). At the end of this period, the aggregates and the medium were transferred into $2 \mathrm{ml}$ fresh medium with papain (Merck, Darmstadt, Germanyl and incubated at $60^{\circ} \mathrm{C}$ for 16 hours to digest the newly formed GAG. To precipitate the sulfated GAG, $2 \mathrm{ml} 10 \%$ celylpyridinium chloride [CPC, Merck, Darmslad!, Germany] in $0.2 \mathrm{M} \mathrm{NaCl}$ was added. The precipitate was harvested atter 16 hours, washed several times with $0.1 \%$ CPC and dissolved in $0.5 \mathrm{ml} 100 \%$ formic acid. The amount of ${ }^{35} \mathrm{~S}$-sulphate incorporated in GAG was determined with a liquid scintillation counler.

Cell proliferation was quantitated by ${ }^{3} \mathrm{H}$-thymidine $\left({ }^{3} \mathrm{H}-\mathrm{TdR}\right)$ incorporation during 16 hours. Each aggregate was supplemented with $15 \mu \mathrm{Ci} / \mathrm{ml}^{3} \mathrm{H}-\mathrm{TdR}$ [specific activity, $5 \mathrm{Ci} / \mathrm{mmol}$, Radiochemical Center, Amersham, United Kingdom). After centrifugation, $2 \mathrm{ml}$ of $10 \%$ trichloroacetic acid (TCA) was added to the pellet, 
which was subsequently incubated for 16 hours at $4^{\circ} \mathrm{C}$. The precipitate was washed and resuspended in $0.5 \mathrm{ml}$ formic acid. The incorporated ${ }^{3} \mathrm{H}-\mathrm{TdR}$ was measured in a liquid scintillation counter. The result of each experiment is the mean of determinations of six different aggregates.

Histology of culiured cells

A representative number of aggregates of each cell culture was used for histologic examination. After fixation in alcohol, the aggregates were embedded in either Technovit 7100 or paraffin and sectioned at $5 \mu \mathrm{m}$. The sections were stained with hematoxylin-eosin, Alcian blue-PAS, thionin and satranin-O-fast green.

\section{DNA experiment}

Quantitative determination of DNA content of the isolated chondrocytes and the pellets was performed from day one to day five of the experiment. Experiments were performed on isolated chondrocytes from cartilage of 12 patients. Biopsies of the cartilage were used to measure the histo-pathological grade of $O A$ of the patients. Measurements of cultures of each patient were carried out in triplo. Pellets were washed in $1 \mathrm{ml}$ of PBS and centrifuged at $1200 \mathrm{rpm}$ for $5-10 \mathrm{~min}$. The pellet was then transferred to an eppendorf and centrifuged in an Hetsich-microliter centrifuge for $10 \mathrm{~min}$. at $2000 \mathrm{rpm}$. After removal of the supernatant, $25 \mu \mathrm{l} \%$ SDS in $0.01 \mathrm{M}$ tris $\mathrm{HCL}$ (Ph 8) was added and mixed with the pellet for 10 minutes at $100^{\circ} \mathrm{C}$. The mixture was cooled down to room temperature slowly, whereafter $87.5 \mu 0.01 \mathrm{M}$ Tris $\mathrm{HCl}$ and $0.001 \mathrm{M} \mathrm{CaCl}_{2}$ and $0.06 \mu \mathrm{g}$ proteinase-K (Boehringer, FRG) were added. Digestion took place at $54^{\circ} \mathrm{C}$ for 24 hours. Samples were then slored at $196^{\circ} \mathrm{C}$ (labarca 19801.

The fluorescent enhancement of an equivalent weight of calt thymus DNA / CT DNA, Worthington, England) was used to compare with the fluorescent enhancement of the samples. I $\mathrm{ng} / \mathrm{ml}$ CT DNA was suspended in Tris-HCL $10 \mathrm{mM}$ and $0.1 \mathrm{mM}$ EDTA at $\mathrm{Ph} 7.7$ to a concentration of $50 \mathrm{mg} / \mathrm{ml}$. $25 \mu$ of the samples was added to 775 $\mu \mathrm{TE}$ buffer. $200 \mu$ of $24.06 \mathrm{~K}_{2} \mathrm{HPO}_{4} .3 \mathrm{H}_{2} \mathrm{O}$ and $2.48 \mathrm{~g} \mathrm{KH}_{2} \mathrm{PO}_{4}$ per $100 \mathrm{ml}$ were added to the samples adjusted to a $\mathrm{Ph}$ of 7.7. I $\mu$ l Hoechst 33258 was added to each sample. Samples were left in the dark for 15 minutes before fluorescence measurements were made. Fluorescence measurements were performed with $350 \mathrm{~nm}$ for the excitation light and an emission at $450 \mathrm{~nm}$.

The DNA content was used to determine the cell content.

\section{Autoradiography}

Pellets of aggregaled chondrocyles were labeled on day four with $50 \mu \mathrm{Ci} / \mathrm{ml}$ $\mathrm{Na}_{2}{ }^{35} 5 \mathrm{O}_{4}$ for 24 hours. Pellets were fixated in $2.5 \%$ Nathiosulfate-pentahydrate $0.24 \mathrm{~g} / \mathrm{ml} \mathrm{H} \mathrm{H}_{2} \mathrm{O}$ (Merck, Darmstadt, FRG) and embedded in paraffin. Sections of 3 $\mu \mathrm{m}$ were cut perpendicular on the carrilage surface and mounled on gelatine coaled 
glass slides. Afier having been deparafinated, the sections were dipped in K5 emulsion (llford, Basildon, Essex, UK) and exposed for 3 weeks. The sections were developed and then stained with hematoxylin and eosin $(H E)$.

\section{Results}

Patient material and histology

The cartilage used for the experiments was obtained equally from the hips and knees Sixty percent of the patients were women, and the mean age of the patients was 72 years (range, $66-78$ years). Table2 lists viability of the cartilage used for the experiments.

\section{Table 2}

Data on patients trom whom cartilage biopsies were iaken

\begin{tabular}{llllll}
\hline $\begin{array}{l}\text { Number of } \\
\text { Patients }\end{array}$ & $\begin{array}{l}\text { Mean } \\
\text { Age }\end{array}$ & $\begin{array}{l}\text { Knee or } \\
\text { Hip }\end{array}$ & $\begin{array}{l}\text { Number of } \\
\text { Experiments }\end{array}$ & $\begin{array}{l}\text { Hisiologic } \\
\text { Score }\end{array}$ & Viability \\
\hline 1 & 06 & $K$ & 8 & 1 & $88 \%$ \\
2 & 71 & $K, H$ & 9 & 2 & $92 \%$ \\
3 & 70 & $K, H, H$ & 9 & 3 & $93 \%$ \\
3 & 73 & $K, H, H$ & 9 & 4 & $90 \%$ \\
2 & 71 & $K, H$ & 9 & 5 & $93 \%$ \\
3 & 74 & $K, H, H$ & 5 & 6 & $93 \%$ \\
2 & 70 & $K, H$ & 5 & 7 & $92 \%$ \\
2 & 73 & $H, H$ & 0 & 8 & $92 \%$ \\
1 & 67 & $K$ & 0 & 9 & $86 \%$ \\
2 & 72 & $H, K$ & 4 & 10 & $87 \%$ \\
2 & 76 & $K, H$ & 5 & 11 & $86 \%$ \\
1 & 78 & $H$ & 5 & 12 & $90 \%$ \\
2 & 74 & $K$ & 5 & 13 & $89 \%$ \\
2 & 73 & $K, H$ & 6 & 14 & $91 \%$ \\
\hline
\end{tabular}

Inspection of the joints showed a gross macroscopic variation of $O A$ within individual pints. Representative areas specific for a certain stage of OA were used for isolation of the chondrocytes. Biopsies of cartilage with more severe forms of $O A$ were difficult to obtain. In such cases, most of the cartilage had largely disappeared, leaving an eburnised joint surface. This hampered the gradation in the severe forms of $O A$. 
For the histopathologic grading of OA, paraffinembedded tissue was used. The paraffinembedded tissue enabled the determination of the content of GAG of the matrix, while the plastic-embedded material permitted an accurate examination of the cell structure. The histopathologic grading system is based on a subjective judgement and depends on the experience of the examiners. Table 2 lists the histopathologic scores. The differences in scoring the grade of OA between two experienced examiners never exceeded two points.

Culture of isolated chondrocytes

The isolation procedure resulted in a suspension of single cells. After isolation, the chondrocytes showed condensed nuclei and little cytoplasm. A smail number of the chondrocytes was still surrounded by a thin layer of Alcian blue stainable material. The viability of the chondrocytes after isolation was not related to the severity of $O A$ expressed by the histopathologic score.

After one day of culture, the isolated cells accumulated in the center of the

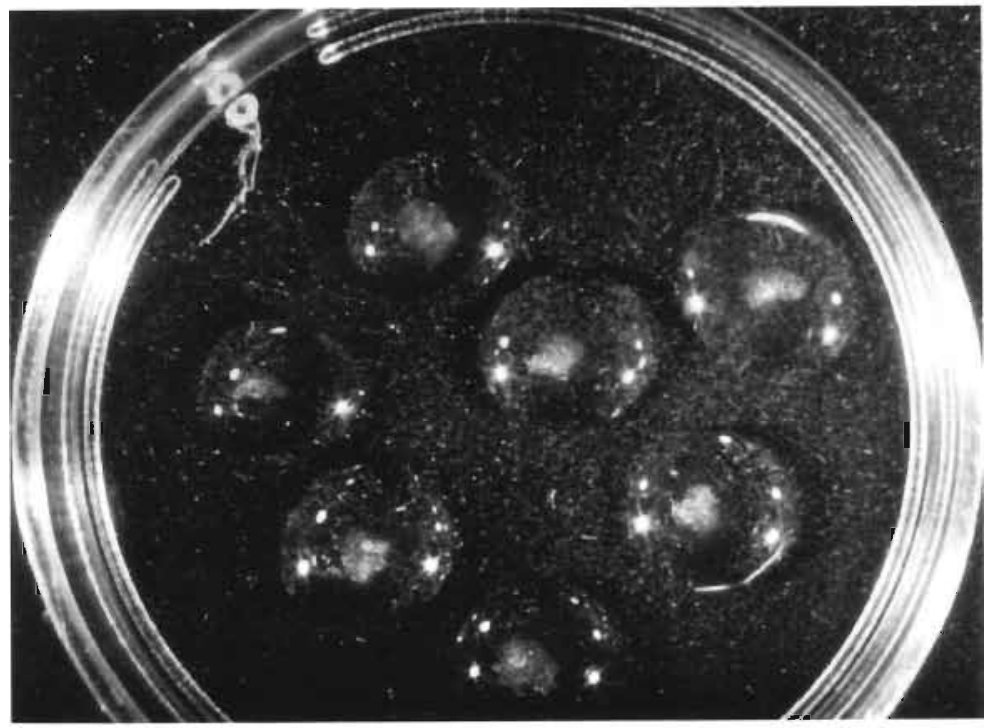

Fig. 1-A:

A cartilage aggregote formed by isolared human chondrocytes in a small drop of culure fluid (AO vil) after four days of cullure (Original magnification $x$ 10)

drop of culture fluid. During the culture period, aggregates were formed. The cohesion of these aggregates increased with time. On the fourth day of cullure, aggregates with a diameter of $2.3 \mathrm{~mm}$ were observed (Fig. IA]. The cohesion of the 
aggregates, oblained at Day 4 of culture, appeared to be dependent on the histopathologic grade of $O A$ of the cartilage from which the chondrocytes were isolated (data not given). Only the chondrocytes derived from cartilage with less severe grades of OA (Grades 5-7) formed coherent aggregates. Such aggregates stayed intact during the fixation and dehydration procedure for histology.

Microscopic examination of these aggregates showed prominent nucleoli in enlarged nuclei. During culture, the amount of cyloplasm increased and the cells became surrounded by newly deposited matrix material thal slained intensively with Thionin (Fig. 18).

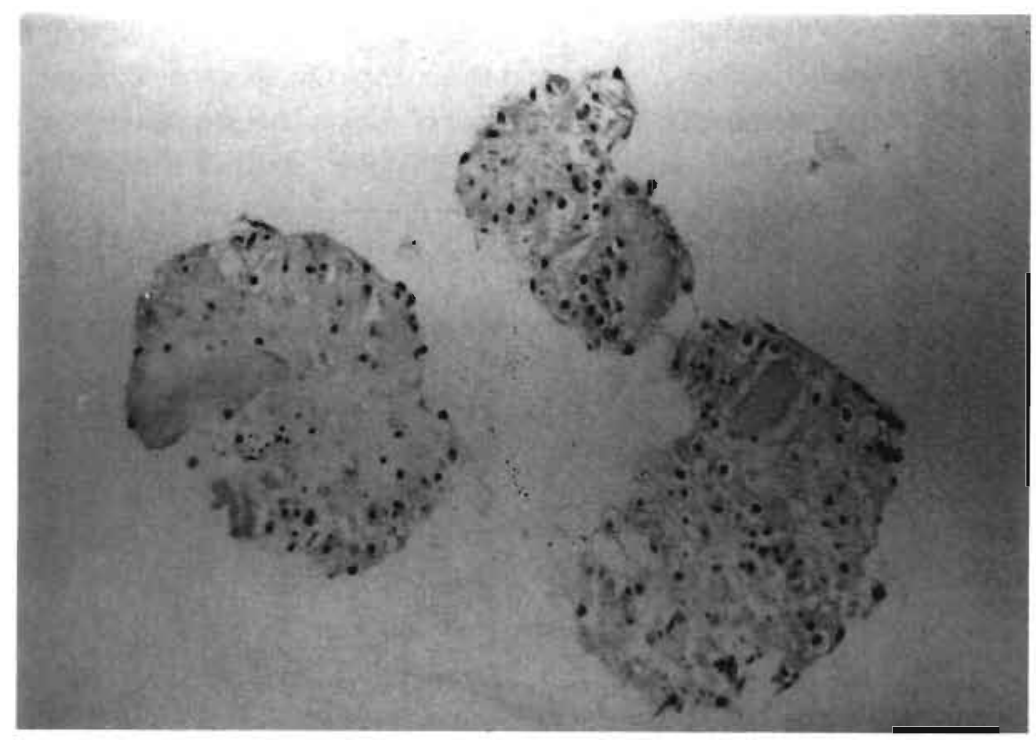

Fig. 1-B.

Photomicrograph of a section of an aggregale in Fig. I.A, showing typical proliferating chondrocytes that reside within a lacuna. The microfissuers are a result of the histologic procedure (Thionin; original magnificution $\times$ (44).

The chondrocytes resided, single or in groups of two or three cells, in a lacuna surrounded by the newly formed matrix material. In the cytoplasm, large round vacuoles and intensively PAS- stained granulae are seen.

Metabolic study

The proliferation of the cultured cells was quantified by determination of ${ }^{3} \mathrm{H}-\mathrm{TdR}$ incorporation. Cultures of chondrocytes obtained from cartilage through grade 11 of $O A$ showed an increasing grade of $O A$ as ${ }^{3} \mathrm{H}-\mathrm{TdR}$ uptake increased. The ${ }^{3} \mathrm{H}-\mathrm{TdR}$ uptake of cartilage from OA Grades $10-11$ is about tenfold of the uptake of normal cartilage. 
However, from grade 11 onward a very low ${ }^{3} H-T d R$ upiake was measured. indicating a strong reduction of cell proliferation in cultures from severely diseased cartilage (Fig. 2).

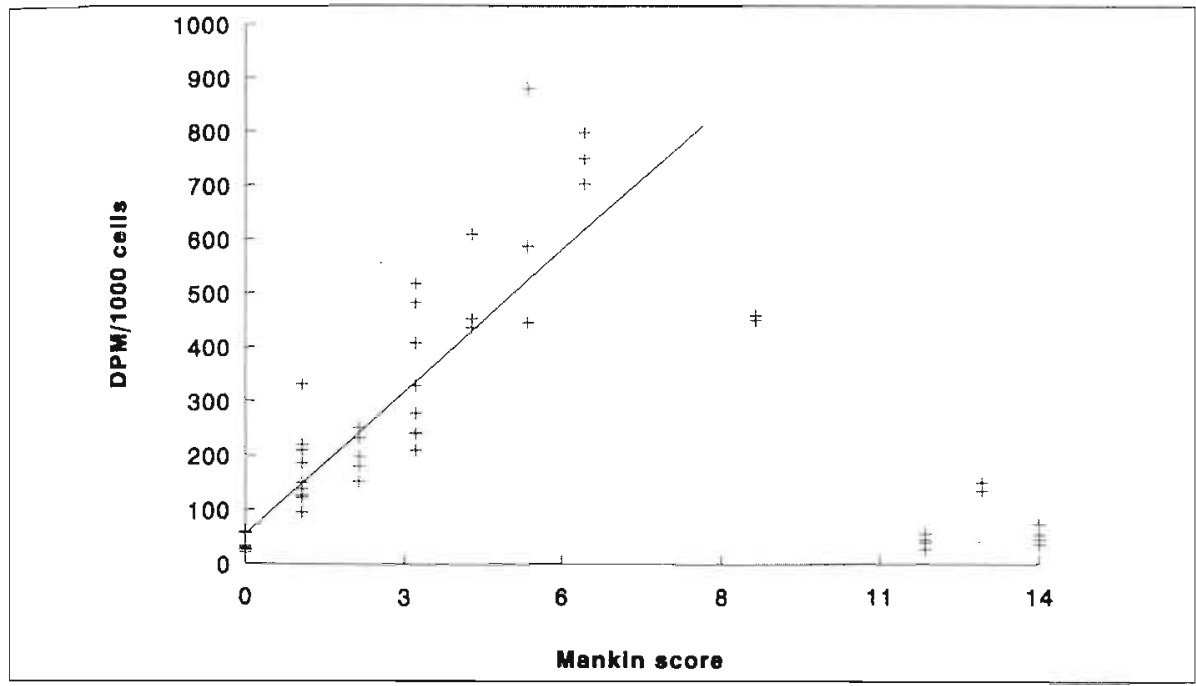

Fig. 2 .

The 3H-TdR uptake in DPM/ 1000 cells of each experiment is indicated in relation to the histopothologic score of the cartilage from which it was derived. The function of the calculaled regression is: $Y=89.8 X+$ 72. The correlation coefficient $=0.87$.

The quantification of GAG synthesis was obtained by determination of ${ }^{35} \mathrm{~S}$. sulphate incorporation in the newly produced matrix. The ${ }^{35} S$-sulphate incorporation increased with severily of the grade of OA. Values of an almost fiftyfold increase of ${ }^{35} S$-sulphate uptake were observed in cartilage cells from OA cartilage through Grade 12 when compared with normal cartilage. The uptake of severely damaged cartilage was comparable with the uptake of normal cartilage, suggesting a low metabolic state of the chondrocyles derived from cartilage whit severe OA (Fig. 3|.

Cell proliferation and matrix synthesis seemed to be closely reloted in chondrocytes obtained from cartilage with a histopathologic score through Grades $11-12$. The correlation coefficient between the ${ }^{3} \mathrm{H}-\mathrm{TdR}$ and the ${ }^{35} \mathrm{~S}$-sulphate uptake was high $(0.87$; Fig. 4$)$.

The quantification of the amount of DNA was achieved by a method that is based on the enhancement of fluorescence seen when Hoechst 33258 binds to DNA. 


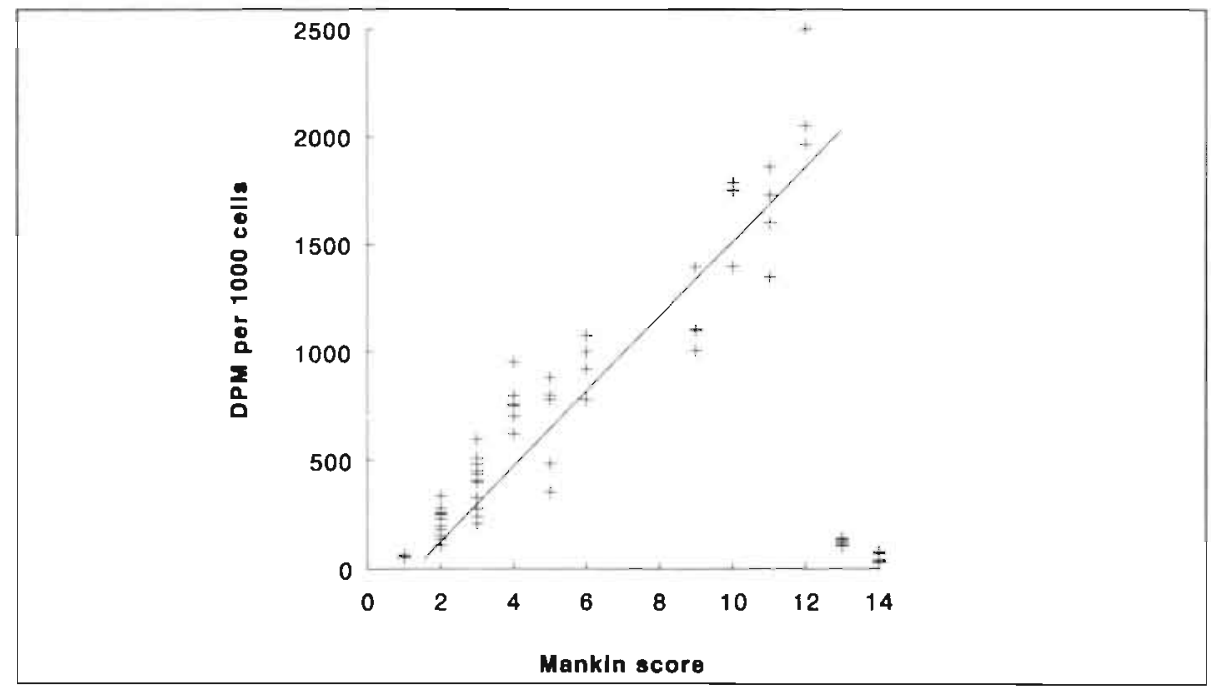

Fig. 3

The ${ }^{35}$ S-Sulphale uplake in DPM/1000 cells of each experiment is indicaled in relotion to the histopathologic score of the cartilage from which it was derived. The function of the colculated regression is: $Y=109 \times \cdot 101$. The correlation coefficien $1=0.95$.

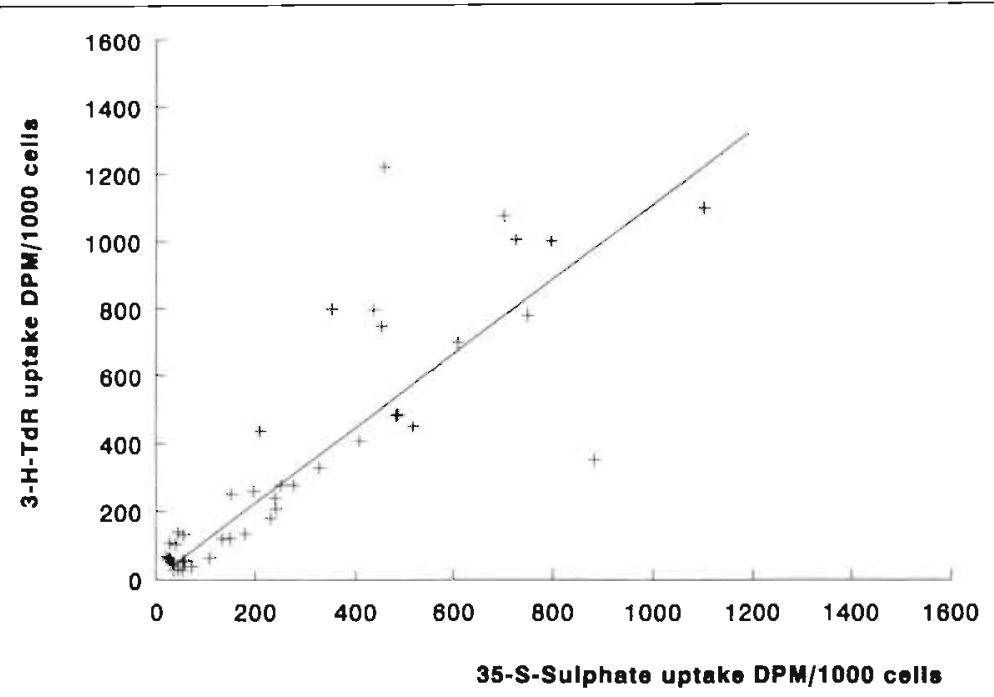

Fig. 4

The HH.TdR uplake is correloled with the "S-Sulphate uplake. The function of the regression is $Y=363 X+$ 0.70 . The civelation coeflicient $=0.87$. 
Analysis of the histopathological score of the cartiloge obtained for this experiment proved that, five patients with healthy cartilage (grade 1-4), four patients with moderate OA (grade 5-8) and three patients with severe OA (grade 9-12) were included in this study. Autoradiography revealed that 3 S-sulfate label was mainly present in the cartilage matrix. In most of the pellets, derived of different grades of OA, the radioactivity was evenly spread over the surface of the peller [Fig. 5).

DNA measurements were performed directly after cell isolation and each following day upto day 5 of culture. The number of moderately and severely $O A$ chondrocytes $(s d 0,8)$ in culture proved to be higher than the number of healthy cells (sd 0.3). The data showed that during culture the number of healthy and moderately OA chondrocyles did nol change $(p=n s)$. A slight decrease in the number of severely $O A$ chondrocytes was observed on day three of culture $(p<0.01)$, but the number of cells stabilized on the following days. The data showed that during culture the number of cells was nol changed on day five compared to the number of cells on day one (Fig 6).

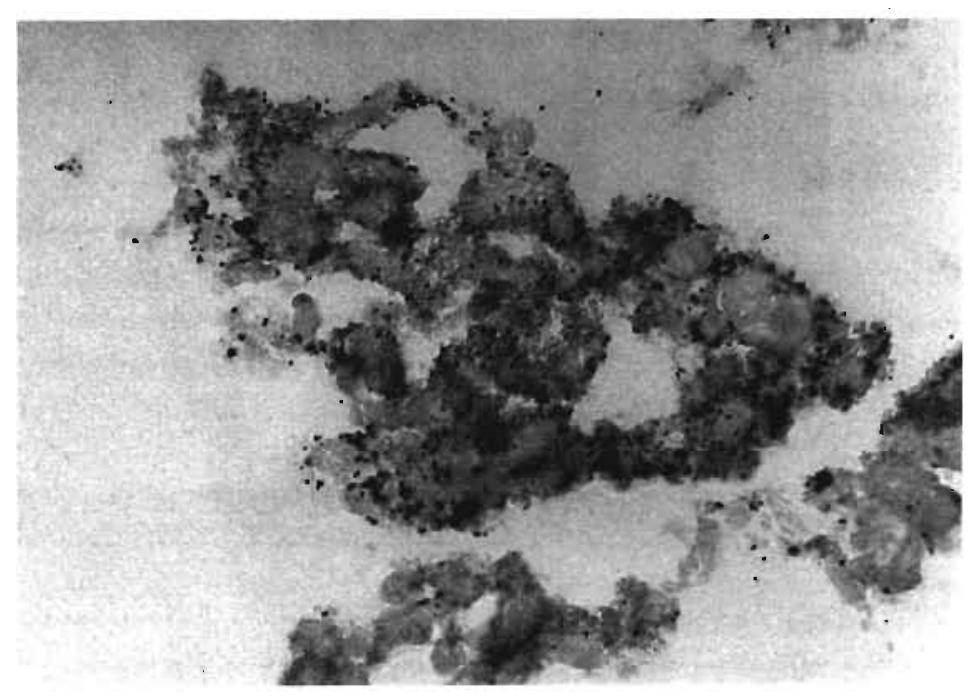

Fig. 5

Micro phologroph of section labeled with ${ }^{35}$ S-sulfate. Rodioactivity is evenly spread over the carilage motrix. 


\section{Discussion}

Cartilage of $O A$ joints of a relatively homogeneous group of patients with a mean age of 72 years (range, $06-78$ years) was used in this study. Age-related changes in the biochemical composition of cartilage and the metabolic properties of chondrocytes, known sources of error in these kinds of studies, were thus excluded $(18,20,29)$. Although biochemical differences between cartilage of the knee and the

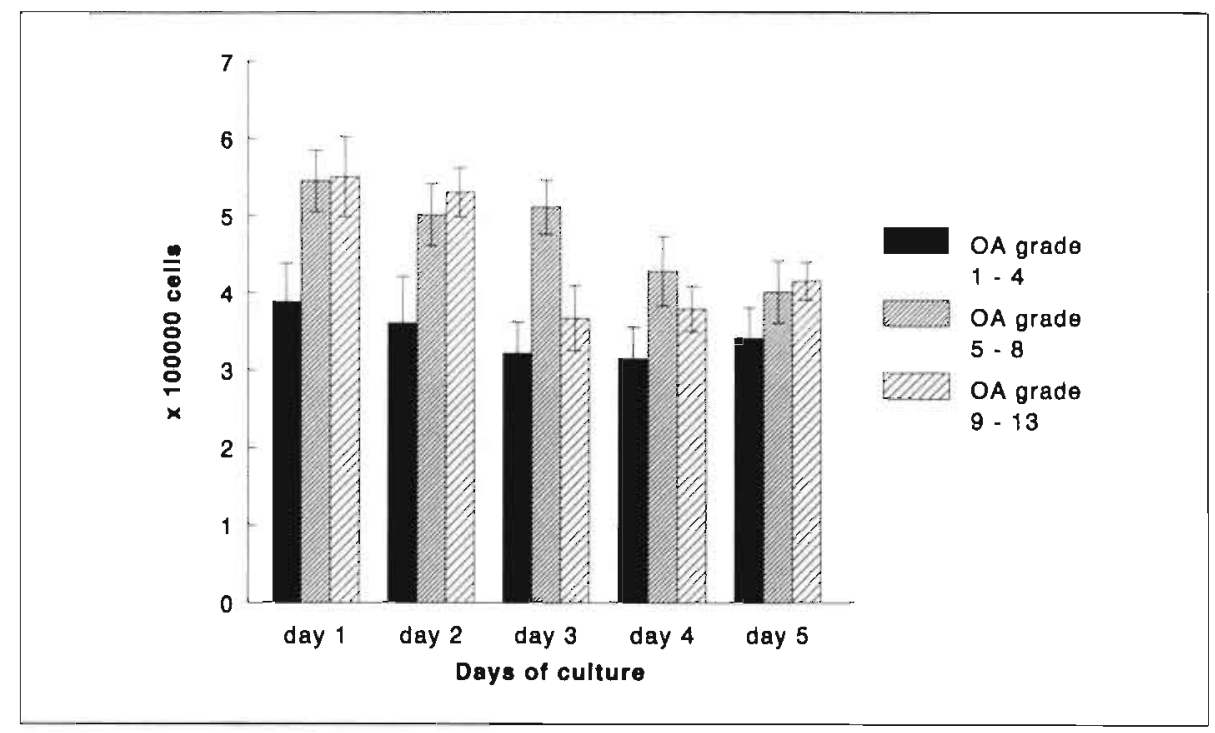

Fig.6.

DNA measurement performed fiom day 0 uplo day 5 of culture. During cullure the nuber of cells did not change significantly.

hip have been reported 111 ), no significant differences in ${ }^{35} \mathrm{~S}$ or ${ }^{3} \mathrm{H}-\mathrm{T} d \mathrm{R}$ uptake were observed in this study. To avoid disturbances caused by focal variations, small areas of cartilage with an uniform macroscopic aspect were used. This hampered the collection of larger amounts of material, while minimal variations of gradation of $O A$ within one specimen could not be excluded.

The isolation of chondrocytes, especially from older cartilage, has been described as difficult with regard to the viability of the cells $(10)$. The use of a relatively low concentration of collagenase for the digestion of cartilage enabled the achievement of an optimal result with regard to the completeness of digestion and the preservation of viability of the chondrocytes. Moreover, the cells were metabolically active during the four-day culture period. 
The isolated chondrocytes accumulated in the center of the drop soon after the onset of culture. This accumulation is a passive phenomenon and facilitates the intercellular contact that seems to be essential for prolonged expression of chondrogenic phenotype in vitro (31). Even after four days of culture, the chondrocytes surrounded by newly synthesized matrix had a healthy aspect. The rounded shape of the chondrocytes together with the prominent vacuoles and the formation of a pericellular lacuna displayed features of healthy cells.

Carlilage samples of biopsies from healthy carlilage cultured in the same system showed very low ${ }^{3} \mathrm{H}$-TdR and ${ }^{35} \mathrm{~S}$-sulphate uplake (dala not given). The cartilage biopsies from $O A$ joinis sampled for this study with low modified Mankin scores also showed low ${ }^{3} \mathrm{H} \cdot \mathrm{TdR}$ and low ${ }^{35} \mathrm{~S}$-sulphate uplake. Because fully healthy cartilage was not present in a majority of $O A$ joints operated upon, cartilage biopsies from individuals were compared inslead of using internal controls of healthy cartilage of the same donor. However, after this study was terminated, both healthy and diseased cartilage was obtained from four patients. Chondrocytes isolated from healthy cartilage showed an equally low ${ }^{3} \mathrm{H}-\mathrm{TdR}$ and ${ }^{35} \mathrm{~S}$-Sulphate uptake after culture as the chondrocytes isolated from virtually normal cartilage (low modified Mankin scorel from diseased joints. Therefor, it seems unlikely that mitogens and growth factors present in fetal calf serum were responsible for the metabolic changes noted in this in vitro culture system.

The ${ }^{3} \mathrm{H}-\mathrm{TdR}$ uptake of healthy and $\mathrm{OA}$ chondrocytes isolated from different histopathologic stages of $O A$ were determined. The ${ }^{3} H-T d R$ incorporation was regarded as a sensitive indicator of cell proliferation. Up to a certain grade of OA, a strong positive correlation between the mitotic activity of isolated chondrocytes and the grade of $O A$ was found. These data are in agreement with those of others $[19,20,34 \mid$ who reported that the loss of cells at the surfoce of the damaged cartilage was compensated for by an increased cell replication. Data from the present study showed that the isolated human chondrocytes retained these proliferative properties in this in vitro culture system.

The isolated chondrocytes showed a rate of sulfated GAG synthesis, determined as the ${ }^{35} \mathrm{~S}$-sulphate uptake, that increased with the severity of the disease A similar increase was reported by others using animal and human carlilage explants to sludy $O A(3,20-23,27)$. Apparently the enhanced synthesis of $G A G$ is characteristic of chondrocytes actively engaged in repairing damaged cartilage. However, the chondrocytes isolated from the severe grades of OA showed a depressed synthesis. This indicates that beyond a certain grade of $O A$, the chondrocytes fail in their reparative function. This conclusion was supported by Mankin (20) and Mankin et al (21). Autoradiography showed that ${ }^{35} \mathrm{~S}$-sulfate is incorporated into the cartilage matrix after 24 hours of labeling. Since ${ }^{35} S$-sulfate has been proven to be highly specific for sulfaled GAG (De Vries 1986), our experiments show that sulfated GAG are produced throughout the cultured pellet. In fact these 
data encourage us to believe that not a selection of the cultured cells but merely all the chondrocytes in culture take part in the production of newly synthesized matrix. A consistent relationship among the histopathologic grade of $O A$, the proliferative behavior of the chondrocytes and the production of GAG in vilro after four days of culture was found. The large differences observed in the culture system may represent an amplification rather than the pure maintenance of the metabolic behavior of the cells in vivo. In vivo, the matrix-dependent inhibition of synthesis and division constrained the metabolic behovior of the cells, a factor that develops after isolation.

The almost linear correlation between the synthesis of sulphated GAG and DNA suggested a strong relationship between these two main metabolic activities of chondrocytes. Both the enhanced proliferation and the enhanced matrix synthesis appeared to be facets of the mechanism of repair in OA cartilage. These properties of the cells were retained during culture, indicating the stability of the phenotype of the chondrocytes in the in vitro culture model. The maintenance of the characteristic metabolic behavior in vitro suggested a regulatory mechanism in the chondrocyte itself that became independent of the original $O A$ environment.

The number of healthy chondrocyles determined with this DNA assay was equal to the number of cells that were resuspended in culture medium on day one However the number of moderately and severely $O A$ chondrocytes proved to be higher $\left(5-6 \times 10^{5}\right)$ than we would have suspected. This deviation might be explained by difficulties encountered in the judgement of the viability of the chondrocytes with the trypan blue exclusion test. Even though slight rypan blue incorporation occurs cells might be able to live for a short time in culture thereafter, as is suggested by our data. However no clear alteration in cell number was noted either in healthy nor in OA chondrocyles during culiure form day 3 lo day 5 . Thereby our data suggest that the observed increase of GAG synthesis by $O A$ chondrocytes, should be regarded as an intrinsic property of the cultured cells.

In conclusion, it is shown that human chondrocytes isolated from different grades of $O A$ retain their morphologic and metabolic characteristics in the highdensity in vitro culture model. The developed culture system seems valuable for further evaluation of the influence of drugs and cytokines on the metabolic behavior of healthy and $O A$ human cartilage. 


\section{REFERENCFS}

1. Abbott, J. and Hollzer, H.: The loss of phenotypic trails by dedifferentiolod coils. III. Reversiblo behovior of chondrocytes in primany culure. J. Cell Biol. 28:473, 1966.

2. Abbolt, J. and Holtzer. H.: The loss of phenotypic traits by dedifferentioled cells. V. The effect of 5 bromodeoxyuridine on cloned chondrocytes. Proc. Nall Acad Sci. USA, 59:1144, 1968.

3. Adams, M.E., Grant, M.D., and Ho, A.: Cortiloge proteoglycan changes in experimental conime. osteoarthritis. J. Rheumatol. 8:107, 1987.

4. Ali, S.Y.: New knowledge of ostecarthrosis. J. Clin. Pathol. 12[Suppl. 31]:191, 1976.

5. Amadio, P.C., Ehrlich, M.G., and Mankin, HJ.: Matrix synthesis in high density cultures of bovine epiphyseal plate chondrocytes. Connect. Tissue Res. 11:11, 1983.

6. Boyliss, M.T., and Ali, S.Y.: isolation of proteoglycons from human cartilage. Biochem. J. 169:123, 1978 .

7. Benlley, G.: Articular changes in chondromalacio patelloe J. Bone Joint Surg. 67B:769, 1985

8. Brondi, K.D.: Enhanced extraciability of articular cartilage proteoglycans in osleoarthritis. Biochem. I. $143: 475,1974$

9. Bryan, J.: Studies on clonal cartilage strains. II. Selective effects on different growth conditions. Exp. Cell Res. 52:327, 1968

10. Delbrück, A., Dresow, B., Gurr, E., Reale, E., and Schröder, H.: In vilro culure of human chondrocytes from adull subjects. Connect. Tissue Res. 15:155, 1986

11. Ficat, C., and Maroudas, A.: Topographical voriation of glycosaminoglycan content in normal and fibrillated tissue. Ann. Rheum. Dis. 34:515, 1973.

12. Fife, R.S.: Alterations in o cartiloge matrix glycoprotein in canine osteoorthritis. Arthritis Rheum. 29:7493, 1986.

13. Fife, R.S., Polmoski, MJ., and Brandi, K.D. Melobolism of a corliloge molix glycoproiein in nomal and osteoarthitic canine arficular corliloge. Arthrilis Rheum. 29.1256, 1987.

14. Garrod, D.R., and Nicol, A : Cell behovior molecular mechanisms of cellcell ochesion Biol Rev. 56. $199,1981$.

15. Holizer, H., Abbott, J., Lash, J., and Holizer, S.: The loss of phenotypic trails by dedifferenlaited cells in vitro 1. Dedifferentiation of cartilage cells. Proc. Nall. Acad. Sci. USA, 46: 1533, 1960

10. Kiviranta, 1., Tammi, M., Jurvelin, J., Sämönen, A.M., and Helminen, H.J.: Demonstration of chondroitin sulphate and glycoproteins in anticular cortilage matrix using acid-Schiff (PAS) method. Histochemistry 83:303, 1985. 
17. Kuether, K.E., Vincent, A., Pauli, B.U., Wrobel, N.C., Thonar, E.J.M., and Daniel J.C.: Synthesis of cartlage matrix by mammalian chondrocyles in vitro. II. Maintenance of collagen and proteoalvcan phenompe. Exp. Cell Res. 167:440,1986.

18. Kuijer, R.: Age related changes in the interoction between proteoglycans and collagen in human articular corriloge. Doctoral Thesis, University of Amsierdam, Amsterdam. The Netherlonds, 1985.

19. Malemud, C.J, and Papay, R.S.: Rabbit chondrocytes maintained in serumfree medium. Exp. Cell Res. 167:440, 1980.

20. Mankin, HJ.: Biochemical abnormalities in arlicular cartilage in osteoarihritis. In Ali, S.Y., Elves, M.W. and leaback, D.M. (eds.): Normal and Osteoarthrolic Articular Cortilage. London, Instifute of Orthopoedics, 1974, p. 153

21. Mankin. HJ., Dorman, H., lipiello, M.S., and Zarins, A. Biochemical and metabolic obnor-malities in aricular cortiloge trom osleo-arintic human hips. I. Bone Joint Surg. 53A.523, 1971

22. Mc. Devitt, C.A., and Muir, H.: Bicchemical changes in the cartilage of the knee in experimental and natural osieoarthritis in the dog. J. Bone Joint Surg. 588:94, 1976.

23. Mc.Devit, C.A., Gilbertson, E.M.M., and Muir, H. An experimental model of osleoarthritis: early morphological and biochemical changes. J. Bone Joint Surg. 598:24, 1977.

24. Moskowitz, R.W., Howell, D.S., Goldberg, V.M., Muniz, O., and Pila, J.C.: Corlilage proteoglycans alteration in an experimentally induced model of rabbit osteoarthritis. Arihritis Rheum $22: 155,1979$

25. Rosenberg, L.: Chemical basis for histological use of safranin $O$ in the sludy of arficular cartilage. J. Bone Joint Surg. 53A.69, 1971 .

26. Roughly, PJ, and While, R.J.: Age related changes in the structure of the proteoglycan subunits from human articular cartiloge. J. Biol. Chem. 255:217, 1980

27. Sondy, J.D., Barrach, H.J., Flannery, C.R., and Ploas, A.H.K. The biosynithelic response of the mature chondrocyle in early osteoorthritis. I. Rheumatol. 8:10,1987.

28. Scoll, J. E. Proleoglycon Hislochemisiry A vulable tool for connective tissue biochemisls. Coll. Relat. Rel 5:541, 1985

29. Sokoloff, L.: Aging and degenerative diseases affecting cantloge in Holl, B.K. led.): Contilage, Biomedical Aspects, Aging and Degeneration, vol. 3. New York. Academic Press, 1983, p. 109.

30. Solursh, M. : Cell-cell interactions and chondrogenesis. In Hall. B.K. (ed.): Carlilage, Development, Differentiation and Growth, vol. 2. New York. Academic Press, 1983, p. 127.

31. van Kompen, G.P. J, and Veldhuyzen, J.P.: Aggregaied chondrocyles as a model to study cartiloge metobolism. Exp. Cell Res. 140:440, 1982. 
32. van Kampen, G.P.J., Veldhuyzen, J.P., Kuyer R., van de Siodi, RJ., and Schipper C.A.: Contloge response to mechanical force in high-density chondrocyle culures. Arthritis Rheum. 28:419, 1985.

33. Vasan, N.: Proleoglycans in normal and severely osleoathritic humon cartilage. Biochem. I. $187: 781,1980$

34. Verbruggen, G., Luyten, F.P., and Veys, E.M.: Repair function in organ cultured human camiloge. Replacement of enzymatically removed proleoglycans during longterm orgon culture. I. Rheumatol. $12: 665,1985$.

35. Vignon, E., Bejui, J., Mathieu, P., Hormann, J.D., Ville, G., Evreux, J.C., and Descolles, J.. Histological cartilage changes in a rabbit model of ostecarthritis I. Rheumatol. 14:104, 1987

36. Weiss, A., von der Mark, K., and Silbermann, M.: A tissue culture sysiem supporting cartilage cell differentiation, extracellular mineralization and subsequent bone formation, using mouse condylar progenitor cells. Cell Differ. 19:103, 1980. 



\title{
The potential of adult human perichondrium to form hyalin cartilage in vitro
}

\begin{abstract}
The usefulness of adult human perichondrium for the restoration of articular cartilage defects depends on the potential to form hyalin cartilage. In order to evaluate the capacity of adult human perichondrium to form hyalin carlilage in vitro, perichondrium of the rib of eight adult human beings was cultured in vitro. After removal of residual cartilage perichondrial explants were cultured for 7 or 10 days The explants were histologically examined using specific stains to prove the presence. of glycosaminoglycans (GAGs) normal for hyalin cartilage. Clear differentiation of perichondrial cells towards chondrocytes was noted. The chondrocyles synthesized new matrix substances normally present in hyalin cartilage. This investigalion supports the usefulness of adulf human rib perichondrium for the restoration of cartilage defects. Due to the enormous potential of the rib perichondrium to form hyalin cartilage in vitro, even defects in joints with a rather thick cartilage layer might be restored using this biological material.
\end{abstract}

\section{Introduction}

The spontaneously regenerated cartilage formed after traumatic and osteoarthritic defects of hyalin cartilage has been proven to be of limited quality $15,6,35,42)$. Possibilities to restore defects in hyalin cartilage, using different autogenous and homologous tissues, have been studied exlensively $(4,7,17,19,25,30,42)$. The results of such studies were in general unsuccessful or not applicable in the clinical situation. The use of perichondrium offers interesting possibilities for the restoration of defecls in hyalin cartilage. An essential property of perichondrium is its chondrogenic potential $(18,21,38)$. Laboratory studies showed that free autogenous perichondrial grafts of the rib and ear of immature and adult animals, were able to form hyalin cartilage when placed in an artificial cartilage defect in a joint $11,8,9,11,14,15,22$ 24,32-34,40,46). Histological, biochemical and biomechanical evaluation showed that certainly after a prolonged time, the newly synthesized cartilage closely resembles normal hyalin cartiloge $(2,3,20,44-46)$.

Clinically, perichondrium already has been used successfully in a limited number of cases, to repair cartilage defects in the remperomandibular joint, the wrist, the knee and finger joints $(10,12,20,26,28,29,36,39,41)$. These autologous 
transplantations were reported to be successful for the restoration of traumatic defects of the articular cartilage.

Although the perichondrium of (immature) animal ear and rib cartilage was proven to have a clear chondrogenic potential, the potential of adult human rib perichondrium to form hyalin cartilage in vitro needs to be evaluated. Therefore, we investigated the potential of adult human rib perichondrium to form hyalin cartilage in vitro. With regard to the essential potential of adult human rib perichondrium to grow out to a thickness necessary to repair defects of the adult cartilage loyer in a joint, especially in the knee, the amount of cartilage formed ofter shortterm in vitro culture was studied The data indicate that shortterm in vitro culture of adult human rib perichondrium results in the formation of cortilage that resembles normal hyalin cartilage, as shown by histology. This property strongly suggests the usefulness of adult human rib perichondrium in the clinical situation, especially for the restoration of rraumatic defects in joinls.

\section{Materials and methods}

\section{Materials}

Perichondrium was obtained from the ribs of eight patients during cardiovascular and reconstructive surgery with informed consent of the patients. The mean age of the patients was 32 years ( $29-42$ years). Explants measuring $0.5 \times 1.0 \mathrm{~cm}$ were immediately after removal transferred to a vial containing saline $(0.9 \% \mathrm{NaCl})$ and kept at $4^{\circ} \mathrm{C}$. Within $2 \mathrm{~h}$ after removal, the perichondrial explants were carefully examined under low power magnification for residues of cartilage. Remaining cartilage parts were removed from the perichondrium. Dissection was carried out using a thin-bladed knife. All explants were cut into four pieces. Two parts were used for direct histological examination and the other two were used for culture.

In vitro culture iechnique

Perichondrial explants were cultured in slerile petri dishes Greiner, Nuertingen,

F.R.G.) in $2 \mathrm{ml}$ of culture medium MI99 (GIBCO. Poisley, U.K.) supplemented with L-glutamine $(250 \mu \mathrm{g} / \mathrm{ml})$, ascorbic acid $(50 \mu \mathrm{g} / \mathrm{ml})$, antibiotic antimycotic solution $[50 \mu \mathrm{g} / \mathrm{ml}$ c containing $10,000 \mathrm{JU} / \mathrm{ml}$ of penicillin, $10.000 \mu \mathrm{g} / \mathrm{ml}$ of streptomycin and $25 \mathrm{mg} / \mathrm{ml}$ of fungizone (GIBCO) and $10 \%$ fetal calf serum (FCS). The medium was changed every second day. Cultures were terminated after 7 or 10 days.

\section{Histology}

Explants were studied histologically before culture, and at 7 and at 10 days after the onset of the culiure. The explants were fixed in neutral buffered formolin, embedded in paraftin and $5 \mu \mathrm{m}$ slices were cut. All sections were stained with hematoxylin and eosin, alcian blue periodic acid-Schiff (PAS) and satranin O-fast green, a specific 
sicin for glycosamino-glycans 131\%

The thickness of the perichondrial explant, as well as the thickness of the newly synthesized cartilage layer, was measured using a calibrated eyepiece micrometer in light microscope. We measured the thickness of each explant $(n=0)$ on five different locations before and after culture

\section{Autoradiography}

For autoradiography ${ }^{3} \mathrm{H}$-thymidine $\{3 \mathrm{H}-\mathrm{TdR}\}$ was used to determine the sile of proliferation of the perichondrial explant. After 4 doys of culture, the culture medium was supplemented with $15^{\circ} \mathrm{Ci} / \mathrm{ml}^{3} \mathrm{H}-\mathrm{TdR}$ (specific activity $5^{\circ} \mathrm{Ci} / \mathrm{mmol}$, the Radiochemical Center, Amersham, UK'. The perichondrial explant was subsequently incubaied for $4 \mathrm{~h}$. The perichondrium was then prepared for micioscopic study. Sections were dipped in llford K-5 photographic emulsion (llford, Mobberley, U.K.l. dried and stored in the dark at $4^{\circ} \mathrm{C}$ for 20 days. The autoradiograms were developed in Kodak D76 solution Kodak, Buffalo, N.Y., U.S.A.) for 3 minules, fixed in Kodak rapid fixer and washed. The paraffin sections were examined unstained. In the central part of the explant, the labeled cells were counted in an area of $2 \mathrm{~mm}^{\text {? }}$.

\section{Immunohistochemistry}

Sections of ethanol or formalin fixed cartlage samples $(5 \mu \mathrm{m})$ were de-paraffinized. Endogenous peroxidase activity was blocked by incubation with $1 \% \mathrm{H}_{2} \mathrm{O}_{2}$ in methanol for 30 minutes. Sections were then digested with $1000 \mathrm{U} / \mathrm{ml}$ resticular hyaluronidase (Aristofarma, Amsterdam, The Netherlands) in $0.1 \mathrm{M} \mathrm{Naphosphate}$ buffer, ph $=5.3$ containing $0.15 \mathrm{M} \mathrm{NaCl}$ al $37 \mathrm{C}$ for $30 \mathrm{~min}$. Nonspecific background staining was reduced by incubating tissue sections in a $10 \%$ solution of normal rabbit serum in 1\% bovine serum albumin/PBS. Polyclongl goat anti-collagen or anticollagen II antisera were used (Southern Biotechnology Associotes, Birmingham, USA). The second antibody was a rabbitantigool immunoglobuline conjugated with peroxidase (Dako A/S, Glostrup, Denmark). Diaminobenzidine solution containing $\mathrm{H}_{2} \mathrm{O}_{2}$ was added to develop color and the sections were counterstained with haematoxylin. Negative control specimens were processed identically using normal goal serum or second anliserum only.

\section{Results}

Sixleen conseculive cultures of perichondrium were performed. Two had to be discarded due to microbial infection. Histological examination revealed the presence of residual cartilage on the inner layer of the perichondrium before culture in two cases. Therefore, cultures with this perichondrium were excluded from the study. In total, perichondrium culfures of 6 individuals were useful for evaluation. 
Histology of explant before culture

When dissecting the perichondrium from the rib, the line of separation is easily found. The dissected perichondrium then consists of a pliable layer, without macroscopic evidence of residual cartilage. The mean thickness of the layer of human rib perichondrium proved to be $471 \mu \mathrm{m}$ (Table 1).

\begin{tabular}{|c|c|c|c|}
\hline & $\begin{array}{l}\text { Before } \\
\text { culture }\end{array}$ & $\begin{array}{l}\text { Affer } 7 \text { days } \\
\text { of culture }\end{array}$ & $\begin{array}{l}\text { After } 10 \text { days } \\
\text { of culture }\end{array}$ \\
\hline $\begin{array}{l}\text { Mean thickness of } \\
\text { explant }\end{array}$ & $\begin{array}{l}471 \mu \mathrm{m} \\
\text { (SD 52) }\end{array}$ & $\begin{array}{l}691 \mu \mathrm{m} \\
\text { (SD 63) }\end{array}$ & $\begin{array}{l}746 \mu m \\
(S D 74)\end{array}$ \\
\hline $\begin{array}{l}\text { Mean thickness of } \\
\text { cartilage layer }\end{array}$ & $0 \mu m^{a}$ & $\begin{array}{l}240 \mu \mathrm{m}^{b} \\
\text { (SD 42) }\end{array}$ & $\begin{array}{l}300 \mu \mathrm{m}^{e} \\
\text { (SD 58) }\end{array}$ \\
\hline \multicolumn{4}{|c|}{$\begin{array}{l}n=0 \\
\text { "Cartilage layer was absent before culture. } \\
\text { "Increase in thickness of cartilage layer is statistically significant, } \\
p<0.001 \text { (paired Student's I test). } \\
\text { "Increase in thickness compared to the } 7 \text { day culture explant is statistically } \\
\text { significant, } p<0.01 \text { (paired Student's t test). }\end{array}$} \\
\hline
\end{tabular}

TABLE 1.

The mean thickness of adult human perichondrium and the newly synthesized cartilage layer after 7 and 10 days of culure

The variation of the thickness of one perichondrial explant on five measurements proved to be less than $3 \%$. Histological examination of perichondrium of human rib revealed three distinct cellular regions (Fig. IA). The outer layer consists of fibrous tissue (A); In the intermediale loyer the cells are elongated and placed longitudinally. The nuclei are oval shaped (B). The inner layer (C), adjacent to the rib cartilage, consists of slightly enlarged cells, containing oval nuclei (Fig. IB). These cells can clearly be distinguished from the adjacent chondrocytes of the rib cartilage since they are not surrounded by alcian blue or safranin $\mathrm{O}$ stainable material. The cells in this layer are presumed to have the capacity to proliferate and to differentiate into chondrocytes. The perichondrial explant as a whole does not stain with safranin $\mathrm{O}$ or alcian blue, indicating the absence of glycosaminoglycans (GAG) typical for hyalin cartilage. 


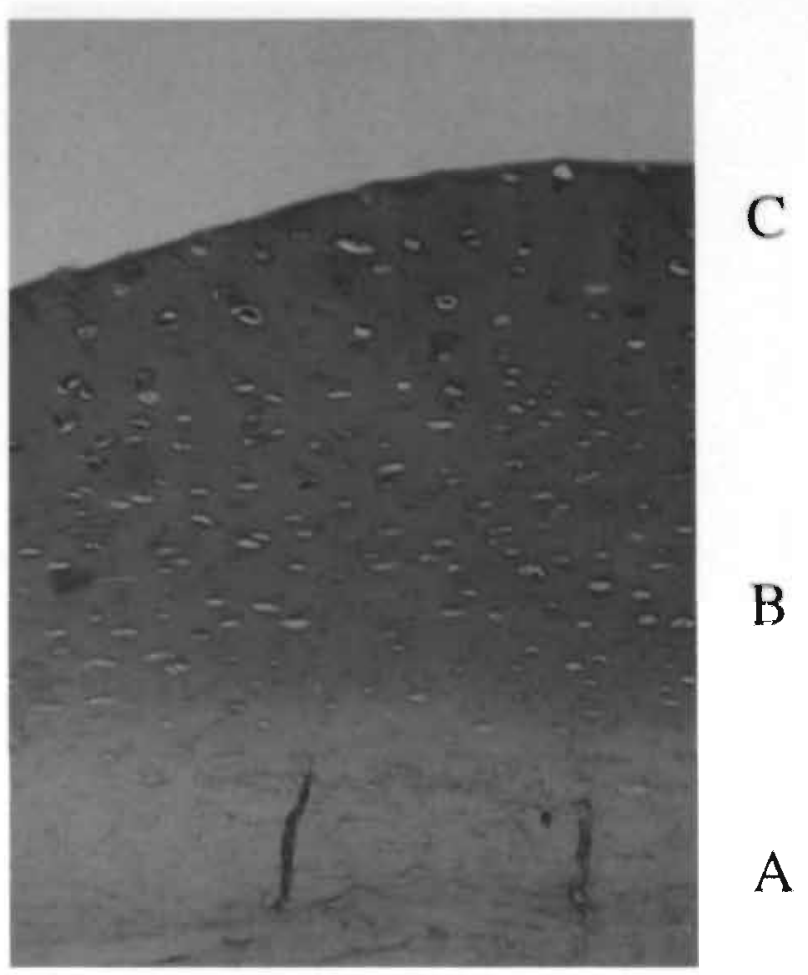

Fig 1A:

Photomicrograph of adult human rib perichondrium, embedded in paraffin and stained with safranin O-fast green. The outer layer is at the bottom side of the picture (A): the intermediate layer is clearly recognized with elongated cells that are longitudinally oriented (B). The inner layer consists of more rounded cells (C). The matrix does not stain greyblack as compared to the cartilage matrix in Fig 2 ( $\times 41)$.

The Histology after 7 days of culture.

After 1 week of culture, the perichondrial explants showed a marked increase in thickness and cell number. The morphology of the cells had changed. A hypercellular zone at the inner layer of the perichondrium had developed in all explants cultured (Fig. 2).

perichondrial cells were differentiated towards a layer of chondrocyte-like cells, with an oval to rounded shape and a lightly stained cytoplasm. The cells resided within a lacuna, surrounded by a zone of matrix, that stained intensively with alcian blue. Furthermore, the matrix stained orthochromatically with safranin $\mathrm{O}$, indicating the presence of GAG, representing newly formed, healthy hyalin cartilage. It is noteworthy that already after 1 week of culture, a loyer of cartilage with a mean thickness of $240 \mu \mathrm{m}$ had developed, which was significantly different from the perichondrium in culture on day 1 (Table 1). 


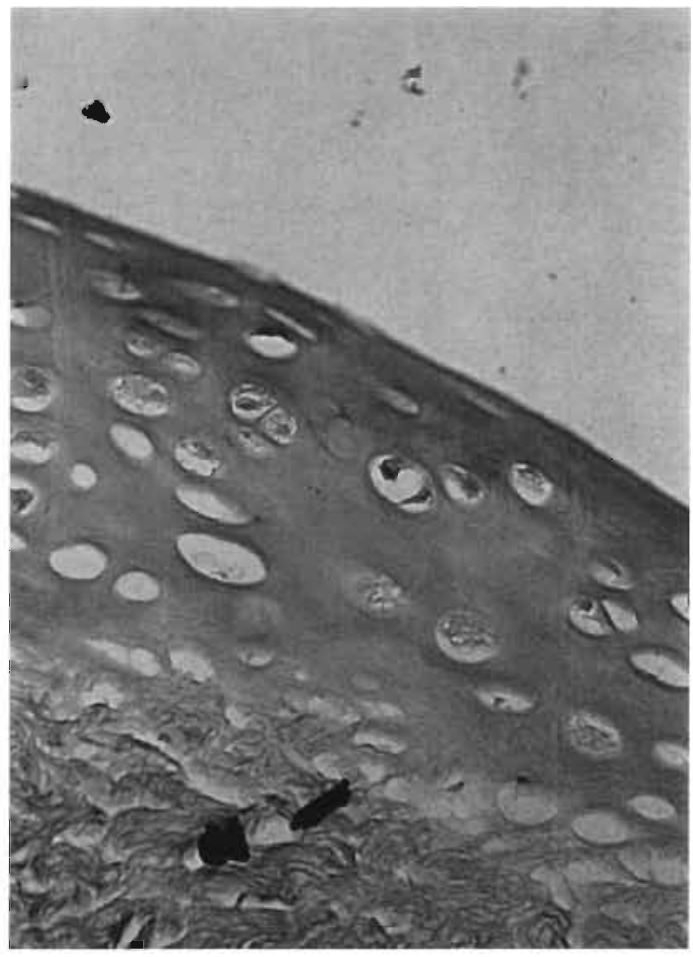

Fig $1 \mathrm{~B}$ :

Photomicrograph of the cells of the inner layer of adult human rib perichondrium. Stained with salranin $O$ fast green. The cells have a rounded appearance with round to ovol nuclei and ore not surrounded by satranin $O$ stainable matrix. The cells are not positioned in clusters (x223)

Histology after 10 days of culiure After 10 days of culture, the thickness of the cartilage layer $(300 \mu \mathrm{m})$ had increased even more compared to that of the 7 day cultures \{Table 1). The newly formed cartilage layer was rather hypocellular (Fig. 31. However, the intense slaining of the zone directly around the lacunae strongly. suggests a further increase in the amount of GAGs synthesized. Compared to the staining after 7 days of culture, the metachromatic staining of the matrix affer 10 days of culture with safranin $O$ had clearly increosed.

The differenliated cells showed the hypical morphological characteristics of adult human chondrocytes (Fig. 4). The cells had a rounded aspect and resided singly or in groups of wo within a lacuna. 


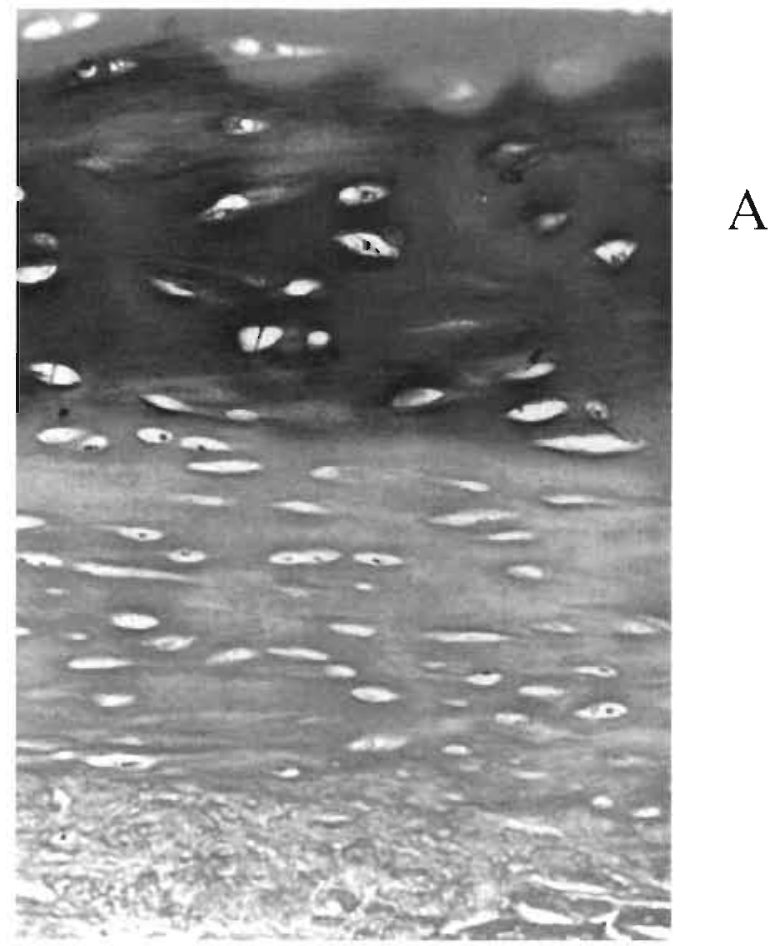

Fig 2:

Adult human rib perichondrium after $>$ days of cutture, stained with safranin O-fast green. The cells of the inner layer differentiated to a more rounded shape. In this newly synthesized cartlage layer (A)., the cells are surrounded by matrix that stains metachromatically red an this pholograph indicating the presence of GAG typical lor hyolin cortiloge $(\times 206)$.

\section{Autoradiography}

The autoradiographic studies performed at day 4 of culture showed a considerable ${ }^{3} \mathrm{H}-\mathrm{TdR}$ uptake in the perichondrial explant. The major part of the label was observed in the cells of the inner layer of the perichondrium (Fig. 5). The grains indicating the presence of the uplake of the ${ }^{3} \mathrm{H}$-TdR label were observed over the nuclei of the cells. The labeling index was determined with the use of light microscopy. It appeared that about $60 \%$ of the cells of the inner layer were labeled with ${ }^{3} \mathrm{H}-\mathrm{TdR}$, suggesting that the major part of the cells of the inner layer took part in the proliferation.

Immunohistochemistry Immunohistochemically it was shown that after 10 doys of culture mainly collogen type II was present in the newly synthesized cartilage layer (Fig. of. Type I collagen was found in the fibrous layer and only sporadic in the cartilaginous layer. 


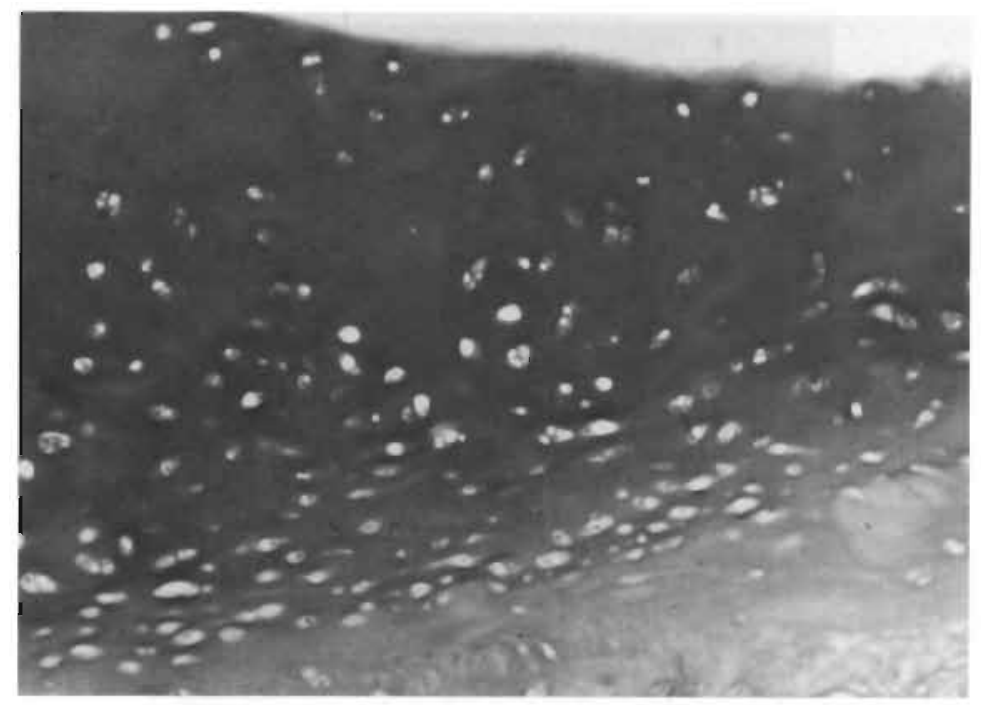

Fig 3 :

Adult human rib perichondrium after 10 days of culture, stained with safranin O-fast green. The cartilage layer has increased in thickness compared to the 7 day culture experi

ment. In the deeper layer cells are seen to lay in clusters. The cells are surrounded by metachromatically red stained matrix $(\times 63)$.

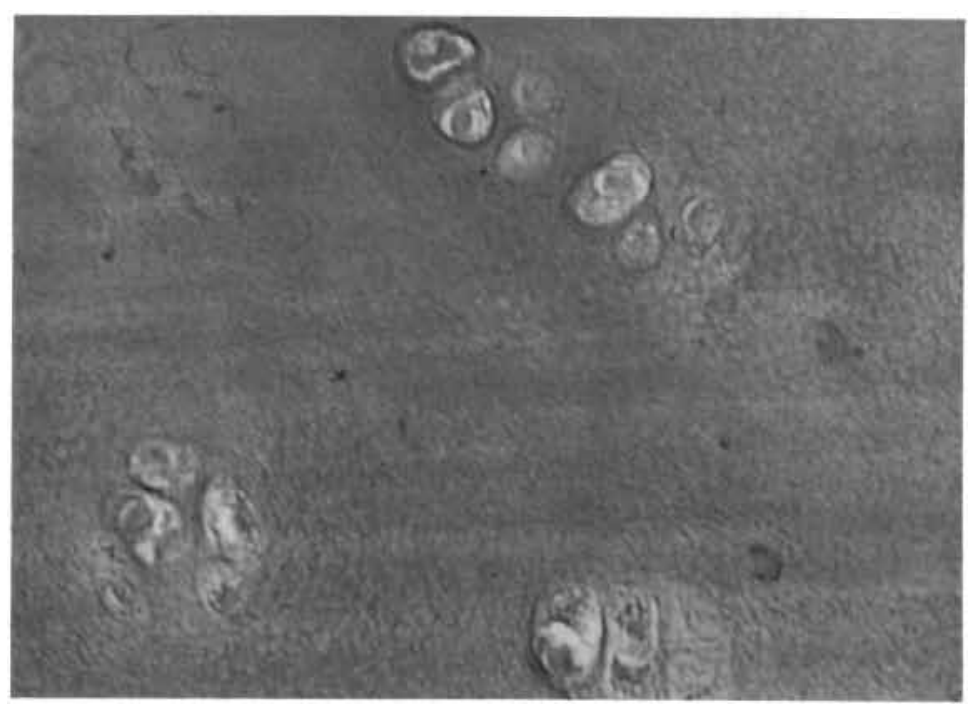

Fig 4:

Photomicrograph of the cells that have matured from the inner layer of the perichondrium after 10 days of culture. The cells have an appearance like chondrocyles laying in clusters and surrounded by melachromatically stained matrix. This section is stained with safranin Ofast green $(\times 241)$. 


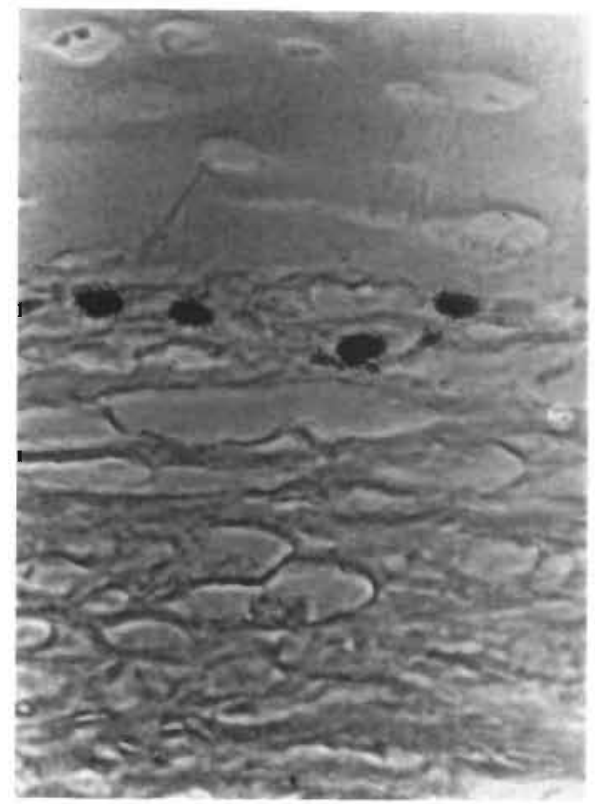

\section{Fig 5:}

Pholomicrogroph of adult human rib perichondrium atter $4 \mathrm{~h}$ of labeling with $\left.{ }^{3} \mathrm{H}\right) \cdot \mathrm{T} d \mathrm{R}$, on day $4 \mathrm{~d}$ of culture. The label wos found above $60 \pm 7 \%$ of the nuclei of the cells of the inner layer. (B) Uploke in this loyer. (C) Uplake in this layer, adjocent to the newly formed cartiloge layer, indicares the presence of proliferating cells. This section is not stained $(x) \mid$ Q)

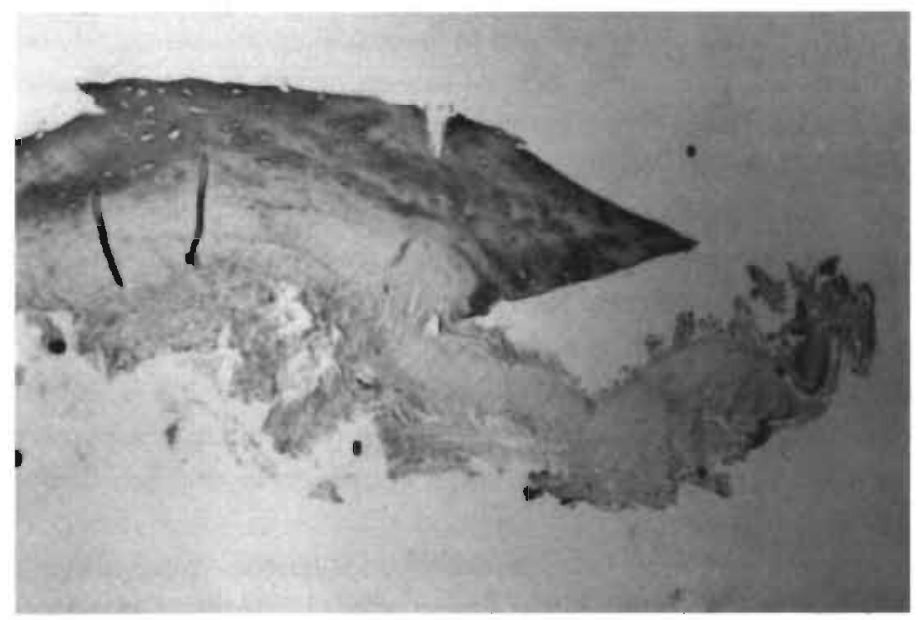

Fig 6 :

Photomiciogroph of immunohistochemistry (with anti type II collagen) showing that afler 10 days of culture mainly collogen type If is present in the newly synthesized cartilage layer. 


\section{Discussion}

In the present study, we evaluated the potential of adult human rib perichondrium to form hyalin cartilage in vitro. In our experiments, every effort was made to remove any residual cartilage from the perichondrium. This was necessary to be certain of true perichondrium-derived chondrogenesis in vitro. Moreover, it does resemble the in vivo situation, since for restoration of a cartilage defect in a joint, a pliable piece of perichondrium is needed that corresponds to the surface of the joint cartilage. This is only possible after removal of the rib cartilage. Although the perichondrial explants. were carefully examined for residual chondrocytes, the possibility of rare chondrocytes left on the inner surface of the perichondrium used for the culture experiments cannot be fully excluded. However, in the clinical situation perichondrium is stripped from the rib of the patient without the use of microscopy; it is therefore inevitable that chondrocytes will be left behind on the grafted perichondrium. Histologically, adult human rib perichondrium resembles the rib perichondrium of a rabbit, as described earlier $(11,13,14,16,38,40)$. The line of natural separation of adult human rib perichondrium however, lies between the inner layer of the perichondrium and the cartilage of the rib. The perichondrial explant consists of three different layers: the outer fibrous layer, the intermediate layer with elongated cells and the inner layer containing more oval cells. This inner layer consists of cells that have the potency to mature towards chondrocytes and to synthesize hyalin cartilage matrix $(2,3,8,10,15,16,22,24,29,33,36,41,43,45-47)$. In the inner layer, the cells already have a more chondracyte-like appearance but lack the orthohromatic staining typical for the GAG of hyalin cartilage matrix (31). We suppose that the cells of the inner layer of adult human perichondrium in favorable conditions quickly mature towards chondrocytes, in the same manner as was proven for animal perichondrium $(2,9-12,24,27-34,37-42)$. This might be one of the reasons why in our study, a rather thick layer of cartilage was formed already after 7 days of culture. The cells of the inner layer show a rapid cellular proliferation, as shown in the histological sections and as ascertained by the pulse label autoradiography experiments. Histologically, the cells of the inner layer appeared to have matured towards cells with a chondrocyie-like appearance. The data indicate that the thickness of adult human rib perichondrium and its potential to form hyalin cartilage is higher than that of rabbit perichondrium $(12,22,30,31,35,38)$. A clear difference however, is the relative hypocellularity of the newly synthesized cartilage layer when compared to the animal experiments (37-40).

The present study shows clearly the potential of adult human rib perichondrium to form hyalin-like cartilage in vitro. At the same time a rather high rate of maturation and synthesis of GAG is noted, as is shown by the use of specific staining methods. Immunohistochemically mainly type II collagen is present in the newly synthesized cartilage layer. 
Therefore, these data strongly suggest that adult human rib perichondrium has the capacily to form a sufficiently thick layer of hyalin cartilage to make it useful to repair defects in joints with a rather thick layer of cartilage, such as the knee, thus permitting resforation of cartilage defects using an autologous, living and actively synthesizing graft. It seems therefore logical to stimulate the clinical use of adult human rib perichondrium to restore cartiloge defects in the knee, especially since the alternatives for restoration of these cartilage defects so far have been very disappointing. 


\section{REFERENCES}

1. Amiel D, Coutts RD, Abel M, Slewart W, Harwood F, Akeson WH: Rib perichondrial grafts for the repair of full thickness articular defects. J Bone Joint Surg [Am] 67:911-920, 1985

2. Amiel D, Coutts RD, Harwood FL, Ishizue KK, Kleiner JB: The chondrogenesis of rib perichondrial grafts for repair of full thickness articular cartilage defects in a rabbit model: a one year postoperafive assess- ment. Connect Tissue Res 18:27-39, 1988

3. Amiel D, Hanwood FL, Abel MF, Akeson WH: Collagen types in neocartilage lissue resulting from nib perichondrial graft in an articular defect-a rapid semiquantilative methodology. Collagen Rel Res 5:337-347, 1985

4. Bentley G: Articular cartilage changes in chondromalacia patellae. J Bone Joint Surg [Bir] 67:769774,1985

5. Campbell Cl: The healing of cartilage defects. Chin Orthop Rel Res 64:45, 1969

6. De Palma AF, McKeever CD, Sabin DK. Process of repair of anticular cortioge by histology and autoradiography with tritiated thymidine. Clin Orhop Rel Res 148:229, 1968

7. De Palma AF, Solter TT, Mader GG: Viability of osteochondral grafts as delemined by uptake of ${ }^{35} \mathrm{~S} J$ Bone Joint Surg $[\mathrm{Am}]$ 45:1565, 1965

8. Diaz-Flores L, Rodriguez E, Gayoso My, Gulierrez R: Growth of two yypes of cortiloge after implantation of free cutogenic perichandrial grafts. Clin Orth Rel Res 234:267-279, 1988

9. Engkvist O: Reconstruction of patella cartilage with free autologous perichondrial grafts. Scand J Plast Reconstr Surg 13:361-369, 1979

10. Engkvist O, Johansson SH: Perichondrial arthroplasty. Scand J Plast Reconstr Surg 14:71-87. 1980

11. Engkvisı O, Johansson SH, Oh/sen I and Skoog T: Reconstruction of articular cartilage using aurologous perichondrial grafts. Scand J Plast Reconstr Surg 9:203-206, 1975

12. Engkvis! O, Skoog V. Pastacaldi P, Yormuk E, Juhlin R: The cartilaginous potential of the perichondrium in rabbit ear and rib. Scand J Plast Reconstr Surg 13:275-280.1979

13. Ham AW: Dense ordinary connective tissue and cartiloge: the development and structure of the perichondrium. In: Histology, ed by Ham AW, Philedelphia, Toronto „3.B. Lippincolt Company, 372373, 1974

14. Kon M: Cartilage formolion from perichondrum in a weigh bearing joint. Eur Surg Res 13:387-396. 1981

15. Kon M, van den Hooff A: Cartilage tube formation by perichondrium: a new concept for tracheal reconstruction. Plast Reconstr Surg 72:791.795: 1983 


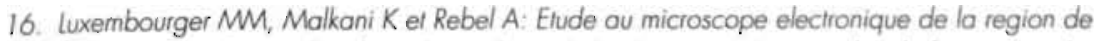
transition entre le perichondre et le cartilage de la plaque epiphysaire chez le foetus de cobaye. Arch Anat Microsc 63:117.132, 1974

17. Malinin Tl, Wagner Jl, Pita JC, lo H: Hypothermic storage and cryopreservation of cartilage. Clin Orthop Rel Res 197:15-26, 1985

18. Malsuoka M: Die Regeneration von Knorpelgewebes. Virchows Arch [A] 175:32, 1904

19. Meyers MH, Chatteriee N: Osteochondral tronsplantation. Surg Clin North Am 58:429.434, 1978

20. Niedermann B, Boe S, lourizen J, Rubak JM: Glued periosteal grafis in the knee. Acta Orthop Scand $56: 457-460,1985$

21. O'Driscoll SW, Keely FW, Salter RB: The chondrogenic polential of free autogenous periosteal grafts for biological resurfacing of major full thickness defects in joint surfaces under the influence of continuous passive motion: on experimental investigation in rabbits. J Bone Joint Surg [Am] 68 : $1017-1035.1986$

22. O'Driscoll SW, Keeley FW, Saller RB: Durability of regenerated articular cartilage produced by free autogenous periosteal grafts under the influence of continuous passive motion: a followup report at one vear. J Bone Joint Surg [Am] 70:595-606, 1988

23. O'Driscoll SW, Salter RB: The repair of major osteochondral defects in joint surfaces by neochondrogenesis with autogenous osteoperiosteal grafts stimulated by continuous passive motion. Clin Orthop Rel Res 208:131-140, 1986

24. Ohlsen L, Widentalk B: The early development of articular cartilage after perichondrial grafting Scand J Plast Reconstr Surg 17:163-177, 1983

25. Ottolenghi CE: Massive osteo and osteo-articular grafts. Clin Orthop Rel Res 87:156-166, 1972

26. Pastacaldi P, Engkvist O: Perichondrial wrist arthroplasty in rheumaloid patients. Hand 11:184:90, 1979

27. Ritsala V, Alphuro S: Regeneration of articular cartilage defects with free perichondrial grafts. IRCS Med Sci 3:49.50, 1975

28 Ritsala V, Poussa M, Rubak J. Snellman O. Osterman K periosteal and perichondrial grafts in reconstruction of the patellar joint surfaces. Acla Orthop. Scand 5!-704, 1980

29. Ritsala V, Poussa M, Rubak J, Snellman O, Osterman K: Periosteal and perichondrial grafis in reconstruction of joint surface. Acta Orthop Scand 52:447, 1981

30. Roffman M, du Toit GT: Osteochondral hemiarthroplasty. Int Orthop 9:69.75, 1985

31. Rosenberg L: Chemical basis for the histological use of safranin $O$ in the study of articular cartilage J Bone Joint Surg [Am] 53:69-82, 1971 
32. Rubak JM: Reconstruction of articular cartilage defects with free periosteal grafts. Acta Orthop Scand $53: 175-180,1982$

33'. Rubak JM, Poussa M, Ritsala V: Chondrogenesis in repair of articular cartilage defects by free periosteal grafts in rabbils. Acta Orthop Scand 53:181.186, 1982

34. Rubak JM, Poussa M, Ritsala V: Effects of joint motion on the repair of articular cartilage with free periosteal grafts. Acta Orthop Scand 53:187-191, 1982

35. Salter RB, Simmonds DF, Malcolm BW, Rumble EJ, MacMichael D, Clements $N$ : The biological effect of continuous passive motion on the healing of full thickness defects in anticular cartilage. An experimental investigation of rabbits. J Bone Joint Surg [Am] 62: I232-1251, 1980

36. Seradge H, Kurz JA, Kleinert HE et al.. Perichondrial resurfacing arthroplasty in the hand. I Hand Surg 6:880-886, 1984

37. Skoog T, Johansson SH: The formation of articular cartilage from tree perichondrial grafis. Plasi" Reconsir. Surg 57:16, 1976

38. Skoog T, Ohlsen L. Sohn SA: Perichondrial potential for cartilaginous regeneration. Scand J Plast Reconstr. Surg 6:123-125, 1972

39. Skoog T, Ohlsen L, Sohn SA: The chondrogenic potential of the perichondrium. Chir Plast (Berl! $3: 91$. 103, 1975

40. Sohn SA, Ohlsen L: Growth of cartilage from a free perichondrial graft placed across a defect in a rabbit's trachea. Plast Reconstr Surg 53:55-60, 1974

41. Tajima S, Aoyiga F, Maruyama Y. Free perichondrial grafting in the reatment of temperomandibular joint ankylosis. Plast Reconstr Surg 61:876-880, 1987

42. Tanaka H. Shinno N. Hiștochemical ștudies on regeneration of articular çartiloge. I Exp Med 18:63: 73,1971

43. Tomford WW, Mankin HV: Investigational approaches to articular cartilage preservation. Clin Orthop Rel Res 174:22:27, 1983

44. Upton 1, Sohin SA, Glowacki f: Neocartilage derived from transplanted perichondrium: what is it? Plast Reconstr Surg 68:166.174, 1981

45. Wasteson A, Ohlsen L: Biosynthesis of chondroitin sulphare in cartilage regenergred from perichondrium. Scand J Plast Reconstr Surg 11:17.22, 1977

46. Woo Sl-Y, Kwan MK, lee TO, Field FP, Kleiner JB: Coults RD: Perichondrial aulograft for articular cartilage. Acta Orthop Scand 58:510-515, 1987

47. Zarnett R, Delaney JP, O'Driscoll SWO, Salter B: Cellular origin and evolution of neochondrogenesis in major full thickness defects of a joint surface treated by free outogenous periosteal grafts and subjected to continuous passive motion in rabbits. Clin Otthop Rel Res 222:267.274, 1987 


\section{The effect of gentamicin on the metabolism of in vitro cultured rat patellar cartilage}

\section{Summary}

Despite early diagnosis and accurate treatment, septic arthritis in most patients results in rapid cartilage destruction and loss of function. Vigorous intravenous antibiotic therapy may be responsible for serious side effects, specially in patients with other risk factors. Considerable intraarticular variation in drug concentration, bacterial resistance and late diagnosis may then result in inadequate therapy. Local delivery systems might enable us to reach higher and more equal antibiotic concentrations, excluding most of the general side effects. Therefore we have studied the short term effects of gentamicin in vitro. The rat patella was used as an explant culture to evaluate the effect of gentamicin on cartilage metabolism. Histological evaluation of the patella revealed that cartilage structure and chondrocyte morphology were not affected by gentamicin. The metabolism of the chondrocytes was measured by ${ }^{35} \mathrm{~S}-$ sulfate incorporation. No significant influence by gentamicin on cartilage metabolism was found.

\section{Introduction}

Bacterial joint infections cause rapid cartilage destruction and loss of function $(7,8,15,21,24,31)$. Despite early diagnosis and aggressive surgical drainage combined with appropriate intravenous antibiotic treatment, considerable profeoglycan loss from the carfilage matrix is noted, even after disappearance of the bacteria $(10,12,20,22,31)$. Experiments by others showed that even after vigorous washing, large numbers of bacteria remained adhered to the cartilage surface and penetrated into the non vascularized cartilage matrix, specially in patients with osteoarthritic (OA) cartilage (20).

Septic: arthritis occurs more frequent in patients with reduced capacity to eliminate bacterial organisms (children, elderly, immune-compromised patients). Until the culture and sensitivity results are available, relafive loxic broadspectrum antibiofics are to be given in order to overcome bacterial resistance. These antibiotics may cause a range of systemic side-effects in these already vulnerable patients $(4,14,18,29)$.

The effectivity of antibiotic treatment is also dependent on the penetration of the drug into the joint space and the surrounding tissue. The intra articular concentrations, found, generally showed a good penetration of the antibiotics into the joint space $(1,9,13,19,27)$. However a considerable inter-patient and intra-patient 
difference in drug concentration was noted and a decrease in concentration often developed with the duration of the disease This makes it necessary to measure frequently not only the serum but also the synovial fluid antibiotic concentrations $(11,26,27)$.

With regard to the good results achieved with local treatment of osteomyelitis (5.33), the intra- articular administration of antibiotics might be beneficial, enabling high local concentrations without general side effects. Local delivery systems containing gentamicin, such as bone cement and gentamicin containing collagen, have acquired wide acceptance in the local treatment of infections (33). However little is known about the effect of gentamicin on cartilage metabolism. Therefore we have sfudied the influence of gentamicin on cartilage metabolism in vitro.

\section{Materials and methods}

Sampling of patellae

Male, 12-14 week old lewis rats were used for these experiments. The rats were sacrificed using ether anesthesia, followed by cervical dislocation. Whole patellae were carefully dissected from the surrounding soft tissue. In total 42 rats were used for these experiments. 78 Patellae were used for the measurement of ${ }^{35} \mathrm{~S}$-sulfate incorporation and another 6 palellae for histological evaluation, after different exposure times to gentamicin.

\section{Culture technique}

After isolation the patellae were transferred to culture disks, containing $3 \mathrm{ml}$ of $\mathrm{Ml}$ l 9 culture medium (Gibco, Paisley, Scotland), supplemented with 10\% fetal calt serum (FCS, Boehringer,Mannheim, FRG), $250 \mu \mathrm{g} / \mathrm{ml}$ l.glutamine and $50 \mu \mathrm{g} / \mathrm{ml}$ ascorbic acid. The patellae were cultured ot 37 degrees Celsius in a humidified atmosphere of $5 \% \mathrm{CO}_{2}$ in air for a preincubation fime of two hours.

\section{Histology}

For histology 6 whole patellae were fixed in cold $4 \%$ neutral buffered formalin for 24 hours, whereafter the tissue was rinsed. The patellae were subsequently demineralized in $5 \%$ formic acid for 48 hours and dehydrated in a series of ethanol solutions. Five micrometer sections were cut perpendicular to the surface and mounted on glass slides, stained with safranin-O fast green, thionin and alcian blue PAS. For the histo-pathologic score of the cartilage a modification of a procedure originally proposed by Mankin et al. $(6,16,17)$ was used.

\section{Experimental protocol}

After a preincubation period of two hours at $37{ }^{\circ} \mathrm{C}$ under $5 \% \mathrm{CO}_{2}$ in humidified air, all 84 paiellae were transferred ta fresh medium, with six different concentrations of 
gentamicin $(0,2,7,16,30$ and $50 \mu \mathrm{g} / \mathrm{mll}$. The incubation was then continued for an additional 6 respectively 48 hours. Each experimental group consisted of six patellae. 78 Paiellae were subsequently labeled with ${ }^{35} \mathrm{~S}$-sulfate, and. 6 were used for histology.

\section{Metabolic study}

The synthesis of glycosamino-glycanes (GA,G| was measured by the specific incorporation of ${ }^{35} \mathrm{~S}$-sulfate (Radiochemical Center, Amersham, United Kingdom). 78 Patellae were labeled for 16 hours with $5 \mu \mathrm{Cl} / \mathrm{ml} \mathrm{Na}_{2}{ }^{35} \mathrm{SO}_{4}$ (specific activity, $38 \mathrm{mCl} / \mathrm{mmoll}$ after a pre-incubation period of two hours.

The patellae were washed three times in PBS and rinsed in water. In 72 patellae the cartilage was removed from the subchondral bone and subsequently digested with protease $\mathrm{K}$ (2.5 U in I ml $0.05 \mathrm{M}$ tris $\mathrm{HCl}, 1 \mathrm{mM} \mathrm{CaCl}, \mathrm{Ph}, 7.9)$ a f $63^{\circ} \mathrm{C}$ for 6 hours. In 6 patellae the whole patella was digested in order to determine the amount of ${ }^{35}$ S-sulfate that was bound to the bone matrix. The amount of ${ }^{35} \mathrm{~S}$-sulfate incorporated in the GAG of the patellae was determined with a liquid scintillation counter (Beckmann IS 380 1).

Pharmacological analysis

Concentrations ranging from 0 to $50 \mu \mathrm{g} / \mathrm{ml}$ of gentamicin in incubation medium were used. The final concentration of gentamicin in vitro was determined just before starting each in vitro experiment. The protein binding of gentamicin was determined in the culture medium M 199 supplemented with 10\% FCS, using fluorescence polarized immunno assay (FPIA).

\section{Results}

\section{Drug concentration}

In this study we used gentamicin concentrations ranging from $\mathrm{O}$ to $50 \mu \mathrm{g} / \mathrm{ml}$. The concentrations measured just before the addition of radioactive label were in accordance with the fifrated concentrations at the beginning of the experiment. Our data showed that gentamicin in our culture system was not protein bound, which means that the total gentamicin fraction matches the free gentamicin fraction (Fig 1).

\section{Histology}

For the histo-pathologic grading of the paraffin embedded patella, we used the modified mankin score. No loss of stainability of cartilage matrix could be seen when we examined the sections with specific stains as safranin-O, thionin and alcian blue. Also it appeared that the cartilage structure and chondrocyte morphology was unaffected by gentamicin (Fig. 2). 


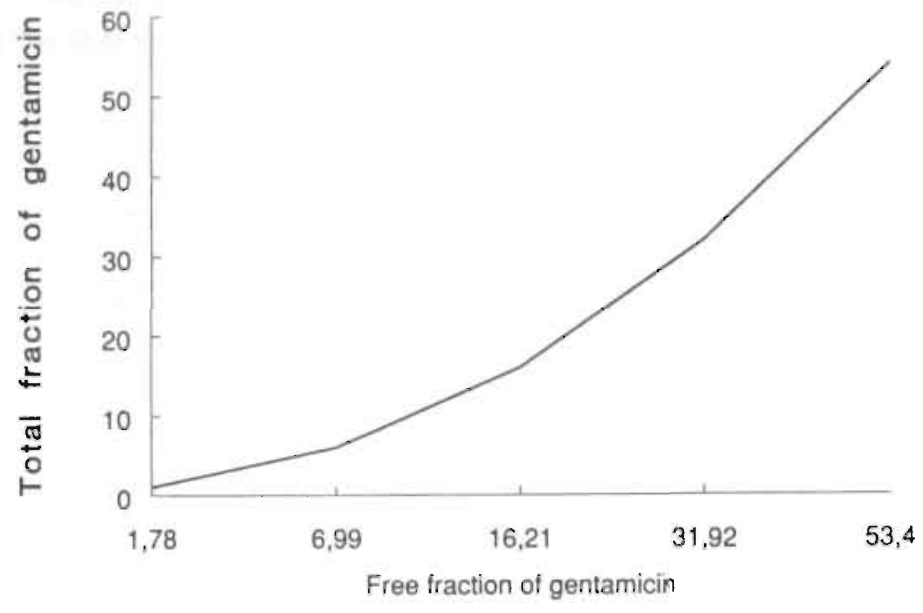

FIG ?

Gentamicin concentration measured in the culture medium by FPIA. yust before the addition of 25 S-sulfate to the medium. Despile the presence of FCS, gentamicin proved to be not protein bound in our culture system.

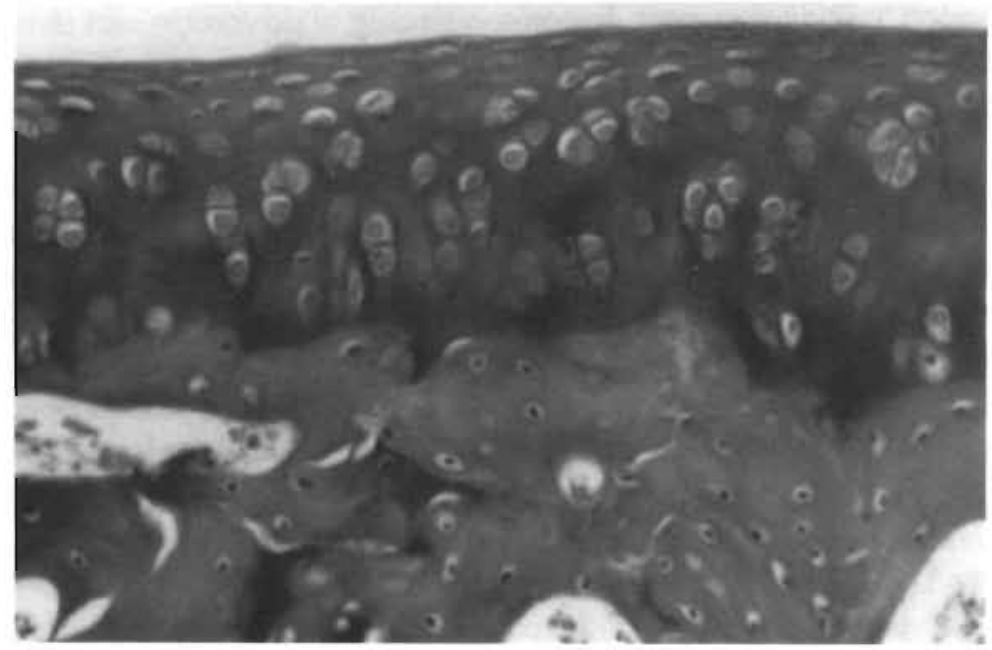

Fig 2.

Photomicrograph of a section of a rat patello, stained with safranin-O. The patella was exposed to gentamicin for fout days of a concentration of $50 \mu \mathrm{g} / \mathrm{ml}$. Cartilage strucfure and chondrocyte morphology were intact. The evenly red stained cantilage matrix represents normal GAG content 


\section{Metabolic study}

In this study the effect of gentamicin on the metabolic capacity of chondrocytes in anatomically intact isolated rat patellae was assessed. The patellae were cultured for

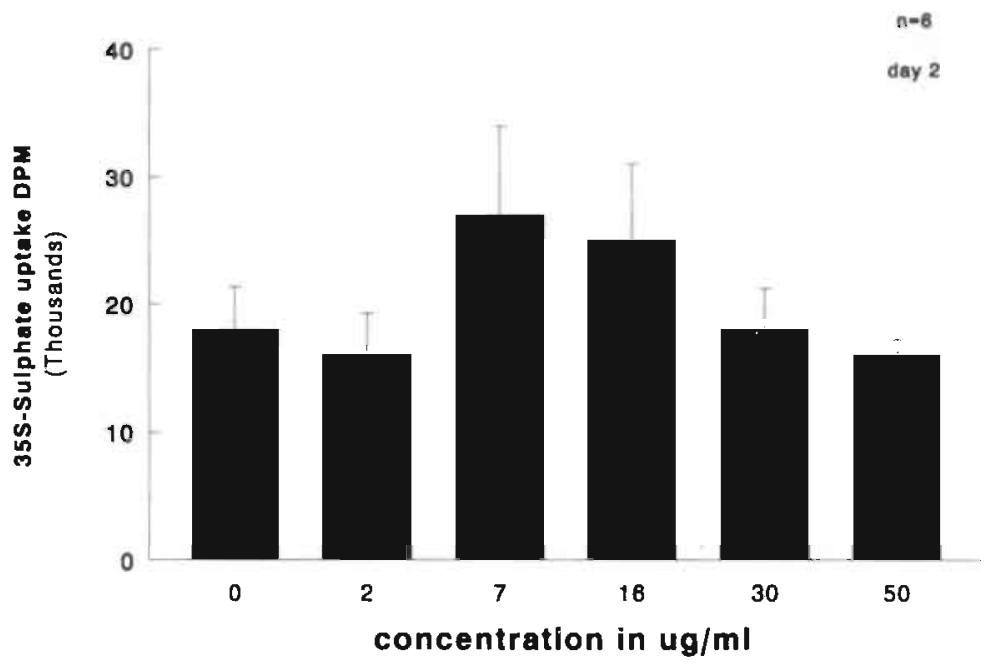

Fig 3 .

The effect of gentamicin on the metabolism of rat patellar explants, cultured for wo days, was assessed The cartilage metabolism, expressed as "Is S-sulfate uptake was not inhibiled by gentamicin.

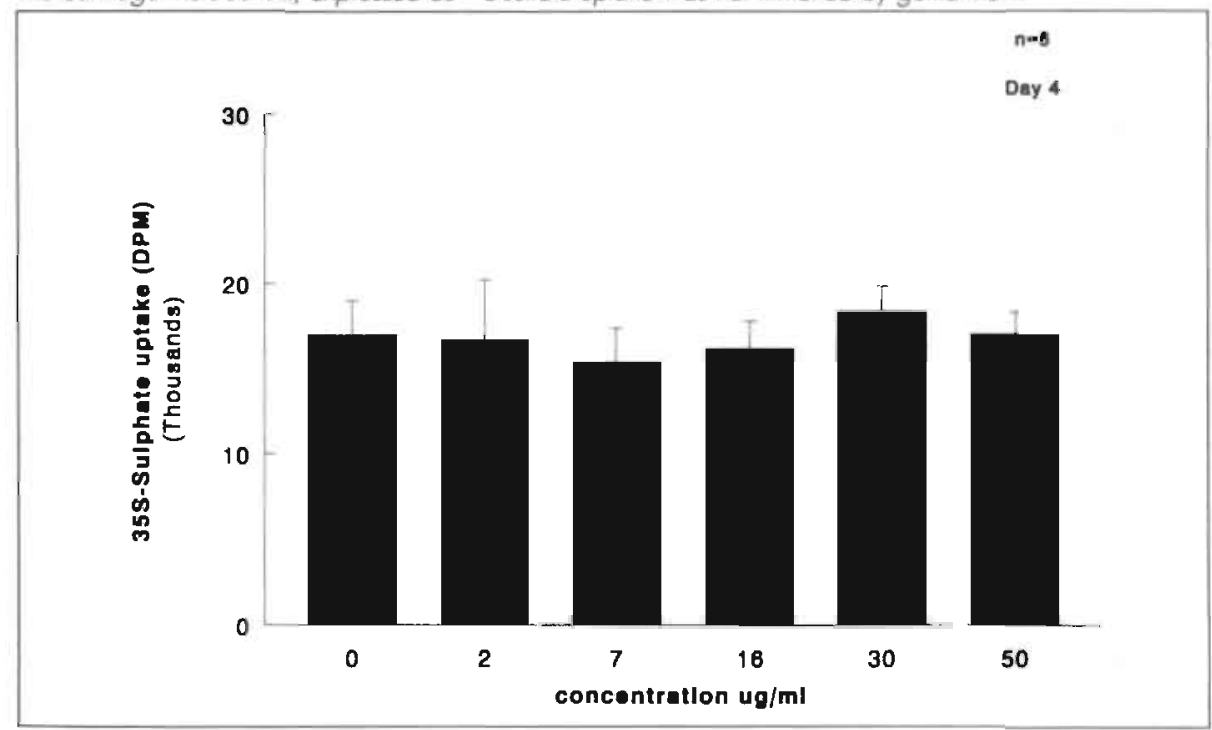

Fig 4 .

Cartilage metabolism was not inhibited by gentamicin ofter four days of culture. 
a short period, in order to prevent leakage of GAG into the culture medium. The ${ }^{35} \mathrm{~S}$ sulfate incorporation was used to quantify the GAG synthesis. Our data showed that even high concentrations of gentamicin did not influence the GAG synthesis of these patellae in vitro. After two days exposure of the patellae to different gentamicin concentrations, no significant change in chondrocyte metabolism was noted (Fig 3). Even after prolonged exposure to gentamicin, the cartilage metabolism was not inhibited by gentamicin (Fig 4). We also found that $98 \%$ of the radiolabel was confined to the cartilage layer of the patella and $2 \%$ to the subchondral bone.

\section{Discussion}

Several problems in the treatment of baclerial arthritis have been reported. Serious side effects of antibiotics $(14,18,33)$ and varying concentrations in the synovial fluid $(11,26)$ may seriously impede the recovery of normal joint function. The need for antibiotic treament is obvious as many authors have clearly shown: Early administration of antibiotics can prevent at least part of the cartilage degradation present after late antibiolic treatment $(2,7,30)$. Therefore we were interested in the possibilities of the addition of local antibiotic therapy to the generally accepted debridement of the joint and intravenously administered antibiotics. Little is known however of the effect of antibiolics alone on cartilage metabolism (2). Therefore the purpose of this study was to evaluate the effect of gentamicin on the morphology and the melabolism of cartilage in vitro. The wide experience with local delivery systems containing gentamicin made our choice for gentamicin obvious 15.331

For these experiments we used the rat patella as an explant culture for a period unto 48 hours. The anatomically intact rat patella offers a suitable model to study drug effects $(3,32)$. Cerlainly in these short term in vitro experiments, only the synthetic capacity of the chondrocyles has to be taken in account, as GAG loss into the culture medium is hardly present $(2 \%$, data not given). Furthermore the whole patella can easily be embedded for hisiological purposes.

The histopathological evaluation of the patellae was performed on paraffin embedded sections. The sections were stained with safranin- $\mathrm{O}$, a stain that is considered to give a quantitative representation of the amount of GAG present in the cartilage matrix $(16,23)$. Also thionin and alcian blue were used for the identification of negatively charged groups in the cartilage matrix and for assessment of cartilage morphology $(6)$. Our data showed that even after high doses of gentamicin of prolonged duration, no histo-pathological changes occurred in the patellar cartilage.

The analysis of the effect of gentamicin on the metabolism of the patella was assessed using $\mathrm{Na}_{2}{ }^{35} \mathrm{SO}_{4}$ incorporation in the GAG. The use of ${ }^{35} \mathrm{~S}$-sulfate incorporation into the GAG has been shown to be a good precursor for quantitative studies on the sulfation of sulfaled GAG's $[25,32)$. Our data showed that even after 48 hours of incubation, the metabolism of the chondrocytes was not inhibited by gentamicin unto a dose of $50 \mu \mathrm{g} / \mathrm{ml}$. 
Pharmacological analysis revealed that in our culture system gentamicin was not bound to serum protein, which might be in contrast to the in vivo situation (13). The effective free drug concentration was therefore in correspondence with the actual drug concentration used

In conclusion our data suggest that the intra-articular administration of gentamicin is not impeding on cartilage metabolism, and might be used for the introarticular therapy of joint infections. In order to acquire a constant intra-synovial and intra-articular concentration of antibiotics, frequent intra-articular administration of gentamicin is necessary. Further study in the development of resorbable antibiolic carriers, that enable slow and prolonged release of the antibiotics into the synovial fluid, might present us with an even better solution. 


\section{REFERENCES}

1. Baciocco E.A. and lles R.L. Ampicillin and kanomycin concentrations in joint fluid. Clin. Pharmacol. and Ther. 1971; 12:858-863.

2. Bailleu E. Paul B. and Koch P. Auswirkungen einmaliger intarontikularer antibiolikagaben aut die knorpelstruktur beim kaninchen. Z. exp. Chir. Iransplant. 1987, 2:94-98.

3. Berg W.B. van den, Kruijsen M.W.M. and Putte L.B.A. van de. The mouse palella assay. An easy method of quantitating anticular cartiloge chondracyte function in vivo and in vitro. Rheumatol. Int 1982; 1:165-169.

4. Brummet R.E., Fox K.E., Bendrick F.W. and Himes D.C. ololoxicity of robramycin, gentamicin, amikacin and sisomycin in the guineo pig J. of Anlimicr. Chemoth. 1978; 4:73-79.

5. Buchholz H.W., Elson R.A., Engelbrecht E, lodenkomper H., Ronger J and Siegel A. Monagement of deep infection of total hip replocement J. Bone Joint Surg. (Br) 1981; 63-B:342-353.

6. Bulstra S.K., Buurman W.A., Walenkamp G.H.I.M. and Linden van der A.J. Melabolic characteristics of in vitro cullured human chondrocyles in relation to the hislopothologic grade of osteoarthritis. Clin. Orthop. Rel. Res. 1989; 242:294-302

7. Curtiss P.H. Cartilage damage in seplic arthritis. Clin. Orthop. Rel. Res. 1969; 64:87.90

8. Daniel D., Boyer J., Green S., Amiel D. and Akeson W. Contlage destruction in experimentally produced staphylococcus aureus joint infection: in vivo study. Surg. Forum 1973; 24:479-481

9. Dee T.H. and Kozin F. Genlamicin and lobramycin peneiration into synovial fluid. Antimicrob Agents and Chemother. 1977; 12:548-549.

10. Editorial Bocterial arthritis. The Lancet 1986; Sept:721.722

11. Frimonotmoller $N$. and Riegels-Nielsen $P$ Anlibiotic penetrotion into the infected knee $A$ rabbit experiment Acto Othop Scand 1987: 58256-259

12. Gillespie WJ. and Nade S. Musculoskeleral infections. I thed. Melbourne: Blackwell Scientific Publications 1987:290293

13. Howell A. Sutherland R. and Rolinson GN Effect of protein binding on levels of ampicillin and cloxacillin in synovial fluid. Clin. Pham. Ther 1972; 5:724.732

14. Jackson G.G. and Arcieri G. Ototoxicity of gentomicin in man: a survey and controled analysis of clinical experience in the united states. J. Inl. Dis. 1971; 124:130-135.

15. Kelly PJ. Infections of bones and joints in odult potienis. Instructionol course lectures 1977, Vol 36 , Mostey, Si lowis, chapier 1:3-13. 
16. Kiviranta N.I., funelin J., Tammi M. and Helminen HJ. Microspectrophotometric quantitalion of glycosaminoglycans in articular cartilage sections stoined with safranin-O. Histochem. J. 1985; $82: 249-255$.

17. Mankin H.J., Dortman H., Lipiello M S. and Zarins A. Biochemical and melabolic abnormalifies in articular contiloge from osleoorhitic humon hips. ]. Bone Joint Surg [Am] 1971; 53.A.523.537

18. Mannion J.C., Bloch R. and Popovich N.G. Cephalosporinaminoglycoside synergistic nephroloxicity: fact or fiction? Drug. Intell and Clin. Pharmacy 1981; 15:248-

19. Marsh D.C., Malthew E.B. and Persellin R.H. Transport of gentamicin into synovial fluid. JAMA 1974: $228: 007$

20. Nade S. and Speers DI Staphylococcol odherence to chicken contlage. Acto Onthop. Scond $1987 ; 58: 351-353$

21. Phemisler D.B. The effect of pressure on anticular surfaces in pyogenic and tuberculous arthritides and its bearing on treatment. Ann. Surg 1924; 80.484 .500

22. Riegels-Nilesen P., Frimondi-Moller N. and Jensen J.S. Rabbit model of seplic arthritis. Acta Orthop. Scand 1987; 58: 14-19.

23. Rosenberg $L$. Chemical basis for histological use of safranin O in the studyof articular cartilage $J$ Bone Joint Surg. 1971; 53-A.69-82.

24. Soller R.B., Bell R.S. and Keeley F.W. The protective effect of continuous passive mation on living articular cartilage in acute septic arthritis. Clin. Orthop, Rel, Res. 1981; 159:224.247

25. Sandy 1.D., Brown H.L.G. and Lowther D.A. Control of protegglycan synthesis Siudies on the activation of synthesis observed during culure of articular cartilages. Biochem I. 1980, 188:119. 130.

26. Sattar M.A., Barran S.P and Cawdey 10. Concentrations of some ambiotics in synoviol thid after oral administration, with speciol reference to antistaphybococcol octivity Ann. Rheum. Dis. 1983. 42:67.74.

27. Schuman D.J. Johnson B.L. Finermon G. and Amsturz HC Antibiotic bone penetration, Concentrations of mehicilin and clindamycin phosphote in human bone raken during total hip replacement. Clin. Orthop Rel. Res. 1975; 111:142-146.

28. Schurman D.J., Hirshman H.P. and Nagel D.A. Antibiolic penetration of synovial thid in infecied and normal kree joinis. Clin. Oth. Rel Res. 1978; 136:304.310.

29. Sensi M., Pozzili P., and Coltell W.R. Gentanicin nephrotoxicin in experimental acure rend talure Acla ther. 1980; 6.65.

30. Smith R.L, Merchant T.C. and Schurmon D.J. In vitro contilage degradorion by escherichio coli and slaphylococcus oureus. Arthritis Rheum 1982; Vol 25. No 4:441-440 
31. Smith R.L., Schurman D.J., Kailyamo G., Bell M. and Gilkerson E. The effect of antibiotics on the destruction of coriliage in experimental intectious orthritis. J. Bone Joint Surg. (Am) 1987; 69 A: $1063-1088$

32. Vies de B.J., Berg W.B. van den, Vitrers E.L. and Puite van de L.A. Quantitation of glycosaminuglycan metabolism in anotomically intact articular cartiloge of the mouse patella: in vitro

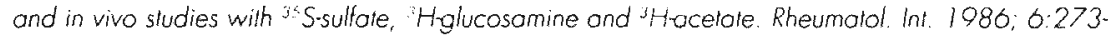
281 .

33. Walenkamp G.H.I.M., Vree T.B. and Rens van TJ.G. genlamicin-PMMA beads. Pharmacokinetic and nephroloxicological study. Clin. Orthop. Rel. Res. 1988: 205:171.183 


\title{
The effect of piroxicam on the metabolism of isolated human chondrocytes
}

\begin{abstract}
The effect of piroxicam on the metabolism of healthy and osteo-arthritic $|O . A$. chondrocytes was studied in vitro. The chondrocytes were oblained from 5 healthy, 5 moderately and 4 severely O.A. hips or knees. The chondrocytes were cultured in a high density short ferm in vitro model. In this culiure, the healihy as well as the O.A. chondrocyles retain their metabolic properties. Piroxicam was used in concentrations ranging from $0 \cdot 10 \mu \mathrm{g} / \mathrm{ml}$, which is comparable to the concentrations reached in vivo after oral administration. In our culture of healthy chondrocyles, piroxicam inhibited proliferation and the synthesis of proteoglycans. The metabolism of moderately damaged chondrocytes was not influenced by piroxicam. In severely damaged cartilage only the proliferation was significantly inhibited by piroxicam. In order to avoid the possible negative side effects of piroxicam on the metabolism of healthy and severely O.A. chondrocytes, we conclude that the treatment of an O.A. joint with synovitis should be restricled to the period of the effusion.
\end{abstract}

\section{Introduction}

In Osteo-Arthritis (O.A.) the metabolism of chondrocytes is aberrant compared to healthy cartilage. This results in a higher synthesis of proteoglycans (PG), and in an exceeding loss of $P G$ from the cartilaginous matrix $[1,4,19,22,26-27)$. Various mechanical and humoral factors modulate chondrocyte metabolism in vivo. In O.A. and Rheumatoid Arthritis (R.A.) enzymatic and humoral factors, are released into the synovial fluid and play an important role in the desirucition of cartilage $(3,5,21$, 27) Therefore, nonsteroidal antiinflammatory drugs (NSAID), such as Piroxicam, have gained an important place in the treatment of R.A. and O.A. Questions have been raised, however, with regard to the place of NSAID in the reatment of O.A. $(2,5,38)$. Numerous reports have been published on possible deleterious effects of certain groups of NSAID on cartilage metabolism $[1,6,11-13,17,20,23-26,35-371$. The effect of NSAID, such as Piroxicam, on cartilage metabolism is reported to vary depending on the experimental model or the species studied $(34,37)$.

In contrast to patients with R.A., synovitis is nol consislently found in O.A. noi even in severely O.A. joints. Effusion of an O.A. joint is merely preseni after (micro) trauma and it disappears in most cases spontaneously or after short term treatment 
with NSAID. In contrast to R.A., in O.A. the disease is usually confined to a single joint. Since most of the NSAID are administered systemically and not locally into a joint, it is important to assess the effects of NSAID on the metabolism of both O.A. cariilage and on healthy cartilage

In an earlier study we presented a shorl term culture model in which isolated human chondrocytes relain their phenotypic charocleristics $(4)$. In this study we report the effect of Piroxicam on the metabolism and proliferation of chondrocytes, derived from healthy and O.A. human cartilage, using this culture model.

\section{Materials and methods}

Pharmacological analysis

Piroxicam was kindly provided by PFIZER NV, The Netherlands. Concentrations ranging from $\mathrm{O}$ lo $10 \mu \mathrm{g} / \mathrm{ml}$ of Piroxicam in incubation medium were used. The final concentration of Piroxicam was determined just before starting each in vitro experiment, using a high performance liquid chromatographic method $(\mathrm{HPLC})(8,10)$. The protein binding of Piroxicam was determined in culture medium M 199 (Gibco, Paisley, UK) supplemented with 10\% Foetal Calf Serum (FCS, Boehringer, Mannheim, FRGl, $250 \mu \mathrm{g} / \mathrm{ml} \mathrm{lg}$ glutamine, $50 \mu \mathrm{g} / \mathrm{ml}$ ascorbic acid and $500 \mathrm{U} / \mathrm{ml}$ penicillin, $500 \mathrm{~g} / \mathrm{ml}$ streptomycin, $0.125 \mu \mathrm{g} / \mathrm{ml}$ fungizone. The free concentration of Piroxicam was determined after ultrafiltration followed by HPLC. For the determination of in vitro protein binding of Piroxicam, $0.8 \mathrm{ml}$ of the sample was ultrafiltrated through a protein filter (Emit, Free level P.M. system 1 filters Syva, Merck, FRG) al 5,000 $\mathrm{rpm}$. The samples were diluted ten rimes with elvens $50 \%$ Acetonitril in bidestillated waler, containing $0.08 \mathrm{~g} \mathrm{KH}_{2} \mathrm{PO}_{4}$ and $1.0 \mathrm{~g}$ phosphoric acid per liter. The mixture

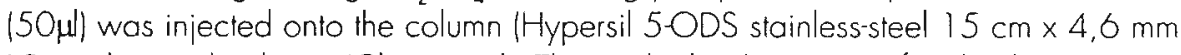
I.D with guard column, [Chrompack, The Netherlands]] using a fixed volume injection loop. Analysis took place with a Waters Associates Model 510 HPLC equipped with a fixed wavelength U.V. delector (model 441 ) and a Shimadzu Cr-3A inlegrator.

Sampling of articular cartilage

Healthy and $O$. A . human articular cartilage samples were obtained from the weight bearing part of the femoral head and the medial femoral condyle of the knee during reconstructive surgery. Healthy cartilage was oblained from 5 different patients with a mean age of 68 years (range $62-72$ years). O A. cartilage samples were obtained from 9 different patients with a mean age of 69 years [range 64.71 years) (Table 1). Immediately atter the operation the specimens were inspected and areas with a macroscopically uniform aspect, representative for the disease, were selected. Osteophytic regions were discarded. A biopsy with a diameler of $1.2 \mathrm{~mm}$ was laken from the cartilage and the subchondral bone layer of the central part of the selected 
area. The biopsies were fixed in 10\% formalin and embedded in plastic Technovit 7100 (Kulzer, Wehrheim, FRG) or in paraffin after dehydration in ethanol. Sections $(5 \mu \mathrm{m})$ were cut perpendicular to the articular surface and stained with hematoxylin and eosin, alcian blue-periodic acid Schiff (PAS), thionin or safranin-O, a special stain for PG (30). For the histopathological score we used a modification of the Mankin score, which was described elsewhere (4).

TABLE 1:

The carlilage used in this siudy was oboined trom healthy (Mankin score II and osteonathritic canligge Monkin score 5,7, 10,11) of the knee and the hip during reconstructive surgery.

\begin{tabular}{llll}
\hline $\begin{array}{l}\text { Number of } \\
\text { Patients }\end{array}$ & $\begin{array}{l}\text { Hip } \\
\text { Knee }\end{array}$ & $\begin{array}{l}\text { Mankin } \\
\text { Score }\end{array}$ & $\begin{array}{l}\text { experiments per } \\
\text { Dose piroxicam }\end{array}$ \\
5 & $3 H / 2 K$ & 1 & 6 \\
2 & $1 H / 1 K$ & 5 & 3 \\
3 & $3 K$ & 7 & 3 \\
2 & $1 H / 1 K$ & 10 & 3 \\
2 & $1 H / 1 K$ & 11 & 3 \\
\hline
\end{tabular}

Cell isolation and culture method

The isolation and culture of chondrocytes was described previously (4). Briefly cartilage was transferred into a sterile vial conlaining culture medium M 199 and kept at $4^{\circ} \mathrm{C}$. Within two hours after removal, the cartlage adjacent to the biopsy was dissected from the subchondral layer. The cartilage fragments were cut into small pieces and digested with crude collagenase (CLS 2, Worthington, Freehold, NJ; $200 \mathrm{U} / \mathrm{ml}$ of culture medium with $10 \% \mathrm{FCS})$ for 16 hours at $37^{\circ} \mathrm{C}$ in a humidified atmosphere of $5 \% \mathrm{CO}_{2}$ in air. The liberated chondrocyles were washed and resuspended in culture medium. A sample of the cell suspension was used for cell counting and to determine the viability of the isolated cells with trypan blue and cytological examination using May-Grünwald-Giemsa (Merck, Darmstadt, FRG). The cells were centrifuged at $800 \mathrm{rpm}$ for ten minutes in order to concentrote the cell suspension and cultured at high density in a petri dish in a drop of $10 \mu$ culture medium containing $2 \times 10^{3}$ cells $\left(10\right.$ drops per petridish), at $37^{\circ} \mathrm{C}$ in a humidified atmosphere of $5 \% \mathrm{CO}_{2}$ in air. Culture was continued for four days.

During the culture period the cells aggregated and synthesized cortilage matrix macromolecules (4). A number of cellular aggregates were used for histological examination. After fixation, the cultures were embedded either in Technovit 7100 or in paraffin and sectioned at $5 \mu \mathrm{m}$. The sections were stained with hematoxylineosin, alcian-blue-PAS, thionin or safranin-O-fast green. 
Metabolic study

The synthesis of sulfated GAG by the chondrocytes in culture was measured by the specific incorporation of ${ }^{35} \mathrm{~S}$ sulfate. Cells were labeled for 16 hours with $5^{\circ} \mathrm{Ci} / \mathrm{ml}$ $\mathrm{Na}_{2} \mathrm{SO}_{4}$ (specific activity $42 \mathrm{mCi} / \mathrm{mmol}$, Radiochemical Center, Amersham, UK). At the end of the incubation period the medium was collected and the cellular aggregates were washed three times with cold M 199 culture medium. Protein bound Piroxicam and the free Piroxicam were determined in the medium fraction. The aggregates were transferred to a vial containing $2 \mathrm{ml}$ of fresh medium and digested with papain (Merck) at $60^{\circ} \mathrm{Cfor} 16$ hours. The GAG were precipitated with $2 \mathrm{ml}$ $10 \%$ cetylpyridinium chloride (CPC) (Merck) in $0.2 \mathrm{M} \mathrm{NaCl}$. After 16 hours at $37^{\circ} \mathrm{C}$ the precipitale [CPC-GAG complex] was collected and washed several times with $0.1 \%$ CPC and then dissolved in $0.5 \mathrm{ml} \mathrm{100 \%} \mathrm{formic} \mathrm{acid.} \mathrm{The} \mathrm{amount} \mathrm{of} 35 \mathrm{~S}$ sulfate incorporated in the GAG was determined with a liquid scintillation counter. Cell proliferation was quantified by ${ }^{3} \mathrm{H}$ thymidine $\left({ }^{3} \mathrm{H}-\mathrm{TdR}\right)$ incorporation as described elsewhere (4). Briefly, the aggregates of chondrocytes were labeled with $15^{\circ} \mathrm{Ci} / \mathrm{ml}$ ${ }^{3} \mathrm{H}-\mathrm{TdR}$ (specific activity, $5 \mathrm{Ci} / \mathrm{mmol}$, Amersham), for a period of 16 hours.

Precipitation took place with 10\% TCA and after resuspension in $0.5 \mathrm{ml}$ formic acid the incorporated ${ }^{3} \mathrm{H}-\mathrm{TdR}$ was measured in a scintillation counter. The uptake of ${ }^{35} \mathrm{~S}$ Sulfate and ${ }^{3} \mathrm{H}-\mathrm{TdR}$ was standardized per culture as DPM per 1000 cells.

\section{Experimental protocol}

After four days of culture when the chondrocytes were tightly aggregated, the effects of concentrations of Piroxicam ranging from $0.10 \mu \mathrm{g} / \mathrm{ml}$, on the incorporation of $35 \mathrm{~S}$ Sulfate in the GAG and on the incorporation of ${ }^{3} \mathrm{H}-\mathrm{TdR}$ in DNA were determined. The concentrations of Piroxicam used covered the therapeutic blood plasma levels reported for this NSAID $(14,15,18,28-29,32,37)$. After a pre-incubation period with Piroxicam of four hours, the radioactive label was added to the culture medium. Each concentration of Piroxicam was tested in triplicate on chondrocytes of one patient lone degree of O.A.). After a labeling period of 16 hours, the aggregates were removed from culture and processed as described above. The dala from patients with the same degree of $O$.A were pooled. Data were analyzed using the paired student's T-test.

\section{Results}

Drug concentration

In this study Piroxicam concentrations within the normal therapeutic range were used (Table 2). We determined the effect of Piroxicam on the metabolism of chondrocytes from healthy and O.A. cartilage in vitro. The tolal concentration as well as the free concentration of Piroxicam in the culture media were measured during the experiments. The data showed that over the concentration range used $(0.10 \mu \mathrm{g} / \mathrm{ml})$ about $40 \%$ of the total concentration of Piroxicam was protein bound (Fig 1). 


\section{Table 2:}

Concentrations of piroxicam measured in vivo, literature dala

\begin{tabular}{llll}
\hline autho & disease & $\begin{array}{l}\text { concentration piroxicam } \mu \mathrm{g} / \mathrm{ml} \\
\text { plasma } \\
\text { synovial fluid }\end{array}$ \\
\hline Hobbs & healthy & $7.6-8.3$ & - \\
Ligniere & healthy & $3.47+/-0.48$ & 1.5 \\
Verbeek & healthy & $0.9-12.9$ & - \\
Verbeek & healthy & $0.0-8.0$ & - \\
Verbeek & O.A. & $2.8-7.7$ & - \\
Verbeek & R.A. & $4-20$ & - \\
Rugstadt & O.A & $2-32[8.3+/-3.4]$ & - \\
Verbeek & R.A. & $10.47+/-0.33$ & - \\
Verbeek & healthy & $10.3+/-1.9$ & -0.85 \\
Julhunen & O.A. & $2.8-7.7$ & \\
& & &
\end{tabular}

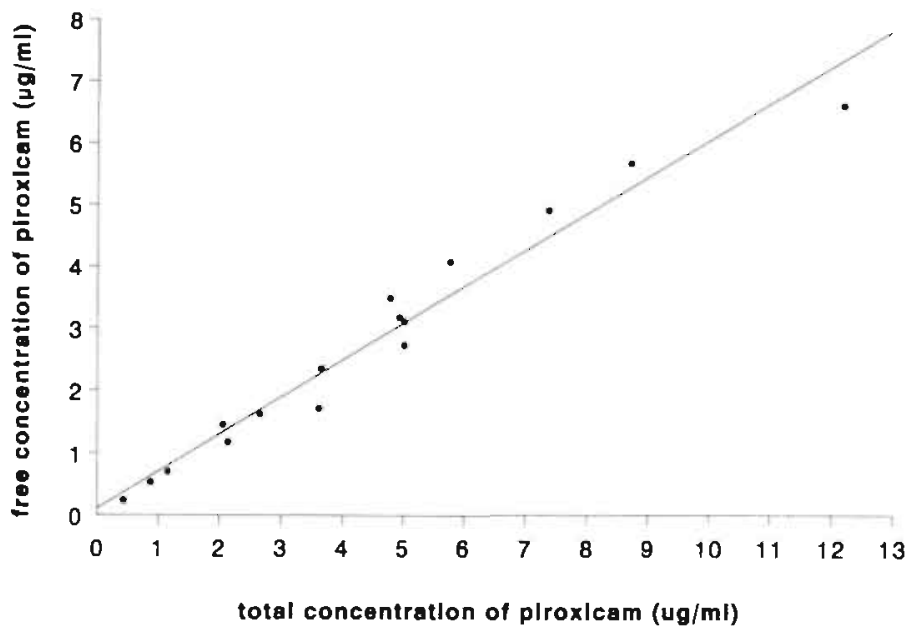

Fig 1.

Prolein binding of piroxicam in tissue culture medium supplemented with 10\% serum. Regression analysis revealed that approximalely $60 \%$ of piroxicam was not bound to protein $(p<0001$ ). 
Metubolic study

In this in vitro study the effect of Piroxicam on the metabolic capacities of healthy and $O$.A. human chondrocyles was assessed. The cells were cultured in a high densily model, in which they retained their specific metabolic capacities, related to the severity of the O.A. of the cartilage from which they were isolaled $(4,6,16,31)$. The influence of Piroxicam on the metabolism of the chondrocytes in a newly synthesized cartilaginous matrix was tested after four days of culture

The dala, oblained with healthy cartilage from five different donors, showed that at Piroxicam concentrations of $1.6 \mu \mathrm{g} / \mathrm{ml}$ and higher the uptake of ${ }^{3} \mathrm{H}-\mathrm{TdR}$ was significantly inhibited $(p<0.01)$. Concentrations of $5 \mu \mathrm{g} / \mathrm{ml}$ and higher completely inhibited cellular proliferation in these cultures (Fig 2).

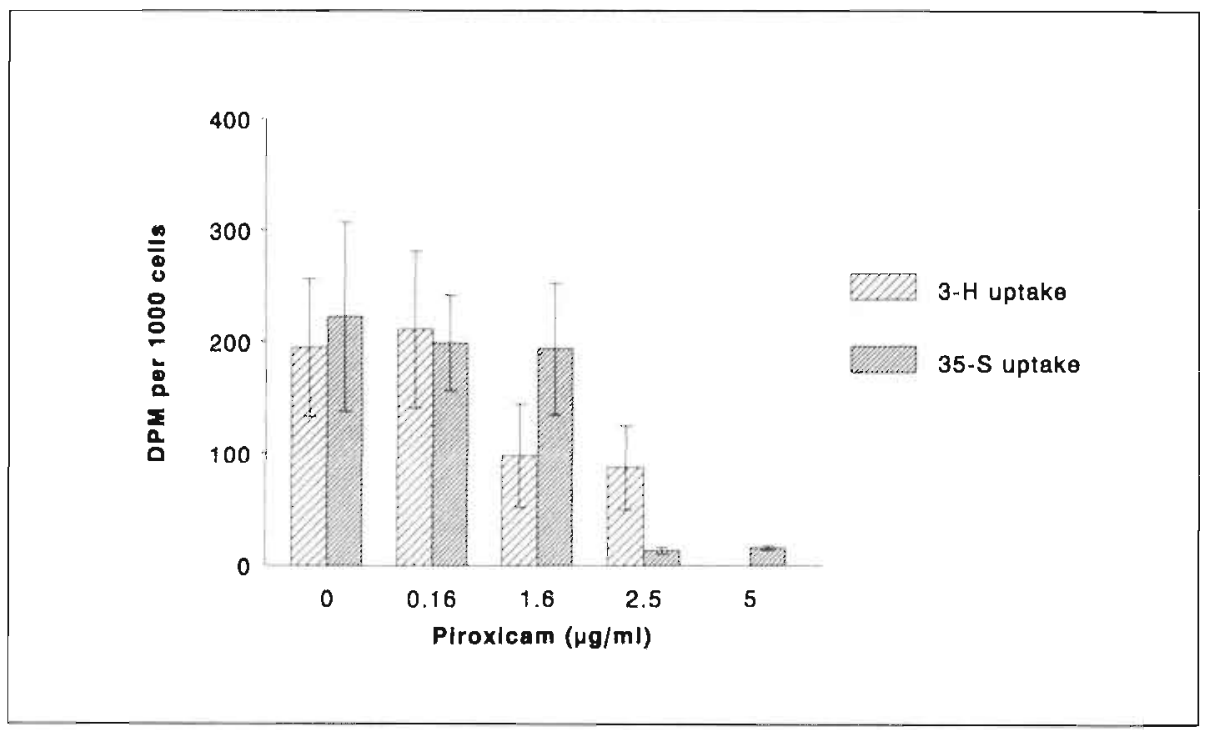

Fig 2.

In heathy carlilage the ${ }^{3} \mathrm{H}$ uptake is significantly inhibiled al a concentralion of $1.6 \mu \mathrm{g} / \mathrm{m} /(0<0.01)$ and obove, the ${ }^{35}$ s uplake is inhibited at $2.5 \mu \mathrm{g} / \mathrm{ml}(\mathrm{p}<0.01)$ and above

The ${ }^{35}$ S-Sulfale incorporation indicative for GAG synthesis was inhibited from $2.5 \mu \mathrm{g} / \mathrm{ml}$ onwards $(p<0.01)$. This indicaled that GAG synthesis by healthy chondrocytes was inhibited in this culture system IFig 2.1.

Next we determined the effect of Piroxicam on the metabolism of chondrocytes from O.A. cartilage. Moderately damaged cartilage samples igrade 57. modified Mankin scorel originating from 5 different patients were used for these experiments. Although there is an inhibition of $3 \mathrm{H} \cdot T \mathrm{dR}$ uptake at 1.25 and $2.5 \mu \mathrm{g} / \mathrm{ml}$ Piroxicam ( $p<0.05)$, the data showed that at higher doses of Piroxicam upto a dose 


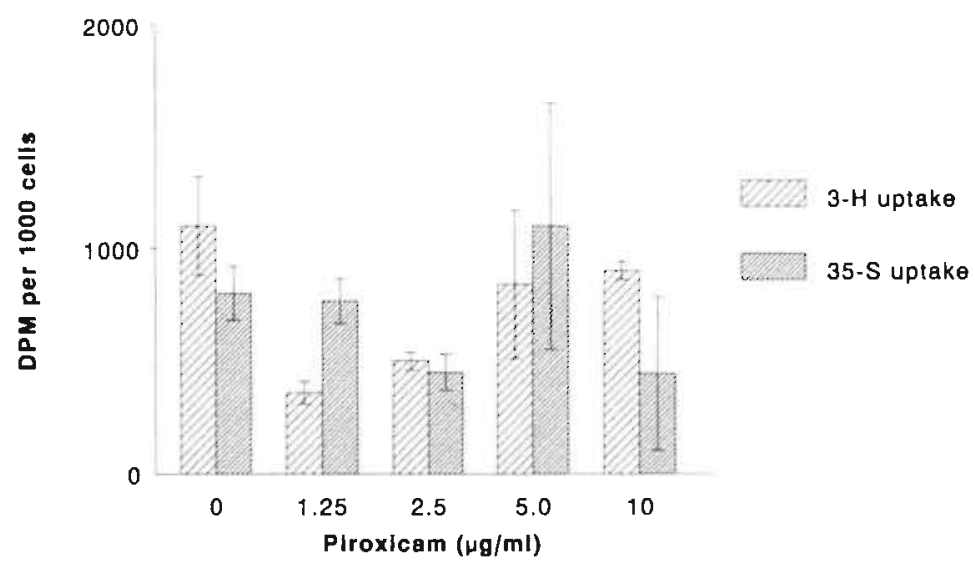

Fig 3 .

In moderately $O A$ contlage lgrade 5-7) the 34 uptake is inhibiled at doses of $1.25 .2 .5 \mu \mathrm{g} / \mathrm{ml} /(\mathrm{p}<0.05)$. Al higher doses the ${ }^{3} \mathrm{H}$ uploke as well as the ${ }^{35} \mathrm{~S}$ uplake are not significantly intibired by piroxicam

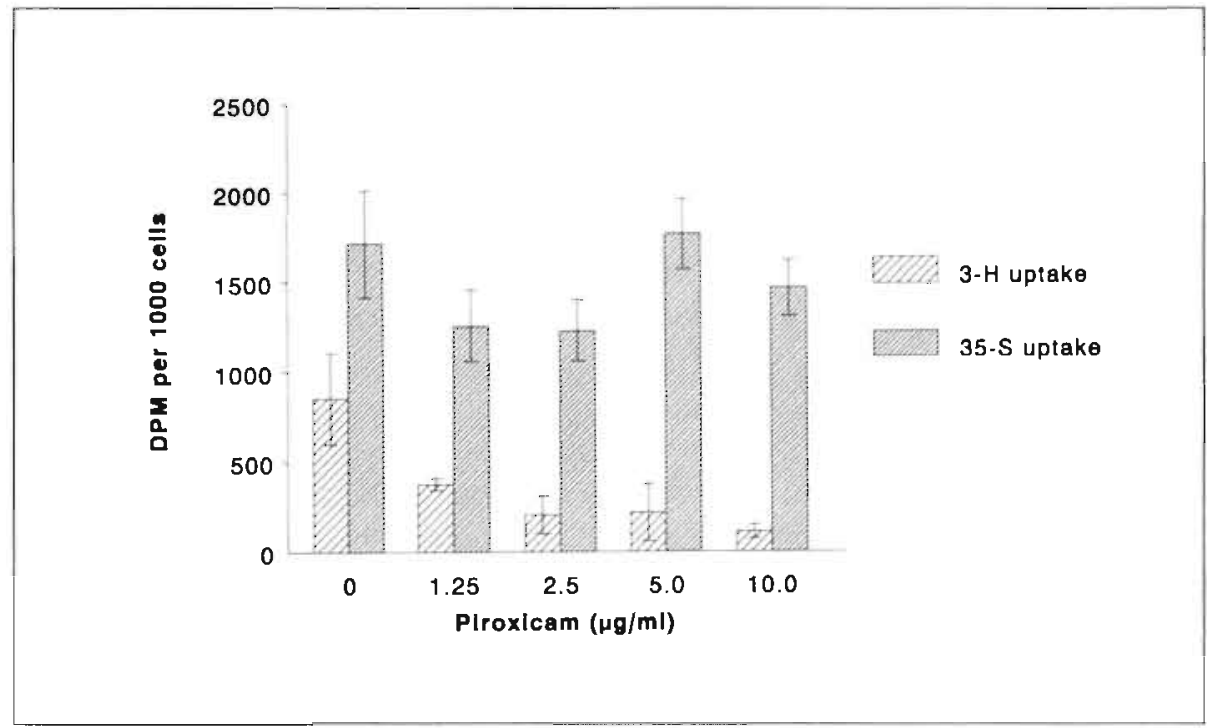

Fig 4 .

In severe $O A$ the $3 H$ uptake is inhibited a a concentration of $1.25 \mathrm{\mu g} / \mathrm{m} /$ and above $(0<0.05)$ : the $35 \mathrm{~s}$ uptake is not significanlly inhibied by piroxicam. 
of $10 \mu \mathrm{g} / \mathrm{ml}$, the ${ }^{35} 5$ uptake and the ${ }^{3} \mathrm{H}$ uptake were not significantly inhibited by Piroxicam (Fig 3). Severely damaged cartilage samples (grade 9-10) were obrained from 4 patients. In chondrocyte cultures derived from this severely damaged cartilage the "H-Tdr uptake was inhibited by doses of Piroxicam from $1.25 \mu \mathrm{g} / \mathrm{ml}$ onwards $\left\{. p<0.051\right.$. However, the ${ }^{35} 5$ uplake was not significantly inhibited by Piroxicam uplo a concentration of $10 \mu \mathrm{g} / \mathrm{ml}$ (Fig 4).

\section{Discussion}

Several NSAID have been reported to impair proteoglycan synthesis in vivo as well as in vivo $(1-2,0,11-12,20,23-26,35-37)$. Piroxicam and some of the other NSAID have been shown to affect PG synthesis although the data varied depending on the experimental model chosen $(34,37)$. The purpose of this study was to evaluate the effect of Piroxicam on chondrocytes from healthy and $O$.A. human cartilage excluding the effects of concomitant synovitis. In the culture model used the cultured cells became within four days surrounded with a newly synthesized matrix that histologically resembled the matrix of the cartilage from which the cells were originally isolated. In earlier experiments (4) a consistent relation between the histopathological grade of $O A$, the proliferative behavior of the chondrocyles and the production of GAG was found after four days in this culture model. This is of importance since it is known that PG depletion and the metabolic state of the chondrocytes influence the sensitivity of cartilage metabolism for drugs such as NSAID $(13,20,22,26)$. Since it was of utmost importance to asses the influence of drugs in a situalion which mimics the in vivo metabolic stale, these properties of this culture system rendered it valuable for lesting the influence of drugs on the metabolism of chondrocytes. In contrast to others we determined the influence of Piroxicam in a short term culture with short exposure limes of chondrocyles (33-34). The uptake of ${ }^{35} \mathrm{~S}$ sulfate and ${ }^{3} \mathrm{H}-\mathrm{Tdr}$ was standardized per culture as DPM per 1000 cells.

Our dala showed that the effect of Piroxicam on the metabolism of chondrocytes from moderately O.A. human cartilage, was only significant for the lower doses of Piroxicam $\{1.25-2.5 \mu \mathrm{g} / \mathrm{m} \mid)$. However no significant inhibition was found for the higher doses of Piroxicam $(5-10 \mu \mathrm{g} / \mathrm{mll})$. This illustrates helerogeneily of the population of chondrocytes in moderately damaged cartiloge, where healthy and O.A. chondrocyles may influence each other. This supports the importance of the treatment of synovitis in moderately $O A$. cartilage with Piroxicam, since the deleterious influence of synovitis on the metabolism of $O$. A . cartilage are inhibited by Piroxicam $(3,5,12,21,27\}$.

In earlier experiments it was shown that in cultures of chondrocytes from O.A. cartilage proteoglycan synthesis and cell proliferation increased with the severity of $O$.A. to reach a maximum beyond which the melabolic and the proliferative activities of the chondrocytes diminished to almost zero $(4,19)$. Our experiments showed that 
the proliferation of severely $O$.A. chondrocytes with high metabolic and proliferative capacities was strongly inhibited by Piroxicam even at a low concentration as low as $1.25 \mu \mathrm{g} / \mathrm{ml}$

Healthy cartilage also appeared to be affected negatively by Piroxicam. The dala showed that the drug inhibiled the proliferation and the GAG synthesis by healthy human cartilage derived chondrocytes beyond a concentration of $2.5 \mu \mathrm{g} / \mathrm{ml}$. This seems of importance since such concentrations are reached after a single oral dose of $20 \mathrm{mg}$ of Piroxicam $[7,1415,18,28,29,32)$.

The drug concentrations used in this study were chosen on the basis of plasma concentralions observed in vivo and were in accordance with those used by others $(34,37)$. Besides the total concentration of Piroxicam a second parameter is suggested to be of importance being the fraction of free in contrast to protein bound Piroxicam. Sofar however, it is unknown whether only free Piroxicam or also protein bound Piroxicam has an effect on cartilage metabolism (37). In our in vivo model we determined the total and the free concentration at the end of the incubation perixi of each experiment. The amount of free Piroxicam proved to be about $60 \%$ of the total content (Fig 1). Little information is available about the concentration of both free and bound Piroxicam in osteo-arthritic joints. Such concentrations are difficult to estimate, since they are dependent on synovitis and related factors such as the protein content of the synovial fluid. An other important factor in relation to drug concentrations in plasma and synovial fluid, is the renal function which decreases with age. Therefore drug concentrations in plasma may rise beyond those found in healthy volunteers $(14,18,28-29)$. This is further complicated by factors such as concomitant drug use.

It was concluded that in our culture model Piroxicam exeried a negotive effect on the metabolism of healthy and severely O.A. chondrocytes. Although we do agree with other authors about the imporlance of treatment of concomitant synovitis in O.A. with Piroxicam, the treatment with NSAID such as Piroxicam should be restricted to the period of the effusion, in order to protect healthy and O.A. cartilage from the other joints, from the negative effects of the drug on its metabolism. It should be emphasized however that our data represent the results of in vitro experiments in which an isolated drug effect was studied. 


\section{Acknowledgement}

We thank Pfizer NV, The Netherlands for providing us with Piroxicam and the financial support for this study.

\section{Literature}

1. Brandi K.D. Palmoski MJ. Effects of solicylate and other anti-inflammalory drugs on articular cortilage. Am. I Med. 77|IAl:05, 1984.

2. Brooks P.M. Potter S.R., Buchonan W.W. Editorial NSAID and osteoorthritisthelp or hindrance? $J$ Rheum Q: 3, 1982.

3. Brown M.F., Hazleman B.L., Dingle J.T., Dandy DJ. and Murley A.H. G. Production of cartilage degrading activity by human synovial tissues. Ann. of Rheum. Dis. 46:319, 1987.

4. Bulstra S.K., Buurman W.A., Walenkamp G.H.IM., and van der Linden A.J.: Metabolic characteristics of in vitro cultured human chondrocyles in relation to the histoputhological grade of osteoarthritis. Clin Orthop. 242:294, 1989.

5. Colin A.: Clinical aspects of the effect of NSAID on cartilage. J. Rheum 16 [suppl. 18]:43, 1989.

6. Coller S. and Ghosh P. Evaluation of the effects of antiathritic drugs on the secretion of proleoglycans by lopine chondrocytes using a novel assay procedure. Ann Rheum Dis. 48:372. 1989

7 Darragh A. Gordon AJ. OByrne H. Hobbs D C. Casey E . Single dose and steody slate phamacokinetics of prioxicam in elderly vs young aduls. Eur. I Clin. Phamacol. 28:305, 1985.

8. Dixon J.S and Lowe J.R.: Rapid meihod tor the deierminction of either piroxicam or tenoxican in plasma using HPIC J.Chrom $310455,1984$.

9. Franchimont C. Bassleer and Henrolin $Y$.: Eflects of hormones and drugs on carilage repair. I Rheum 16 [suppl 18): 5, 1989.

10. Fraser A.D. and Woodbury J.P.L.: Liquid Chromatographic deleminotion of Piroxicam in serum Ther. Drug Monit. 5:2, 1983.

11. Gay R.E., Palmoski MJ., Brand K.D. and Gay S.: Aspirin couses in vivo synhesis of type 1 collagen by atrophic articular cartilage: Arthritis Rheum. 20:1231, 1983.

12. Herman J.H., Appel A.M. and Hess E.V.: Modulation of cartiloge destuclion by select nonsteroidd antinflammatory diugs. Arthritis. Rheum. 30:257, 1987. 
13. Hess E.V., Herman J.H. Contlage meicbolism and anti-inflammolony drugs in osleoarthritis. Am. J. Med. 81 [supp/ 58]:36, 1986.

14. Hobbs D. C. Piroxicam pharmacokinetics: Recent clinical results relating kinelics and plasma levels to age, sex and adverse effects. Am. J. Med. 81 [suppl 5B].22, 1980.

15. Huskisson E.C. International clinical experience with piroxicam in osteoarthritis. Int Med. 3:34, 1983.

16. Kalbhen D.A.: Konnen kortikosteroide und nicht-steroidale anirheumalika athrosen induzieren oder fordern?. Therapiewoche 33:2597, 1983.

17. Kampen van G.PJ. and Veldhuyzen J.P. Aggregaled chondrocytes as a model to study cortilage metabolism. Exp. Cell Res 140:440, 1982.

18. Ligniere G.C., Montognani G. and Acerbi D.: Plasma and synoviol fluid concentrations of prioxicam during prolonged trealment with piroxicam pivalic ester. Arzneim. Forsch. Drug. Res. 37:560, 1987.

19. Mankin H.J., Dorfman H., Lipiello M.S. and Zarins A. : Biochemical and melabolic abnormalities in articular cartilage from osteo-arthritic human hips. J. Bone Joint Surg. 53A.523, 1971

20. McKenzie L.S., Horsburgh B.A., Gosh P and Taylor T.K.F.: Effect of anti-intlanmatory drugs on sulphated glycosaminoglycan synthesis in oged human articulor corilage. Ann Rheum Dis. $35: 487,1976$.

21. Moroles T.1. and Hascall V.C.: Faclors involved in the regulotion of proleoglycan metobolism in articular carlilage. Arthrilis Rheum. 32:1197, 1989.

22. Palmosky MJ and Brandi K.D. Proteoglycon depletion, rother than fibrllotion, determines the effecls of salicylate and indomethacin on osteoarthritic cortilage. Arthitis and Rheum. 28.548, 1985

23. Palmoski M.J. and Brandi K.D. In vivo eflect of aspirin on canine osteoarthritic cartilage: Arthritis Rheum. 26:994, 1983.

24. Palmoski MJ and Brandi K.O. Effects of some nonstervidal antiinflommatory drugs on proleoglycon melabolism and organization in canine articular cortilage. Arihritis Rheum. 23:1010, 1980.

25. Polmoski M.J. and Brandi K.O.: Elfeci of salicylate on proteoglycon metabolism in normal conine articular cartilage in vilro. Arthritis Rheum. 22:746, 1979.

26. Palmoski M.J., Colyer R.A. and Brandi K.D.: Morked suppression by solicylare of the ougmented proteoglycan synthesis in osteoarthritic carlilage. Arthrilis Rheum. 23:83,1980

27. Pelletier J.P. and Mortel.Pelletier JM. Evidence for the involvment of interteukin- 1 in humon osteoarthritic carlibge degradation: prolective ellect of NSAD. ). Rheum 16 (suppl 18) 19, 1989

28. Richardson CJ., Blocka K.LN. Ross S.G, Verbeeck R.K. Eflecls of age and sex on piroxicam disposition. Clin. Phomacol. Ther 37: 13, 1985 
29. Rosenberg L.: Chemical basis for histologicol use of solranin $O$ in the study of articular cartilage J. Bone Joint Surg. 53A:89, 1971.

30. Rugstad H.E. The norwegian study: Plasma concentrotions, efficacy; and adverse events. Am. J. Med. 81 [suppl 58]: 11, 1980.

31. Solursh M. Cellcell interaction and chondrogenesis. In Hall, B.K. led): Cartiloge, Development, Differentiation and Growth, Vol 2, New York, Academic Press, 1983, p 127.

32. Verbeeck R.K., Richordson C.J. and Bicoka K.L.N.: Clinical Pharmacokinetics of Piroxicam. J. Rheumald 13.789, 1986.

33. Verbruggen G., Veys E.M., Mallait A.M. Cocker P., Schateman L., Wieme N., Heynen G. and Brodelez C. Proteoglycan melabolism in tissue cultured human anticular cartilage. Influence of piroxiam. J. Rheum 16.355,1989.

34. Verbruggen G., Veys E.M., Malloit A.M. Schottemon L., Wieme N., Heynen G, Vonhoutte V. and Brodelez C. Proteoglycan melabolism in isoloted chondrocyles from human anticular cartilage and in short term lissue cultured human articular cartilage. Chin. Exp Rheumatol. 7:13, 1989.

35. de Vries B.J: Murine patellar cartilage and its susceptibility to nonsteroidal antiinflammatony drugs. Doctoral Thesis, University of Nijmegen, Nijmegen, The Netherlands, 1987.

36. de Vries B.J., van den Berg W.B and van de Pulte L. B.A. Salicylate induced depletion of endogenous inorganic sullate. Arthrilis Rheumatol. 28:922, 1985

37. de Vries B.J, van den Berg W B., Vitters E. and van de Putte L.B.A. The effect of salicylate on anotonically intact articular cartilage is inluenced by sullote and serum in the culture medium $J$. Rheumald 13:686, 1986.

38. Wad C.S : Are nonsteroidal anti-inllammatory drugs indicated in the meomen of asteocmbrosis? Arthroscopy $2: 13,1986$ 


\section{Summary}

Osteoarthritis $(O A)$ is a disorder of joints characterized by erosion of the cartilage, proliferation of fibrous tissue and the formation of osteo-cartilaginous tissue at the margins of the joint. In contrast to Rheumatoid Arthritis (RA) inflammation plays not a primary role in the etiology of $O A$. In the last decade the number of patients needing treatment for $O A$ has increased considerably. Although interest in the pathology as well as the therapy of $O A$ has grown, relatively little is known about the pathogenesis of $O A$ in humans. In this thesis different approaches to the study of the pathology and therapy of $O A$ are used.

In the first chapter of the thesis, a survey of epidemiological, etiological and pathophysiological aspects relevant to the study of $O A$ is given. $O A$ is found to be the cause of large numbers of patients who need orthopaedic care. Although the macroscopic aspect of $O A$ is well known, it is difficult to predict if chondromalacia at a young age will proceed to more extensive $O A$ resulting in further deterioration of cartilage.

Biochemical changes, which occur during the process of $O A$, have mostly been studied in animal models. Some of the changes seen in animal $O A$, however, do not apply to the changes found in humans. There is clear evidence that the increase in water content, breakage of the collagen fibres, and the changing metabolic state of the chondrocytes result in further deterioration of the cartiloge in $O A$

For the etiology of $O A$, different hypotheses have been suggested. In secondary $O A$ (e.g. post-traumatic, $R A$, congenital malformations) a process resulting in abnormal mechanical loading of the cartilage preceeds the actual $O A$. In the majority of patients, however, no clear efiological onset for $O A$ can be found (primary $O A$ ). Essentially in the concepts of the etiology of primary $O A$, either the subchondral bone or the cartilage itself are thought to be the primary localion for $O A$. From there on exogenous as well as endogenous factors are involved in the further breaking down of cartilage.

In the therapy for patients with $O A$, non-operative treatment plays an impor- 
tant role. The function of analgesics, non steroidal anti-inflammatory drugs (NSAID) and socalled "chondroprotective drugs" is discussed in this thesis. Prudence is needed regarding the use of these drugs, because in some of them, not only the effectiveness in treating $O A$ is questionable, but adverse effects also have been found. Several surgical procedures are discussed in the last part of chapter one. Recent developments in arthroscopy have enlarged the possibilities of surgical procedures for patients with $O A$. The possibility to restore localized cartilage defects, especially in younger patients, has been the subject of recent studies.

Chapter wo introduces and discusses the experimental work. In this thesis attention is paid to three different aspects of the research on OA. Study one and two concern the histological aspects of $O A$. Study three and four deal with aspects of the culture of human chondrocytes and perichondrium and, in study five and six, some therapeutical aspects of the treatment of patients with $O A$ are studied.

The first study deals with the reliability of the Mankin score for OA. Previous investigations confirmed that the criteria normally used for the histopathological classification of the severity of $O A$ could not easily be interpreted by different observers. In our $O A$ cartilage sections there seemed to be differences in structure and stainability with advancing disease compared to the experiments described by Mankin ef al. Hence, we developed more extensive criteria for the evaluation of the severity of $O A$. It is demonstrated that these new criteria made possible a faster and slightly more adequate qualification of $O A$ sections.

In the second study we evaluated the characteristics of glycolmethacrylate IGMAlembedded cartilage stained with safranin $O$ and thionin. Others have shown that the satranin $O$ fast green staining method is a sensitive procedure, for assessment of the quality of the cartilage in paraffin embedded cartilage. Decalcification, dehydration and paraffin-embedding produces changes in matrix and chondrocyte structure which reduce the sensitivity of the histopathological score of cartilage. Our study demonstrated that GMA embedding produced sections with a better conservation of the structure of cartilage and chondrocytes than paraffin-embedded sections. Thionin staining enabled us to get a thorough estimale of the glycosaminoglycan (GAG) content of these GMA-embedded sections

In the third study a method for culturing isolated human chondrocytes in high density is described. With this culture method the phenotypic characteristics of healthy and osteo-arthritic (OA) chondrocyles could be maintained. A positive correlation between the severity of $O A$ and the proliferative and metabolic capacity of the 
isolated chondrocytes in culture appeared. By this method a stable short term culture system for the study of adult human chondrocytes was crealed. The dala suggesled that the changed metabolism of OA chondrocytes, compared to healthy chondrocytes, might be an intrinsic properly of the cell itself.

In the fourth study the potential of adult human perichondrium to form hyalin cartilage is discussed. Since (immature) animal perichondrium had already been proved to be able to form hyalin cartilage in vitro and in vivo, it appeared useful to investigate if adult human perichondrium could do so. Clinically, the perichondrium could serve as an autologous biological graft capable of restoring localized cartilage defects. Therefore, we investigated the capacity of adult human perichondrium to form hyalin cartilage in vitro. Our dala indicated that in vitro culture of human perichondrium results in the formation of hyalin cartilage after a short culture period. Moreover, the potential of perichondrium to form hyalin cartilage in vitro seemed to increase in a longer culture period.

In the fith sludy, we evaluated the effect of gentamicin on the metabolism of in vitro cultured rat patellar cartilage. Bacterial joint infections have been shown to be the cause of fast destruction of the joint cartilage. Patients with reduced capacily to eliminate these bacteria, and patients with already destructed cartilage due to e.g. $O A$ run a greater risk of developing these infections. Due to late diagnosis and inadequate intra-articular antibiotic concentration, fast destruction of the joint cartilage takes place. Many of the administered antibiotics have serious toxic side effects. The intra-articular administration of antibiotics might overcome some of these problems, but we must be certain that the antibiotics do not impede cartilage metabolism. In this study, therefore, we evaluated the effeci of high doses of gentamicin on the metabolism of cartilage in vitro. Our data indicated that even high doses of gentamicin did not impede cartilage metabolism. We concluded that frequent introanticular administration of gentamicin might offer a good supplement to the normal therapy for joint infection.

In the last study we evaluated the effect of piroxicam on the metabolism of healthy as well as $O A$ human chondrocytes in vitro. Non steroidal anti-inflammatory drugs (NSAIDI, such as piroxicam, are frequently used for the treatment of patients with pain in the OA joint's). It has been suggested that seve-ral NSAID may have serious adverse effects on the general health and the cartilage metabolism of these patients. In fact NSAID are meant to be used in patients with synovitis as in R.A. In contrast to RA, synovitis in $O A$ does not seem the primary cause of the disease and 
clear synovitis is only present after /microltrauma of the joint. We therefore investiguted the effect of piroxicam on the metabolism of human chondrocytes in vitro. Our data indicated that piroxicam inhibits the metabolism of healthy and $O A$ chondrucyles in vitro. We therefore suggest that the treatment with NSAID of patients with $O A$ and clear synovitis should be restricted to the period of effusion. 


\section{Samenvatting}

Osteoarthrose $(O A)$ is een ziekte waarbij het gewrichtskraakbeen erodeert, proliferatie van fibreus weefsel vanuit het onderliggende bot optreedt en benige vitstulpingen bedekt met kraakbeen (osteotyten) aan de randen van het gewricht worden gevormd. In tegenstelling tot Rheumatoide Arthritis (RA) staat bii OA ontsteking als ethiologische factor niet op de voorgrond. In het laatste decennium is het aantal patienten dat behandeling nodig heeft wegens $O A$ van één of meer gewrichten aanzienliik gestegen. Athoewel de interesse voor de pathologie en de behandeling van $O A$ is roegenomen is er relatief weinig bekend over de pathogenese van $O A$ bij de mens. In dit proefschrift worden verschillende benaderingen voor de bestudering van de pathogenese, histologie en de therapie van OA gepresenteerd.

In het eerste hoofdstuk van dit proetschrift wordt een overzicht gegeven van epidemiologische, ethiologische en pathofysiologische aspecten die relevant ziin voor de bestudering van $O A$. Het blijkt dat een groot aantal patienten orthopaedische behandeling nodig heeft voor OA. Alhoewel het macroscopische aspect van OA bekend is, blijki het moeilijk voorspelbaar te zijn of macroscopisch afwijkend kraakbeen zoals we dat regelmatig op jonge leethid aontreffen (chondromalacia), zal gaan uitmonden in $\mathrm{OA}$ met uitgebreide destructie van het kraakbeen. Biochemische veranderingen die zich voordoen in OA kraakbeen zijn vooral bestudeerd in dier modellen. Het is echter gebleken dat sommige biochemische veranderingen, die we in het diermodel zien, niet gevonden worden in OA kraakbeen van de mens. Het is wel duidelijk dat de toename van het water gehalte, het breken van de collagene vezels en veranderingen in het metabolisme van de kraakbeen cel uiteindelijk resulteren in $O A$.

Ethiologisch kunnen we bii $O A$ wee groepen onderscheiden; bii secundaire $O A$ (bv. post-traumatisch, RA, congenitale misvormingen) resulteert abnormale mechanische belasting van het kraakbeen in $O A$. Bij de meerderheid van de patiënten met $O A$ kan geen duidelijke oorzaak voor het ontstaan van $O A$ worden vastgesteld (primaire OA). De meest waarschijnlijke hypothesen voor het ontstoan van primaire $O A$, gaan uit van een afwilking in het subchondrale bot of in het kraakbeen 
zelf als oorzaak voor het ontstaan van OA. Daarna spelen zowel factoren van buiten het kraakbeen als uit het kraakbeen zelf een rol bii de verdere afbraak.

Bii de behandeling van patienten met $O A$ speelt de conservatieve behandeling een belangrijke rol. De rol van piijnstillers, niet steroide ontstekingsremmende middelen (NSAID) en zogenaamde "kraakbeen beschermende" medicamenten wordt in dit proetschriff besproken. Omdat de effectiviteit van deze geneesmiddelen niet in alle gevallen is bewezen en er zelfs schadelijke effecten beschreven worden, dienen deze geneesmiddelen met de nodige reserve te worden gebruikt. De verschillende chirurgische technieken voor de behandeling van patienten met $O A$ worden in het laatste deel van hoofdstuk I besproken. Nieuwe ontwikkelingen in de arthroscopische chirurgie lijken de behandelings mogelijkheden voor patienten mer $O A$ te verruimen. De mogelijkheid om geisoleerde kraakbeen defecten /bv. met perichondrium/ te herstellen, vooral bij jonge patiënten, is het onderwerp van een aantal studies uit de recente literatuur.

In hoofdstuk 2 word thet experimentele werk van dit proefschrift geintroduceerd en behandeld. In dit proefschrift worden drie verschillende aspecien van het $O A$ onderzoek besproken. De eerste en de wweede studie betreffen her histologisch onderzoek van $O A$. In de derde en vierde studie worden verschillende aspecten van her kweken van perichondrium en kraabeen behandeld. In studie vijf en zes worden een tweetal therapeutische aspecten van de behandeling van patienten met OA belicht.

De eerste studie behandelt de betrouwbaarheid van de Mankin score voor $O A$. Uit eerdere onderzoeken was namelijk gebleken dat de kriteria, die gebruikt worden voor het vaststellen van de graad van $O A$, niel goed door verschillende onderzoekers werden geinterpreteerd. Onze kraakbeencoupes bleken verschillen te vertonen voor wat betreft de structuur van het kraakbeen en de kleurbaarheid van de matrix bij $O A$ in vergelijking met de experimenten zoals deze door Mankin zijn beschreven. Daarom hebben we de kriteria voor de beoordeling van de graad van $O A$ veranderd en uitgebreid. In deze studie wordt aangetoond dat de nieuwe kriteria een betrouwbaarder maat geven om de ernst van $O A$ in onze coupes te bepalen.

In de weede studie worden de eigenschappen van in glycolmethacrylate (GMA) ingebed kraakbeen gekleurd met safranine-O en thionine bestudeerd. Hel is bekend dat safranine-O een betrouwbare kleurstof is om de kwaliteit van kraakbeen dat in paraffine is ingebed te beoordelen. Door decalcificatie, dehydratie en het inbedden in paraffine verandert echter de matrix en de kraakbeencel structuur. 
waardoor de beoordeling van de ernst van $O A$ word bemoeilikt. In deze studie wordt aangetoond dat de structuur van her kraakbeen ingebed in GMA beter wordt behouden dan in paraffine ingebed kraakbeen. Met behulp van thionine kan in regenstelling tot safranine-O een goede indruk worden verkregen van het gehalte aan glycosamino-glycanen (GAG) van deze in GMA ingebedde kraakbeen coupes.

In de derde studie wordt een methode beschreven voor het kweken van geisoleerde kraakbeencellen in hoge dichtheid. Mei deze methode van kweken kan het fenorype van gezonde en OA kraakbeencellen worden behouden. Er blijkt een positieve correlatie te bestaan tussen de ernst van de $O A$ en de proliferatieve en metabole eigenschappen van de kraakbeencellen in kweek. Met deze methode is een stabiel kweekmodel voor geisoleerde menselijke chondrocyten gecreeeerd. De resultaten suggereren dat het veranderde metabolisme van de OA kraakbeencellen niet door factoren van buitenaf, maar vanuit de chondrocyten zelf wordt geinitieerd.

In de vierde studie wordt de potentie van volwassen menselijk perichondrium om hyalien kraakbeen te vormen besproken. Door anderen is al bewezen dat lonvolwassen/ dierlik perichondrium zowel in vitro als in vivo in staat is om kraakbeen te vormen. Er is echter betwiffeld of volwassen menselijk kraakbeen deze mogelijkheid nog wel heeft. Daarom is een onderzoek gedaan naar de potentie zowel qualitatief als quantitatief van volwassen menselijk perichondrium om hyalien kraakbeen te vormen. Onze resultalen laten zien dar het rib perichondrium al na korte tijd kraakbeen vormt met specifiek hyaliene kenmerken. De hoeveetheid kraakbeen die wordt gevormd blijkt met het verlengen van de kweektijd in omvang toe te nemen.

In de viffde studie is in vitro het effect van gentamicine op het rat patella kraakbeen bestudeerd. Bacteriële gewrichtsinfecties zijn er de oorzaak van dat zeer snelle kraakbeen afbraak optreedt. Patiënten met een verminderde weerstand en reeds beschadigd kraakbeen hebben een duidelijk verhoogd risico voor het on wikkelen van dergelijke infecties. De diagnose van de infectie wordt vaak laat gesteld en dientengevolge treedt er dan vitgebreide kraakbeen destructie op. Vele van de gebruikelijke antibiotica bii gewrichtsinfecties hebben ernstige bijwerkingen. Het introanticulair toedienen van antibiotica kan enkele van de eerder genoemde problemen voorkomen, maar we moeten dan wel zeker zijn dat deze antibiotica het kraakbeen metabolisme niet beinvloeden. In deze studie is daarom het effect van gentamicine op het kraakbeen metabolisme bestudeerd. Uit onze gegeveris blijkt dat gentamicine het kraakbeen metabolisme in vitro niet beinvloed. We conduderen daarom dar het 
frequent toedienen van gentamicine intra-articulair, een goed addendum kan zijn bii de behandeling van gewrichtsinfecties.

In de laatste studie is het effect van piroxicam op zowel gezond als $O A$ menseliik kraakbeen in vitro bestudeerd. Niet steroide ontstekingsremmende genees. middelen (NSAID), zoals piroxicam, worden vaak gebruikt voor de behandeling van patiënten met piinlijke OA gewrichten. Vele NSAID hebben echter niet alleen ernstige algemeen lichamelijke bijwerkingen, maar remmen ook her kraakbeen metabolisme van deze patienten. Oorspronkelijk zijn de NSAID ook bedoeld als ontstekingsremmend middel ter bestrijding van de synovitis bij bv. RA. Synovitis speelt bii arthrose echter geen oorzakelijke rol en komt voornamelijk voor na een trauma van het gewricht. Daarom werd in deze studie het effect van piroxicam op het kraakbeen metabolisme van menselijke kraakbeeencellen in vitro bestudeerd. De resultaten van deze studie laten zien dat piroxicam het metabolisme van gezonde en $O A$ chondrocyten in vitro remt. Het lijkt daarom verstandig de behandeling met NSAID van patiënten met $O A$ te beperken tot de periode waarin er sprake is van een duidelijke synovitis. 


\section{Publications presented in this thesis}

S.K.Bulstra, G.N.Homminga, W.A.Buurman, E.Terwindt-Rouwenhorst and A.) van der Linden. The potential of adult human perichondrium to form hyalin cartilage in vitro. J. Ort. Res. 8:328-335, 1990.

S.K.Bulstra, W.A.Buurman, G.H.I.M.Walenkamp, E.Terwindt Rouwenhorsi and A.) van der linden. Metabolic characteristics of in vitro cultured human chondrocyles in relation to the histopathological grade of osteoarthritis. Clin. Ort Rel. Res. 242:294-302, 1989

J.A. van der Sluijs, S.K. Bulstra, R.Kuyer, and R. G.T. Geesink

The reliability of the mankin score for osleoarthritis.

J. Ort. Res. 10:58-61, 1992.

S.K.Bulstra, W.A.Buurman, E.Tenvindt-Rouwenhorst, P.J.M. Guelen and A.J. van der Linden. The effect of piroxicam on the metabolism of isolated human chondrocyles in vitro. accepted for publication Clin. Ort. Rel. Res. june 1991.

S.K.Bulstra, P.H.A.Eerdmans, G.H.I.M.Walenkamp and A.J van der linden The effect of gentamicin on the metabolism of in vitro cultured rat patellar cartilage. submitted for publication Clin. Ort. Rel. Res. oktober 1991

S.K. Bulstra, W.A.Buurman, R. Kuijer, J.D.Drukker, and A.J. van der Linden. Thionin staining of paraffin and plastic embedded cartilage sections. Biotechnic and Histochemisiny, accepted for publication march 1992 



\section{Dankwoord}

Dit proefschrift is mede ontstaan door de inzet van velen, die ik wil bedanken voor hun geweldige inzet.

In het biizonder bedank ik Ton van der linden, die door zijn altijd moliverende vilspraken en een stroom van nieuwe ideeen, een wetenschappelijk klimaat wist te creeeren waarin lookl dit proefschrift kon rijpen. Innoverend en sterk doelgericht ondersteunde Wim Buurman het laboratorium onderzoek, waardoor de onderzoekslipn bleef lopen en de basis voor menige volgende discussie werd gelegd. De interesse van mijn collega's voor een dergelijk "onderzoeks-buitenbeentje" is bij het tot stand komen van dit proefschrifteen onschatbare steun geweest. Els Terwindt-Rouwenhorst bedank ik voor het grote aantal histologische coupes dat zil maakte terwill ze ook als zeer ter zake deskundig referent fungeerde bij de beoordeling envan. Natuurlijk bedank ik allen en met name jan Drukker, werkzaam op de afdeling Histologie en Anatomie, die mij bijstonden bii het oplossen van de vele acute problemen. Trudy Jeunhomme en de groep werkzaam op het laboratorium van de Algemene Heelkunde, jullie bedank ik voor de steun vooral tijdens de moeilijke beginperiode van het onderzoek. Onschatbaar waren jullie tips voor het in leven houden van de cellen. Miek Havenith, Jack Cleutjens, Peter Frederik, Paul Bosmans en alle anderen werkzaam op de afdeling pathologie en elecironenmicroscopie bedank ik voor hun hulp bil vele facetten van dit proefschrift. Roel kuijer je hebt me tijdens het laatste jaar bij de voorbereidingen van dit proefschrift veel geholpen en daarmee de waarde enan zeker vergroot. Ton van de Bogaard, Pefer Kelderman en de zeer toegewijde dierenverzorgers bedank ik voor de hulp bij de vele dierexperimenten

De beoordelingscommissie bestaande vit Prof.dr. J.M. Greep, Prof.dr. J.W. Arends, Prof.dr. J. Drukker, Dr. G.P.J. van Kampen en Prof.dr. R.P.H. Veth wil ik bedanken voor de lijd die zij aan dif proetschrift hebben besteed en voor de waardevolle adviezen die werden gegeven. Ik bedank mijn ouders die een stevige basis hebben gelegd, nodig om dit onderzoek te volbrengen.

Gerie je was en bent mijn onvermoeibare steun, vraagbaak en kritisch toehoorder. Tegelijkertijd wist je er toch ook nog voor te zorgen dat ik af en toe aun wat anders dan het proetschritt docht. 
De auteur van dit proefschrift werd geboren op 18 april 1955 te Bergen (NH). In 1974 behaalde hij het gymnasiun- $B$ diploma aan het stedelijk gymnasium te Apeldoorn. Van 1974 tot 1981 studeerde hij geneeskunde aan de Rijksuniversiteit Groningen, alwaar hij in 1981 zijn artsexamen behaalde. Tijdens zijn studie was hij onder andere werkzaam als student assistent op de afdeling biochemie, fysiologie en orthopaedie. Op de afdeling orthopaedie van het Academisch Ziekenhuis Groningen (Hoofd: Prof.dr.H.K.L.Nielsen) werd onder andere onderzoek verricht naar de diagnostiek en de behandeling van het "Brodie's abces", de ziekte van "Perthes" en de congenitale heupluxatie. Van 1981 tot 1982 was hij werkzaam als dienstplichtig luitenant-arts bij het $43^{e}$ pantser infanterie batalion te Assen. In 1982 startte hii de opleiding orthopaedie als assistent-chirurg in het ziekenhuis De Heel te Zaandam (opleider: Dr.S.Bouma). Hier werd een onderzoek/verricht waarbii de resultaten van de operatieve behandeling van het laterale enkelbandletsel werden vergeleken met die van de conservatieve behandeling. Vanaf 1 januari 1985 vervolgde hij zijn opleiding op de gfdeling Orthopaedie van het Academisch Ziekenhuis te Maastricht 10plejder: Prof.dr. A.J. van der Linden).

Het in dit proefschrift beschreven wetenschappelijke onderzoek is vanaf 1986 verricht op de addeling Orthopaedie van het Academisch Ziekenhứis Maastricht, in het "Biomedisch Laboratorium" van de vakgroep Algemene Heelkunde (Hoofd: Dr. W. A. Buurman) en in het "Laboratorium voor Anatomie en Histologie" (Hoofd: Prof.dr.J.Drukker) in het Biomedisch Centrum te Maastricht. Vanaf 1 januari 1989 is hij werkzaam als Orthopaedisch Chirurg op de afdeling Orthopaedie van het Academisch Ziekenhuis Maastricht. 